UNIVERSIDADE DE SÃO PAULO

ESCOLA DE ENFERMAGEM

FERNANDA AMENDOLA

CONSTRUÇÃO E VALIDAÇÃO DE UM ÍNDICE DE VULNERABILIDADE DE FAMÍLIAS A INCAPACIDADES E DEPENDÊNCIA

SÃO PAULO

2012 
FERNANDA AMENDOLA

\section{CONSTRUÇÃO E VALIDAÇÃO DE UM ÍNDICE DE VULNERABILIDADE DE FAMÍLIAS A INCAPACIDADES E DEPENDÊNCIA}

Tese apresentada à Escola de Enfermagem da Universidade de São Paulo para obtenção do título de Doutor em Ciências

Área de concentração: Saúde Coletiva

Orientadora: Profa Dra Maria Amélia de Campos Oliveira

SÃO PAULO

2012 
Nome: Amendola, $\mathrm{F}$

Título: Construção e validação de um índice de vulnerabilidade de famílias a incapacidades e dependência

Tese apresentada à Escola de Enfermagem da Universidade de São Paulo para obtenção do título de Doutor em Ciências

Aprovado em:

\section{Banca Examinadora}

Prof. Dr. Instituição:

Julgamento: Assinatura:

Prof. Dr. Instituição:

Julgamento: Assinatura:

Prof. Dr. Instituição:

Julgamento: Assinatura:

Prof. Dr. Instituição:

Julgamento: Assinatura:

Prof. Dr. Instituição:

Julgamento: Assinatura: 
As familias da minha vida, gue assim o são porgue me envolvem de amor, de segurançae de paz. Que me deram a vida, a oportunidade de crescer, conhecer, aprender, viver, viver e aprender... e ser feliz....Que conheci ao nascer, ao brincar, ao estudar, ao me casar, ao viajar, ao trabalhar.... A's familias que me ajudaram a realizar esse e tantos outros sonhos... 


\section{AGRADECIMENTOS}

A meus pais pelo amor incondicional, pelo apoio incansável, pela torcida incessante. Vocês me deram a vida e fazem dela o melhor lugar para se viver. Agradeço muito por ter vocês!

Ao meu irmão Gilberto pela presença gentil, amável, sempre me incentivando e apoiando.

Ao Vitor pelo apoio para que eu pudesse realizar o doutorado-sanduíche.

Às famílias que participaram do estudo e que tão gentilmente nos receberam em suas casas e sem saber, nos ensinaram muito e enriqueceram esse trabalho e nossas vidas.

Às equipes de saúde da família, em especial as agentes comunitárias de saúde, que tornaram esse trabalho possível.

A todos os gestores e gerentes pela atenção dispensada e por viabilizarem a coleta de dados.

A todas as funcionárias do Serviço de pós-graduação da EEUSP, pelo apoio, disponibilidade e competência.

À querida Márcia Regina Martins Alvarenga, por sua presença constante em todos os momentos, contribuições indispensáveis desde a elaboração inicial do Projeto e pelo privilégio da sua amizade.

A todos os juízes que participaram com suas riquíssimas contribuições a esse trabalho. 
A minha prima Roberta, tio Nenê e tia Carmem por todo amor e entusiasmo em toda minha trajetória de vida e profissional.

Às irmãs Vivi e Fá, por fazerem parte de tudo e de todos os momentos mais importantes da minha vida.

Aos meus tios, Diamantina e Alcides, por todo carinho, apoio e principalmente, por tudo que fizeram para que eu pudesse realizar o estágio em Barcelona.

Às queridas amigas Wânia e Mayumi, obrigada por todo apoio, parceria, aprendizado. Toda minha admiração, carinho e gratidão a vocês.

A Dona Silvia, mulher sábia, por todo seu amor, sua preocupação, carinho e palavras de incentivo para que pudesse concluir esse trabalho.

A todos do grupo de pesquisa que tanto contribuíram ao trabalho em nossas discussões e em especial, a Cíntia, Valéria e Jaqueline, por compartilharem momentos de aprendizado e crescimento. É muito bom poder contar com vocês!

Às bolsistas Débora e Juliana, pelo envolvimento, competência, responsabilidade, disposição e tantas outras qualidades que as fazem ser excelentes profissionais e pessoas. Obrigada por todo o apoio! Sem vocês a coleta de dados não seria possível.

A todos os funcionários e professores do departamento de saúde coletiva da EEUSP, por contribuírem de diversas formas e em vários momentos nessa trajetória.

A todas as professoras da Universidade de Barcelona, funcionários de todos os Serviços de Saúde visitados, muito obrigada pela acolhida, pela troca, pelo aprendizado e pela hospitalidade. Momentos que estarão gravados para sempre em meu coração!

A todos os amigos, alunos, pessoas que me ajudaram direta e indiretamente na tese, a todas as pessoas que me ofereceram palavras de apoio, incentivo, força e ensinamentos durante todo esse período, muito obrigada! 
À FAPESP por viabilizar o Projeto, através de auxílio e concessão de duas bolsas TT-3.

À CAPES pela concessão da bolsa-sanduíche por três meses, na Universidade de Barcelona. 


\section{AGRADECIMENTOS ESPECIAIS}

À Prof ${ }^{a}$ Dra. Maria Amélia de Campos Oliveira ou simplesmente, Méia. Aliás, simples é a sua palavra. Poucos sabem simplificar como ela. Talvez por isso, nunca hesita em apostar, acreditar e seguir adiante. Méia, obrigada pelos ensinamentos, pelo comprometimento, pelo entusiasmo, pela confiança, paciência, carinho e por sua alegria. Tudo isso tornou esse trabalho possível e muito feliz, sempre muito feliz.

À Profa Dra. Maria do Rosário Latorre pelas inestimáveis contribuições no método e nas análises estatísticas, mas principalmente, pela atenção, dedicação e cuidado dispensados ao trabalho e a mim. Aprendizados que estão em minha cabeça e em meu coração.

À Profa Esperanza Ballesteros Perez por ser responsável por toda acolhida e aprendizado que vivenciei em meu estágio de doutorado-sanduíche na Universidade de Barcelona. Sempre disposta e incansável, não poupou esforços para viabilizar todos os meus anseios (que não eram poucos!) em conhecer os serviços de saúde destinados a pessoas com alguma incapacidade ou dependência e em discutir e traduzir o instrumento proposto na tese. Muchas Gracias! 
"No momento em que nos comprometemos, a providência divina também se põe em movimento. Todo um fluir de acontecimentos surge ao nosso favor. Como resultado da atitude, seguem todas as formas imprevistas de coincidências, encontros e ajuda, que nenhum ser humano jamais poderia ter sonhado encontrar. Qualquer coísa que você possa fazer ou sonhar, você pode começar. " $A$ coragem contém em si mesma, o poder, o gênio e a magia.” 


\section{RESUMO}

Amendola F. Construção e validação de um índice de vulnerabilidade de famílias a incapacidades e dependência [tese]. São Paulo: Universidade de São Paulo, Escola de Enfermagem, 2012. $189 f$.

No contexto atual de saúde, é relevante a criação de instrumentos válidos e confiáveis que possam, sob o olhar da integralidade, captar a vulnerabilidade das famílias a incapacidades e dependência. Este estudo objetivou construir e validar um índice de vulnerabilidade de famílias a incapacidades e dependência (IVF-ID). Adaptou-se o Índice de Desenvolvimento da Família, que contém indicadores sociais, acrescentando indicadores de relações sociais e de saúde relacionados a incapacidades e dependência. O instrumento foi submetido à validação aparente, por meio da técnica Delphi, tendo passado duas rodadas de avaliação dos juízes, até atingir o consenso. O instrumento resultante foi aplicado a 248 famílias acompanhadas pelas equipes da Estratégia Saúde da Família de uma região do município de São Paulo para construção IVF-ID e posteriormente a outras 248 famílias de outra região do Município, com perfil demográfico e social distinto, para validação. Assim, o índice final contém 40 questões, divididas em quatro componentes e duas dimensões: a dimensão "Condições Sociais" (CSO) que engloba os componentes "Condições sociais favoráveis" e "Condições sociais desfavoráveis", e a dimensão "Condição de Saúde" (CSA), que congrega os componentes "Envelhecimento, incapacidade e dependência" e "Doenças crônicas". Foram definidos pontos de corte para o IVF-ID Total e para a Dimensão CSA, o que permitiu discriminar as dimensões da vulnerabilidade a incapacidades e dependência entre as famílias. O IVF-ID mostrou-se confiável e válido ao ser aplicado em duas populações com vulnerabilidades sociais e perfis demográficos distintos. Ao aplicar o IVF-ID total, verificou-se que não houve diferença significativa entre as duas regiões $(54,8 \% \times 58,1 \% ; p=0,469)$, porém em relação à vulnerabilidade relacionada à Dimensão CSA, houve diferença significativa entre as duas regiões, sendo que na região da Lapa foi encontrada um número maior de famílias vulneráveis do que na Cidade Ademar (47,6\% X 31,5\%; $p<0,001)$. Pretende-se que o IVF-ID seja utilizado para o planejamento de ações que visem o monitoramento dos determinantes das condições de vida e saúde das famílias vulneráveis a incapacidades e dependência. O índice poderá servir como um instrumento diagnóstico e de intervenção tanto na gestão como na assistência às famílias no âmbito da ESF.

Palavras-chave: vulnerabilidade, índice, incapacidade, dependência, família, Programa Saúde da Família 


\begin{abstract}
Amendola F. Development and validation of an index of family vulnerability to disability and dependence [thesis]. Sao Paulo: University of São Paulo, School of Nursing, 2012. 189p.

In the current context of health, it is important to propose valid and reliable instruments to capture, under the perspective of integrality, the vulnerability of families to disability and dependency. This study aimed to develop and validate an index of vulnerability of families to disability and dependency (FVI-DD). The Index of Family Development, which contains social indicators, was adapted and social network and health-related indicators were added. The instrument was subjected to apparent validation, through the Delphi technique, in two rounds of evaluation of judges to reach consensus. The resulting instrument was administered to 248 families accompanied by Family Health Strategy (FHS) teams in a region of São Paulo city to define the components of FVI-DD and was later applied to other 248 families from another region of the city, with distinct social and demographic profile, for validation. Thus, the final index contains 40 questions divided into four components and two dimensions: the dimension "Social conditions" (SC) which comprises the components "Favorable social conditions" (FSC) and "Unfavorable social conditions" (USC), and the dimension "Health conditions" (HC), which the components "Aging, disability and dependency" and "Chronic disease". Cutoffs were defined for FVI-DD Total and the HC Dimension. The FVI-DD was reliable and valid when applied to two populations with social vulnerabilities and different demographic profiles. By applying the FVI-DD Total, it was found that there was no significant difference between the two regions (54.8\% vs. $58.1 \%, p=0.469)$, but in relation to the vulnerability related to $\mathrm{HC}$ Dimension, significant differences were found between the two region: Lapa had a greater number of vulnerable families that Cidade Ademar $(47.6 \%$ vs. $31.5 \%, p<0.001)$. The FVI-DD is intended to be used to plan actions to the monitoring of the determinants of health and living conditions of vulnerable families to disability and dependency. The index may serve as a diagnostic and intervention tool both in management and in care providing to families in the FHS.
\end{abstract}

Keywords: vulnerability index, disability, dependency, family, Family Health Strategy. 


\section{LISTA DE ILUSTRAÇÕES}

Figura 01 - Mapa das subprefeituras do município de São Paulo. São Paulo,

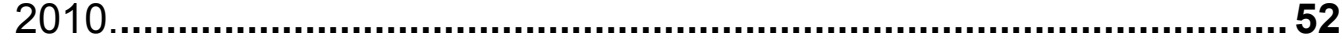

Figura 02 - Mapa das Coordenadorias Regionais de Saúde do município de São Paulo. São Paulo, 2011.....................................................................53

Figura 03 - Mapa das Supervisões Técnicas de Saúde da Coordenadoria Regional Centro-oeste. São Paulo, 2011. Fonte: Prefeitura de São Paulo.............................................................................................54

Figura 04 - Mapa das Supervisões Técnicas de Saúde da Coordenadoria Regional Sul. São Paulo, 2011....................................................................56

Figura 05 - Representação, em fluxograma, da avaliação e classificação das famílias através da aplicação do IVF-ID TOTAL e da dimensão CSA.

Gráfico 01 - Distribuição das combinações entre as duas vulnerabilidades entre as regiões da Lapa e Cidade Ademar. São Paulo,

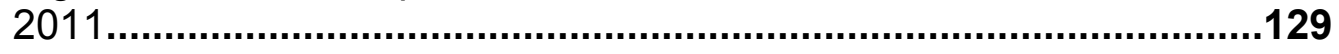




\section{LISTA DE QUADROS}

Quadro 01 - Aspectos a serem considerados nas três dimensões das análises de vulnerabilidade.

Quadro 02 - Combinação entre as condições de saúde e sociais favoráveis e desfavoráveis com famílias dependentes e independentes

Quadro 03 - Composição do instrumento final, segundo domínios, componentes e número de questões. São Paulo, 2011.

Quadro 04 - Número de questões dos novos componentes e domínios e componentes ao qual pertenciam no índice original...........................105

Quadro 05 - Dimensões e componentes do IVF-ID Total. São Paulo,

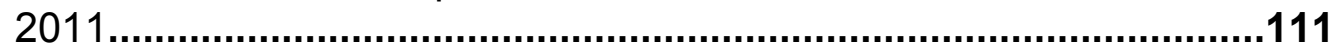

Quadro 06 - Classificação da vulnerabilidade das famílias, segundo o IVF-ID Total e a Dimensão $\quad$ CSA. São Paulo,

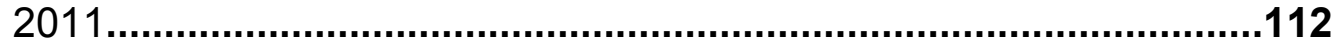




\section{LISTA DE TABELAS}

Tabela 01 - Distribuição em números da composição geral do Índice, segundo dimensões, componentes e questões, na $1^{\mathrm{a}}$ e $2^{\mathrm{a}}$ rodadas São Paulo,

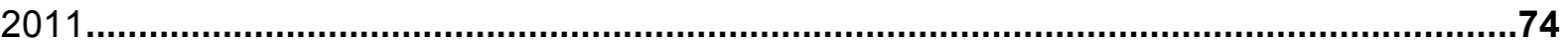

Tabela 02 - Distribuição dos itens do Índice com porcentagem de concordância menor de $80 \%$, entre os juízes, relacionado à forma, na $1^{\text {a }}$ rodada. São Paulo, 2011.

Tabela 03 - Distribuição dos itens do Índice com porcentagem de concordância menor de $80 \%$ entre os juízes, relacionada ao conteúdo, na $1^{\text {a }}$ rodada. São Paulo, 2011

Tabela 04 - Distribuição dos itens do Índice com porcentagem de concordância menor de $80 \%$ entre os juízes, relacionada à forma, na $2^{\mathrm{a}}$ rodada. São Paulo, 2011.

Tabela 05 - Distribuição dos itens do Índice com porcentagem de concordância menor de $80 \%$ entre os juízes, relacionada ao conteúdo, na $2^{a}$ rodada. São Paulo, 2011 82

Tabela 06 - Número e porcentagem de membros das famílias entrevistadas, na região da Lapa, segundo a Unidade Básica de Saúde. São Paulo, 2011.

Tabela 07 - Número e porcentagem dos membros das famílias entrevistadas, na região da Lapa, segundo o sexo. São Paulo, 2011

Tabela 08 - Número e porcentagem de membros das famílias entrevistadas, na região da Lapa, segundo a faixa etária. São Paulo, 2011.

Tabela 09 - Estatística descritiva dos membros das famílias entrevistadas, na região da Lapa, segundo o número de pessoas, idade, pontuação total do Índice de Katz e pontuação total da Escala de Lawton. São Paulo, 2011.

Tabela 10 - Número e porcentagem dos membros das famílias entrevistadas, na região da Lapa, segundo o Índice de independência nas atividades básicas da vida diária, Katz. São Paulo, 2011.

Tabela 11 - Número e porcentagem dos membros das famílias entrevistadas, na região da Lapa, segundo a presença de alguma dependência para as atividades básicas da vida diária. São Paulo, 2011.

Tabela 12 - Número e porcentagem dos membros das famílias entrevistadas, segundo a presença de alguma dependência para as atividades instrumentais da vida diária. São Paulo, 2011. 
Tabela 13 - Número e porcentagem das famílias entrevistadas, na região da Lapa, segundo a Unidade Básica de Saúde. São Paulo, 2011

Tabela 14 - Estatística descritiva das famílias entrevistadas, na região da Lapa, segundo o número de pessoas na casa, média familiar da pontuação no Índice de Katz e média familiar da pontuação na Escala de Lawton. São Paulo, 2011. .91

Tabela 15 - Número e porcentagem das famílias entrevistadas, na região da Lapa, segundo o número de pessoas na casa. São Paulo, 2011

Tabela 16 - Número e porcentagem das famílias entrevistadas, na região da Lapa, segundo a presença de dependência para as atividades básicas da vida diária entre algum membro da família. São Paulo, 2011.

Tabela 17 - Número e porcentagem das famílias entrevistadas, na região da Lapa, segundo a presença de dependência para as atividades instrumentais da vida diária entre algum membro da família. São Paulo, 2011

Tabela 18 - Número e porcentagem de respostas de valor 0 ou 1. São Paulo, 2011

Tabela 19 - Descrição dos fatores dos resultados da análise fatorial (após a rotação varimax). São Paulo, 2011.

Tabela 20 - Descrição do fator 1. São Paulo, 2011 100

Tabela 21 - Descrição fator 2. São Paulo, 2011 101

Tabela 22 - Descrição do fator 3. São Paulo, 2011. 102

Tabela 23 - Descrição do fator 4. São Paulo, 2011.

Tabela 24 - Descrição do fator 5. São Paulo, 2011. 103

Tabela 25 - Descrição do fator 6. São Paulo, 2011. .104

Tabela 26 - Descrição do fator 7. São Paulo, 2011. 104

Tabela 27 - Estatística descritiva do IVF-ID. São Paulo, 2011 106

Tabela 28 - Estatística descritiva dos indicadores do IVF-ID, segundo a presença de dependência para as atividades básicas da vida diária do Índice de Katz. São Paulo, 2011. 107

Tabela 29 - Estatística descritiva dos fatores do IVF-ID, segundo a presença de dependência para as atividades instrumentais da vida diária da Escala de Lawton. São Paulo, 2011. 
Tabela 30 - Coeficientes de correlação de Spearman $\left(r_{\mathrm{sp}}\right)$ entre os indicadores do IVF-ID e a média de pontuação familiar do Katz e Lawton. São Paulo, 2011.

Tabela 31 - Distribuição das famílias segundo a presença de vulnerabilidade, na Lapa. São Paulo, 2011

Tabela 32 - Número e porcentagem dos membros das famílias entrevistadas, segundo o sexo. São Paulo, 2011

Tabela 33 - Número e porcentagem de membros das famílias entrevistadas, segundo a faixa etária. São Paulo, 2011.

Tabela 34 - Estatística descritiva dos membros das famílias entrevistadas, segundo o número de pessoas, idade, pontuação total do Katz e pontuação total do Lawton. São Paulo, 2011

Tabela 35 - Número e porcentagem dos membros das famílias entrevistadas, segundo o Índice de independência nas atividades básicas da vida diária, Katz. São Paulo, 2011.....118

Tabela 36 - Número e porcentagem dos membros das famílias entrevistadas, segundo a presença de alguma dependência para as atividades básicas da vida diária. São Paulo, 2011 119

Tabela 37 - Estatística descritiva das famílias entrevistadas, segundo o número de pessoas na casa, média familiar da pontuação no Índice de Katz e média familiar da pontuação na Escala de Lawton. São Paulo, 2011.

Tabela 38 - Número e porcentagem das famílias entrevistadas, segundo a Unidade Básica de Saúde, na região da Cidade Ademar. São Paulo, 2011

Tabela 39 - Número e porcentagem das famílias entrevistadas, segundo o número de pessoas na casa, na região da Cidade Ademar. São Paulo, 2011

Tabela 40 - Número e porcentagem das famílias entrevistadas, segundo a presença de dependência para as atividades básicas da vida diária entre algum membro da família, na região da Cidade Ademar. São Paulo, 2011.

Tabela 41 - Número e porcentagem das famílias entrevistadas, segundo a presença de dependência para as atividades instrumentais da vida diária entre algum membro da família, na região da Cidade Ademar. São Paulo, 2011

Tabela 42 - Número e porcentagem da frequência de respostas das questões que compõe o IVF-ID, na região da Cidade Ademar. São Paulo, 2011.

Tabela 43 - Estatística descritiva do IVF-ID. São Paulo, 2011 .124 
Tabela 44 - Estatística descritiva dos componentes do IVF-ID, segundo a presença de dependência para as atividades básicas da vida diária do Índice de Katz. São Paulo, 2011.

Tabela 45 - Estatística descritiva dos componentes do IVF-ID, segundo a presença de dependência para as atividades instrumentais da vida diária da Escala de Lawton. São Paulo, 2011

Tabela 46 - Coeficientes de correlação de Spearman $\left(r_{\mathrm{sp}}\right)$ entre os componentes do IVF-ID e a média de pontuação familiar do Katz e Lawton. São Paulo, 2011. 125

Tabela 47 - Distribuição das famílias segundo a presença de vulnerabilidade, na Cidade Ademar. São Paulo, 2011 


\section{SUMÁRIO}

1. INTRODUÇÃO.................................................................................. 20

1.1 Atenção à saúde das pessoas com incapacidades e dependência........ 26

1.2 Aspectos relacionados à capacidade funcional................................... 28

1.3 Vulnerabilidade em saúde................................................................. 33

1.4 Indicadores em saúde............................................................... 37

1.5 Indicador de vulnerabilidade das famílias a incapacidades e
dependência............................................................................ 43

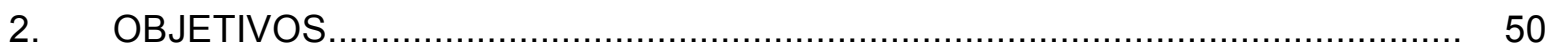

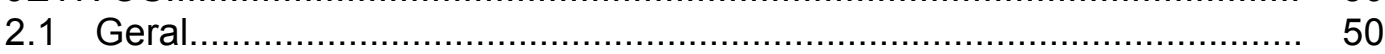

2.2 Específicos....................................................................... 50

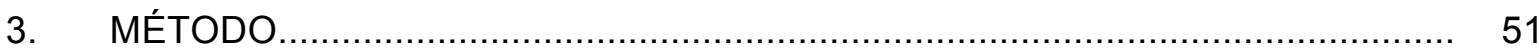

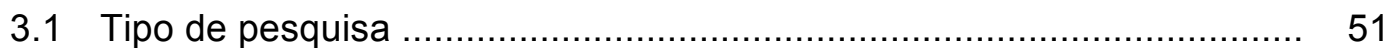

3.2 Local do estudo................................................................... 51

3.2 População do estudo.................................................................. 58

3.3.1 Cálculo da amostra...................................................... 59

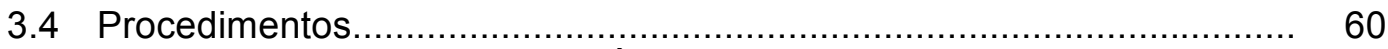

3.4.1 Desenvolvimento do Índice........................................... 60

3.4.2 Pré-teste.................................................................. 62

3.4.3 Validade aparente - o uso da técnica Delphi......................... 63

3.4.4 Coleta de dados............................................................... 64

3.4.4.1 Instrumentos............................................... 65

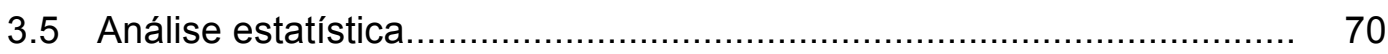

3.5.1 Desenvolvimento dos indicadores..................................... 70

3.5.2 Validação na Cidade Ademar........................................... 72

3.6 Aspectos ético-legais.............................................................. 72

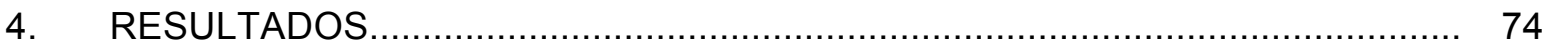

4.1 Avaliação dos juízes - técnica delphi........................................... 74

4.2 Aplicação do Índice - região da Lapa............................................. 88

4.2.1 Caracterização dos membros das famílias entrevistadas........ 88

4.2.2 Caracterização das famílias entrevistadas............................ 91

4.2.3 Descrição do IVF-ID........................................................ 93

4.2.4 Análise fatorial do IVF-ID para definição dos indicadores......... 96

4.2.5 Descrição dos indicadores.................................................. 106

4.2.6 Validação dos indicadores em relação à dependência por meio da validade discriminante............................................. 107

4.2.7 Validação dos indicadores em relação à dependência por meio da validade concorrente............................................ 108

4.2.8 Definição dos pontos de corte para o IVF-ID Total e para a Dimensão CSA.

4.2.9 Classificação das famílias da região da Lapa, segundo o IVFID ............................................................................ 115

4.3 Validação do IVF-ID em outra população.......................................... 116

4.3.1 Caracterização dos membros das famílias entrevistadas......... 117

4.3.2 Caracterização das famílias entrevistadas............................. 119

4.3.3 Descrição do IVF-ID.................................................... 121

4.3.4 Validação dos indicadores em relação à dependência por meio da validade discriminante

4.3.5 Validação dos indicadores em relação à dependência por meio da validade concorrente. 
4.3.6 Classificação das famílias da região da Cidade Ademar, segundo o IVF-ID

4.3.7 Comparação das duas populações em relação ao IVF-ID total e a Dimensão CSA.

5. DISCUSSÃO

5.1 Contribuição da etapa de validação aparente na construção do IVF-ID.. 130

5.2 Perfil das famílias.............................................................................. 136

5.3 A construção do IVF-ID .............................................................. 140

5.4 Validação em outra população......................................................... 150

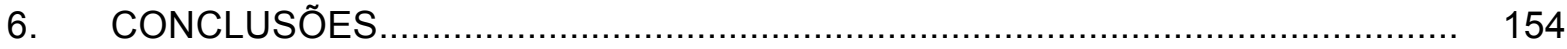

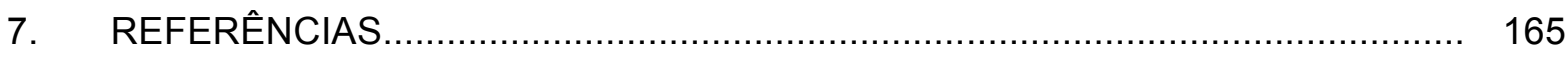

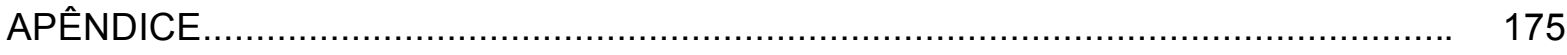

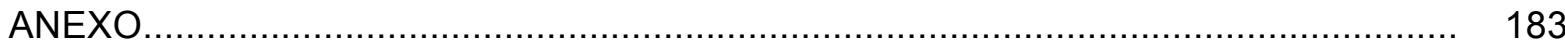




\section{INTRODUÇÃO}

A transição demográfica que marcou o século $X X$, em decorrência dos avanços da ciência e da tecnologia e da melhoria das condições de vida da população, produziu grande impacto nos perfis epidemiológicos das coletividades humanas, assim como no controle e no tratamento das doenças.

As doenças crônicas não-transmissíveis, as neoplasias e as causas externas despontaram como as principais causas de morbimortalidade, superando as doenças transmissíveis, tanto nos países desenvolvidos como naqueles em desenvolvimento ${ }^{1}$.

Efeitos desse cenário são o envelhecimento populacional e o aumento de pessoas com incapacidades e dependência. Para atender essas novas demandas, políticas públicas e ações em saúde fizeram-se necessárias.

As crises sucessivas do modelo hegemônico de atenção à saúde, orientado por uma lógica reducionista, biologicista e centrada na assistência médicohospitalar, levou à reestruturação dos sistemas de saúde de vários países, em direção a novos modelos de atenção à saúde, pautados nos princípios da Atenção Primária, com ações de promoção e prevenção à saúde, melhoria nas condições de vida e trabalho e adoção de hábitos saudáveis. Além de responder às mudanças demográficas e epidemiológicas, tais modelos baseiam-se na compreensão ampliada do processo saúde-doença, que leva em conta os determinantes sociais em saúde. 
Rasanathan, Montesinos, Matheson et $\mathrm{al}^{2}$ ressaltam que a Atenção Primária à Saúde e os determinantes sociais em saúde são dois paradigmas relacionados que priorizam a equidade em saúde. Compartilham princípios semelhantes, como a visão ampliada da saúde, a ação intersetorial e a participação das comunidades empoderadas, porém diferença entre eles reside principalmente no enfoque dado ao setor saúde, prioritário na APS. Mas, para que a APS consiga reduzir as desigualdades em saúde, uma de suas principais estratégias deve ser a ação sobre os determinantes em saúde.

O Brasil, na década de 70, iniciou um movimento de Reforma Sanitária liderado por profissionais e a sociedade civil que culminou, em 1988, na inclusão na Constituição Federal brasileira a premissa da saúde é um direito de todos e dever do Estado, premissa essa que deu origem ao Sistema Único de Saúde (SUS).

O modelo de atenção à saúde adotado na implementação do SUS é baseado nos princípios da Atenção Primária à Saúde. Tem como princípios a universalidade, a integralidade, a equidade e a participação social e como diretrizes, a descentralização, a regionalização e a hierarquização dos serviços, com comando único em cada esfera de governo. Foram regulamentados pelas Leis Orgânicas da Saúde 8080 de 1990 e 8142 de $1991^{3}$.

Em 1994, o Ministério da Saúde propôs a Estratégia Saúde da Família para reorganizar a Atenção Primária no Brasil. Ao fazê-lo, priorizou o acompanhamento longitudinal e integral das famílias, por meio do monitoramento das condições de vida e dos determinantes de saúde das coletividades ${ }^{4}$. 
Atualmente, um dos maiores desafios na atenção à saúde consiste em qualificar as equipes de saúde da família para identificar, planejar, implementar e avaliar estratégias de intervenção sob essa perspectiva ampliada da determinação social e dos diversos condicionantes do processo saúde-doença, especialmente nas famílias mais vulneráveis.

A ESF trabalha com prioridades de atendimento a grupos ou condições mais vulneráveis ao adoecimento e à morte. As prioridades da Estratégia são as gestantes, as crianças até dois anos de idade, os hipertensos, diabéticos, pacientes com tuberculose e hanseníase. Há, porém, um grupo relacionado ao ciclo vital, que tem se destacado nos últimos anos devido à mudança demográfica: - os idosos.

O envelhecimento per se já traz um conjunto de processos biológicos, psicológicos e sociais que tornam os idosos mais vulneráveis. Aqui cabe elucidar que esse grupo passa por processos distintos, porém muito relacionados, chamados de senescência, referente às modificações peculiares do envelhecimento, e senilidade, decorrente de processos mórbidos, frequente entre os idosos ${ }^{5}$. Trata-se, portanto, de um grupo vulnerável por sua própria condição no ciclo vital.

Comfort apud Papaléo Netto ${ }^{6}$ caracteriza o envelhecimento como "progressiva incapacidade de manutenção do equilíbrio homeostático em condições de sobrecarga funcional". Isso significa que o próprio processo de envelhecimento, associado a possíveis doenças crônicas, prevalentes nessa faixa etária, podem comprometer a manutenção da independência e da capacidade funcional dos idosos. 
Ribeiro, Oliveira e Silva, Modena et al ${ }^{7}$ realizaram uma pesquisa qualitativa para analisar as representações de envelhecimento e qualidade de vida entre 29 idosos membros de um grupo da terceira idade de Viçosa, Minas Gerais. Verificaram que, para esses idosos, tais representações não estão vinculadas apenas a presença ou ausência de doenças, mas dizem respeito à capacidade de realizar atividades da vida diária com autonomia, sem a interferência de outras pessoas. Esses idosos consideravam velhas as pessoas incapazes de desempenhar atividades físicas ou mentais, indicando influência da capacidade funcional na autopercepção da saúde.

Para Ramos ${ }^{8}$, o conceito clássico de saúde da Organização Mundial da Saúde (OMS) não é adequado para descrever saúde dos idosos, já que a ausência de doenças é privilégio de poucos e o completo bem-estar pode ser atingido por muitos, independentemente da presença ou não de doenças, pois o importante não é a presença de doenças e sim seu controle. Caso contrário, pode haver seqüelas, levando a incapacidades e dependência.

A própria Organização Mundial de Saúde (OMS) reconheceu que conhecer as causas mais freqüentes de morte e adoecimento, por meio da Classificação Internacional de Doenças e Problemas relacionados à Saúde - CID, já não é suficiente para o planejamento das ações em saúde. É preciso conhecer o que acontece com as pessoas após o diagnóstico de incapacidade e as repercussões da dependência nas diversas dimensões de sua vida ${ }^{9}$.

Em 2001, na Assembléia Mundial de Saúde, a OMS aprovou a criação de uma nova classificação para a capacidade funcional, intitulada Classificação Internacional de Funcionalidade, Incapacidade e Saúde - CIF $^{9}$. 
Com a CIF, o termo incapacidade deixou de ser a mera designação de um componente das dificuldades de um indivíduo para realizar uma atividade e passou a ser usado como um termo genérico global que abrange três perspectivas: corporal, individual e social ${ }^{10}$.

Incapacidade é, portanto, um termo genérico que inclui deficiências, limitações nas atividades e restrições em participação (perspectiva social). Indica os aspectos negativos da interação entre o indivíduo (com uma determinada condição de saúde) e seus fatores contextuais (sócio-ambientais) ${ }^{10}$.

A capacidade funcional refere-se a aspectos positivos, indicando a potencialidade para desempenhar as atividades da vida diária ou determinada ação, sem precisar de ajuda ${ }^{11}$. As medidas mais utilizadas para verificar a capacidade funcional são os instrumentos que avaliam a independência para as atividades da vida diária (AVD), as atividades instrumentais da vida diária (AIVD) e mobilidade.

As atividades da vida diária (AVD), também chamadas de atividades básicas da vida diária (ABVD), estão relacionadas às tarefas de autocuidado, como banharse, vestir-se, comer e utilizar o banheiro. Em geral, quanto maior o número de incapacidades para as atividades da vida diária, maior a severidade da incapacidade e maior a dependência ${ }^{12}$.

As atividades instrumentais da vida diária (AIVD) são consideradas mais complexas porque estão relacionadas à cognição do indivíduo. Indicam tarefas necessárias para a vida em comunidade, como usar o telefone, fazer compras, tarefas domésticas, preparar refeições. 
Já a mobilidade refere-se às atividades que uma pessoa realiza para mudar ou manter a posição ou o lugar do corpo; para carregar, mover e utilizar objetos, para caminhar, mover-se ou para se deslocar utilizando meios de transporte ${ }^{13}$. Por sua complexidade, é considerada um grau intermediário entre as ABVD e as AIVD.

A deficiência é outro termo que está relacionado ao conceito de incapacidade, pois se refere a anormalidades ou perda de uma estrutura ou função corporal ${ }^{13}$. A deficiência pode gerar diferentes graus de incapacidades.

Considera-se dependente alguém que não consiga realizar sem ajuda qualquer das atividades básicas ou instrumentais da vida diária, em decorrência de alguma deficiência física ou mental, pela senilidade ou por sequelas de alguma doença. González ${ }^{10}$ define dependência como a "situação em que a pessoa com incapacidade, precisa de ajuda técnica ou pessoal, para a realização (ou melhorar o rendimento funcional) de uma determinada atividade" (pág 18).

Estudo ${ }^{12}$ que verificou o perfil de dependência na população espanhola por meio da avaliação da gravidade das incapacidades encontrou algumas associações entre esses dois conceitos: quanto mais graves as incapacidades em relação às atividades da vida diária, menor grau de dependência entre as incapacidades sensoriais e maior grau de dependência para a mobilidade e para realizar atividades da vida diária. 


\subsection{Atenção à saúde das pessoas com incapacidades e dependência}

Por iniciativa de alguns estados e municípios, serviços de assistência domiciliária já estão sendo implantados no setor público brasileiro, em resposta a necessidades e demandas de pessoas com alguma dependência e que necessitam de cuidados no domicílio.

A partir de 2011, no Brasil, por meio da Portaria 2.029 de 24 de agosto foi instituída atenção domiciliária no âmbito do Sistema Único de Saúde (SUS) ${ }^{14}$. De acordo com a Portaria, o Serviço de Assistência Domiciliar (SAD) poderá ser oferecido aos pacientes com condições de concluir o tratamento em domicílio, conforme diagnóstico médico.

O SAD está inserido no contexto das Redes de Atenção à Saúde do SUS, como as unidades básicas de saúde, as UPAs (Unidades de Pronto Atendimento 24 horas), o SAMU (Serviço de Atendimento Móvel de Urgência) e a ESF. Destina-se a pessoas com necessidade de reabilitação motora, idosos, pacientes crônicos sem gravidade ou em situação pós-cirúrgica. Os que demandam monitoramento ininterrupto (como aqueles que necessitam de ventilação mecânica), assistência contínua de Enfermagem ou tratamento cirúrgico deverão permanecer internados ou mantidos sob cuidados ambulatoriais.

Segundo a Portaria ${ }^{14}$, os profissionais do SAD devem ser organizados em Equipes Multiprofissionais de Atenção Domiciliar (EMAD), compostas por até dois médicos, até dois enfermeiros, um fisioterapeuta ou um assistente social e quatro auxiliares/técnicos de enfermagem. Devem contar com o suporte de Equipes Multiprofissionais de Apoio (EMAP), quando necessário, e também com o auxílio de 
profissionais da ESF ${ }^{14}$.

Os serviços de atenção a pessoas com alguma incapacidade ou dependência, em seu domicílio, está em ascensão no Brasil, em decorrência da nova demanda provocada pelas mudanças no perfil demográfico e epidemiológico da população. Esses serviços deverão trabalhar integrado com as equipes da atenção primária, em especial, as equipes de saúde da família, que devem estar preparadas para atuar na assistência a esses indivíduos dependentes e principalmente, na detecção precoce da presença de vulnerabilidades no indivíduo e na família. Nessa perspectiva é importante a criação de ferramentas que auxiliem os profissionais da atenção primária a identificar tais condições e a intervir com ênfase nas ações de prevenção ou de redução de danos.

Há diversas condições, sociais e de saúde, que podem estar presentes nas famílias e que fortalecem os potenciais de desgaste para o aparecimento de incapacidades e dependência. Por exemplo, por razões familiares ou sociais, há no Brasil muitos idosos frágeis que moram sozinhos, famílias pobres com restrição no uso de transportes, pessoas com transtornos mentais, entre outros. Do ponto de vista da atenção integral à saúde, essas condições são propícias ao surgimento de incapacidades e dependência, deixando tais famílias em situação de maior vulnerabilidade.

Não se trata, porém, apenas do cuidado às necessidades decorrentes da dependência física. Há um grande contingente de pessoas com dificuldades para acessar o sistema de saúde e que necessitam de cuidados de saúde específicos para garantir sua autonomia e independência ou, ao menos, reduzir suas limitações. 
Nesse sentido, é fundamental que as equipes de Saúde da Família estejam atentas a essa realidade no acompanhamento das famílias sob seus cuidados. Ações de promoção à saúde, bem como o monitoramento das condições desfavoráveis, devem ser sistematizadas para que as incapacidades não apareçam ou não se agravem. Para isso são necessários instrumentos confiáveis, que possam auxiliar as equipes da Atenção Primária na identificação das famílias vulneráveis, por meio da investigação dos aspectos relacionados à incapacidade funcional, evidenciados na literatura.

\subsection{Aspectos relacionados à capacidade funcional}

Verbrugge e Jette ${ }^{15}$ referem-se à capacidade funcional como um construto multidimensional, afirmando que não se trata de um estado estático e sim de uma condição multifatorial que difere em relação a causas, natureza, forma de aparecimento, ritmo e implicações sociais.

Com base na concepção multifatorial de risco, esses autores desenvolveram um modelo teórico do processo de instalação da incapacidade que envolve três aspectos: 1) fatores predisponentes, ligados a características sociodemográficas; 2) fatores individuais, associados a estilos de vida, atributos psicossociais, mudanças de comportamento, maneiras de lidar com dificuldades, doenças e modificações de atividades que podem afetar resultar em incapacidade e 3) fatores extra-individuais, que englobam intervenções dos serviços de saúde e de reabilitação, uso de medicamentos, suportes externos, ambiente físico e social.

Utilizando esse modelo, Giacomin, Peixoto, Uchoa et al ${ }^{16}$ estudaram condições associadas à incapacidade funcional entre idosos na Região 
Metropolitana de Belo Horizonte, Minas Gerais, tendo encontrado uma prevalência de incapacidade de $16 \%$ ( $8 \%$ leve e $8 \%$ grave).

Entre as características estudadas, a idade e a autoavaliação negativa da saúde apresentaram associações positivas e independentes em ambos os níveis de incapacidade. Hipertensão e artrite apresentaram associações com incapacidade leve ou moderada, enquanto diabetes e acidente vascular cerebral apresentaram associações com incapacidade grave. A associação negativa com incapacidade grave foi observada para visita de amigos nos últimos trinta dias.

No Brasil, um dos primeiros estudos populacionais que envolveu a avaliação multidimensional de idosos foi realizado na cidade de São Paulo em $1984{ }^{17}$. Quase a metade dos idosos entrevistados na ocasião referiu precisar de ajuda para realizar pelo menos uma das atividades da vida diária (AVD), instrumentais ou pessoais (limpar a casa, ir ao banheiro, comer, trocar de roupa, etc.). Idosos de baixa renda, que moravam com filhos e netos em arranjos domiciliares multigeracionais, apresentaram maior grau de dependência para as AVD.

Ao investigar a influência de condições socioeconômicas, demográficas, atividades sociais e avaliação subjetiva da saúde sobre a capacidade funcional dos idosos em amostra representativa do município de São Paulo, realizado em 1989, Rosa, Benicio, Latorre et al ${ }^{18}$ encontraram as seguintes características associadas à dependência moderada ou grave: ser analfabeto, aposentado, pensionista, dona de casa, não ser proprietário da moradia, ter mais de 65 anos, composição familiar multigeracional, ter sido internado nos últimos 6 meses, ser "caso" no rastreamento de saúde mental, não visitar amigos, ter problemas de visão, história de AVC, não 
visitar parentes e ter avaliação pessimista de saúde ao se comparar com seus pares.

Um levantamento realizado por Costa ${ }^{19}$ com base na PNAD de $1998^{9}$ verificou que, de 28.943 idosos, 2,0\% eram incapazes de tomar banho, alimentar-se e ir ao banheiro sem ajuda, sendo que esse índice triplicava após os 70 anos em ambos os sexos, alcançando 7,9\% entre as mulheres após os 80 anos.

O estudo também mostrou que $4,4 \%$ dos participantes $(5,7 \%$ e $2,7 \%$ das mulheres e homens, respectivamente) não conseguia se abaixar, ajoelhar-se ou curvar-se e 6,2\% não eram capazes caminhar mais de um quilômetro (7,9 \% e 4,2\% das mulheres e homens, respectivamente), limitações que aumentavam com a idade em ambos os sexos. O perfil menos favorável foi verificado na população feminina, o que pode ser explicado pelo viés de sobrevivência seletiva e pela idade como variável de confusão. Nas palavras do autor:

"Em um estudo de natureza seccional, como a PNAD, os homens portadores de limitações das atividades, principalmente as mais intensas, estariam, possivelmente, subrepresentados, tendo em vista a maior carga de morbidade e a mortalidade mais precoce no sexo masculino, verificadas em diferentes estudos. A diferença observada entre os sexos pode ser explicada pelo efeito de confundimento da variável idade - ainda que residual, após a estratificação por faixa etária -, tendo em vista a estrutura mais envelhecida da população feminina e a associação positiva entre idade e freqüência de limitação das atividades verificada neste estudo." (Costa, 2006, p. 938) ${ }^{19}$ 
O Projeto SABE (Saúde, Bem-estar e Envelhecimento) ${ }^{20}$, realizado entre janeiro de 2000 e março de 2001, com 1.769 idosos residentes no Município de São Paulo, investigou a influência de doenças crônicas (hipertensão arterial, diabetes mellitus, doença cardíaca, doença pulmonar, câncer e artropatia) na capacidade funcional (atividades de vida diária - AVD - e atividades instrumentais de vida diária - AIVD) dos idosos ${ }^{21}$.

Os resultados revelaram que as doenças crônicas exercem grande influência na capacidade funcional do idoso. A presença de hipertensão arterial aumentou em $39 \%$ a chance de o idoso ser dependente nas AIVD, a doença cardíaca em $82 \%$, a artropatia em 59\% e a doença pulmonar em 50\%. Para a dependência nas AIVD e AVD, a chance mais que dobrou com a presença de cada uma dessas doenças crônicas. A presença de câncer ou de diabetes mellitus, entretanto, não ocasionou um impacto estatisticamente significativo na dependência funcional do idoso.

Inquérito populacional domiciliário realizado na população idosa de Joaçaba, Santa Catarina, entre 2003 e 2004, com objetivo de estimar a prevalência de capacidade funcional inadequada e condições associadas indicou que a taxa de prevalência de diminuição da capacidade funcional em $37,1 \%$ dos entrevistados, associada a idade (70 anos ou mais), sexo feminino autopercepção negativa da situação econômica. ${ }^{22}$

Em investigação que relacionou condições de saúde, capacidade funcional e inserção social, Lima-Costa, Matos e Camarano ${ }^{23}$ buscaram verificar alterações nas desigualdades sociais em saúde de adultos (20- 64 anos) e idosos (> 65 anos) brasileiros entre 1998 e 2003. O estudo foi realizado em amostras das PNAD de 1998 e 2003, com 203.455 e 239.700 participantes, respectivamente. 
Os resultados evidenciaram que, nos dois anos considerados, indivíduos dos estratos mais baixos de renda apresentavam piores condições de saúde, pior função física e menor uso de serviços de saúde, tanto na faixa etária de 20-64 quanto na de $>65$ anos de idade.

Revelou ainda que as desigualdades sociais afetam igualmente as condições de saúde de adultos e idosos e que, em ambos os períodos, as desigualdades mais evidentes diziam respeito ao uso de serviços de saúde, indicadores gerais da condição de saúde e capacidade funcional, que apresentaram impacto maior sobre a qualidade de vida relacionada à saúde que a presença de doenças crônicas ou o número dessas doenças, indicando a influência dos determinantes sociais nas condições de saúde da população.

Gaspar, Oliveira e Duayer ${ }^{24}$ verificaram o perfil dos pacientes com perdas funcionais e dependência atendidos pela ESF na cidade de São Paulo. Os distritos de saúde do Município foram agrupados em relação ao Índice de Exclusão Social por meio de uma análise de cluster, seguida da descrição estatística das variáveis, comparando-os entre si. Para o município como um todo, verificaram a predominância de mulheres idosas, com incapacidade leve e que requerem cuidados de menor complexidade, compatíveis com a Atenção Básica. Nos distritos com maior exclusão social, foi maior a proporção de homens com menos de 60 anos e crianças com incapacidade severa, que necessitavam de cuidados de maior complexidade.

Em síntese, os grupos com exclusão alta e moderada apresentaram em média maior número de pessoas com incapacidades e dependência, com maior proporção de homens com menos de 60 anos com incapacidade severa e que 
demandavam cuidados de maior complexidade, sendo o AVC a doença predominante.

Os grupos com exclusão baixa e muito baixa continham proporcionalmente mais mulheres idosas com incapacidade leve e moderada e que requeriam cuidados de menor complexidade, sendo o AVC e a hipertensão as patologias predominantes.

A revisão da literatura evidencia que a maioria das publicações sobre incapacidades e dependência está relacionada à população idosa, sendo poucos estudos na população geral. Além disso, não foram encontradas investigações dedicadas à avaliação da vulnerabilidade de famílias a incapacidades e dependência, foco da presente investigação.

\subsection{Vulnerabilidade em saúde}

Na tentativa de superar, no sentido dialético do termo, o conceito de risco próprio da Epidemiologia clássica, este estudo adotará o conceito de vulnerabilidade, tal como proposto por Ayres ${ }^{25}$.

O conceito de risco busca identificar fatores quantificáveis, mensuráveis e associáveis, relacionados ao surgimento das doenças que são para, por meio deles e da comprovação estatística, produzir inferências sobre a causalidade da doença, denominados fatores de risco.

Na concepção da vulnerabilidade, a chance de exposição a determinado agravo resulta não apenas de aspectos individuais, mas também coletivos e contextuais que acarretam maior suscetibilidade e, de modo inseparável, maior ou menor disponibilidade de recursos protetores. 
As análises de risco trabalham com uma racionalidade analítica na qual os fenômenos em estudo precisam ser partidos, isolados e discriminados. Já as análises de vulnerabilidade trabalham com uma racionalidade sintética que privilegia a construção de significados, a agregação de elementos diversos que contribuem para que os fenômenos em estudo sejam compreendidos como uma totalidade dinâmica complexa ${ }^{25}$. A vulnerabilidade antecede o risco e determina os diferentes riscos de adoecer e morrer ${ }^{26}$.

O conceito de vulnerabilidade foi incorporado à área da saúde na década de 90, com os estudos sobre a aids, quando ainda se falava dos grupos de risco para contrair o HIV/aids $^{25}$. A culpabilização atribuída ao indivíduo e ao seu comportamento frente às situações de risco suscitou um movimento de oposição que foi buscar na área dos Direitos Humanos o conceito de vulnerabilidade. Sua adoção representou uma contribuição efetiva à diminuição do estigma e da discriminação contra os portadores de HIV/aids, ao difundir a idéia de que todos são suscetíveis, a depender não apenas do comportamento e da adoção de medidas preventivas em nível individual, mas também de aspectos sociais e estruturais envolvidos na exposição ao agravo.

Segundo Ayres $^{25}$, o conceito de vulnerabilidade está conformado por três planos interdependentes de determinação e, consequentemente, de apreensão da vulnerabilidade de indivíduos, grupos sociais e coletividades. As três dimensões são individual, social e pragmática (QUADRO 1).

Na dimensão individual, parte-se do princípio de que todos os indivíduos são suscetíveis e que os modos de vida podem expor ou proteger contra o agravo. No caso do HIV/aids, as premissas em que se fundamenta a vulnerabilidade individual 
são: qualquer pessoa é vulnerável ao HIV/aids; os meios de que dispõe para se proteger determinam sua vulnerabilidade; quanto maior o amparo social e a assistência à saúde, menor será a vulnerabilidade. Nessa dimensão, a vulnerabilidade é determinada por condições cognitivas (acesso à informação, reconhecimento da suscetibilidade e da eficácia das formas de prevenção), comportamentais (desejo e capacidade de modificar comportamentos que definem a suscetibilidade) e sociais (acesso a recursos e capacidade de adotar comportamentos de proteção).

A dimensão social da vulnerabilidade diz respeito a condições contextuais que definem a vulnerabilidade individual, entre elas a possibilidade de obter informações, o acesso aos meios de comunicação, a disponibilidade de recursos cognitivos e materiais, o poder de participar de decisões políticas e em instituições.

A dimensão programática ou institucional busca avaliar como, em circunstâncias sociais dadas, as instituições, especialmente as de saúde, educação, bem-estar social e cultura, atuam como elementos que reproduzem, quando não aprofundam, as condições socialmente dadas de vulnerabilidade. 
Quadro 1 - Aspectos a serem considerados nas três dimensões das análises de vulnerabilidade.

\begin{tabular}{|c|c|c|}
\hline INDIVIDUAL & SOCIAL & PROGRAMÁTICA \\
\hline $\begin{array}{l}\text { Valores } \\
\text { Interesses } \\
\text { Crenças } \\
\text { Credos } \\
\text { Desejos } \\
\text { Conhecimentos } \\
\text { Atitudes } \\
\text { Comportamentos } \\
\text { Relações Familiares } \\
\text { Relações } \\
\text { Amizade de } \\
\text { Relações afetivo- } \\
\text { sexuais } \\
\text { Relações } \\
\text { profissionais } \\
\text { Situação material } \\
\text { Situação psico- } \\
\text { emocional } \\
\text { Situação física } \\
\text { Redes e suportes } \\
\text { sociais }\end{array}$ & $\begin{array}{l}\text { Relações entre gerações } \\
\text { Normas e crenças religiosas } \\
\text { Estigma e discriminação } \\
\text { Emprego } \\
\text { Salários } \\
\text { Suporte social } \\
\text { Acesso a saúde } \\
\text { Acesso a educação } \\
\text { Acesso a justiça } \\
\text { Acesso a cultura, lazer e } \\
\text { esporte } \\
\text { Acesso a mídia } \\
\text { Liberdade de pensamento e } \\
\text { expressão } \\
\text { Participação política } \\
\text { Cidadania }\end{array}$ & $\begin{array}{l}\text { Compromisso político dos governos } \\
\text { Definição de políticas específicas } \\
\text { Planejamento e avaliação das políticas } \\
\text { Participação social no planejamento e } \\
\text { avaliação } \\
\text { Recursos humanos e materiais para as } \\
\text { políticas } \\
\text { Governabilidade } \\
\text { Controle social } \\
\text { Sustentabilidade política, institucional e } \\
\text { material da política } \\
\text { Articulação multissetorial das ações } \\
\text { Atividades intersetoriais } \\
\text { Organização do setor saúde } \\
\text { Acesso aos serviços } \\
\text { Qualidade dos serviços } \\
\text { Integralidade da atenção } \\
\text { Equidade das ações } \\
\text { Equipes multidisciplinares } \\
\text { Enfoques interdisciplinares } \\
\text { Integração entre prevenção, promoção e } \\
\text { assistência } \\
\text { Preparo tecnocientífico dos profissionais e } \\
\text { equipes } \\
\text { Compromisso e responsabilidade dos } \\
\text { profissionais } \\
\text { humanos } \\
\text { Participação comunitária na gestão dos } \\
\text { serviços } \\
\text { Responsabilidade social e jurídica dos } \\
\text { serviços }\end{array}$ \\
\hline
\end{tabular}

Fonte: Ayres JR, Calazans GJ, Saletti Filho HC, França Junior I. Risco, vulnerabilidade e práticas de prevenção e promoção da saúde. In: Campos GWSC, Minayo MCS, Akerman M, Drumond Júnior $M$, Carvalho YM, organizadores. Tratado de Saúde Coletiva. São Paulo/Rio de Janeiro: Editora Hucitec/Editora Fiocruz; 2006. p. 407. 
O conceito de vulnerabilidade, ao superar o âmbito individual e multifatorial de risco, vincula-se ao marco teórico-metodológico da Saúde Coletiva e da determinação do processo saúde-doença, na medida em que contempla as dimensões singular, particular e estrutural da realidade para analisar os determinantes do processo saúde-doença de determinado grupo social.

Baseado nesse conceito de vulnerabilidade e no referencial teóricometodológico da Saúde Coletiva, esse estudo procurará adaptar e validar um Índice capaz de indicar famílias em situação de vulnerabilidade para incapacidades e dependência. Tomará como base um instrumento existente, intitulado Índice de Desenvolvimento da Família - IDF ${ }^{27,28}$. Sua finalidade é identificar famílias em situação de maior vulnerabilidade e com isso subsidiar o planejamento de ações que visem ao monitoramento dos determinantes de suas condições de vida e saúde, assim como as intervenções mais adequadas às suas necessidades. $O$ índice poderá servir como um instrumento diagnóstico e de intervenção tanto na gestão como na assistência às famílias no âmbito da ESF.

\subsection{Indicadores em saúde}

Um indicador é uma variável, característica ou atributo capaz de sintetizar, representar ou dar maior significado ao que se quer avaliar. Uma das formas de expressar um indicador é por meio de índices. Um índice é um indicador multidimensional, ou seja, é capaz de expressar diversas dimensões ou facetas de uma situação. Nos últimos anos, os chamados indicadores sociais têm sido mais amplamente desenvolvidos. 
Segundo Cobo e Sabóia ${ }^{29}$, indicadores sociais "são medidas estatísticas que resumem aspectos importantes sobre as condições de vida das pessoas". São compostos por variáveis referentes a demografia, mortalidade, morbidade, condições de saúde, educação, cultura, mercado de trabalho, rendimento, moradia, saneamento básico, condições vida, qualidade de vida, meio ambiente, entre outros.

Permitem perceber e avaliar as mudanças que ocorrem na sociedade, identificar locais e segmentos da população que necessitam de ações prioritárias do governo e acompanhar a implementação de determinadas políticas e programas governamentais ${ }^{29}$. Apresentam um campo amplo de estudos e utilização, visto que há uma grande demanda, tanto em nível nacional como internacional, para conhecer o grau de desenvolvimento humano e avaliar os efeitos e os impactos das políticas públicas sobre o bem-estar das coletividades ${ }^{29}$.

A pobreza, outro fenômeno multidimensional, é um exemplo de indicador social medido por meio de índices, ainda que comumente seja reduzida somente à insuficiência de renda. De fato, no modelo econômico atual, o acesso a grande parte dos recursos necessários à sobrevivência digna estão relacionados à disponibilidade de recursos monetários, porém há diversas dimensões envolvidas em uma situação de pobreza. Portanto, a composição de um índice que se propõe medir a pobreza deve antes de tudo determinar quais as dimensões que deverão representá-la.

Os indicadores sintéticos medem conceitos multidimensionais resumidos em um único índice que busca sintetizar a informação de diversos indicadores básicos. Um indicador sintético é uma regra de escolha, pois combina dimensões distintas, atribuindo pesos a cada uma delas. De forma geral, as dimensões incorporadas assumem pesos positivos ou neutros, diferenciados ou não ${ }^{27,} 28$. 
Variados são os critérios para se obter os limites e o peso de cada indicador, sendo alguns puramente estatísticos, outros uma mescla de conveniência e critérios substantivos e estatísticos. Para Carvalho, Barros e Franco 27 "a escolha final de quais indicadores devem compor o índice sintético e de que pesos devem ser utilizados não é uma questão técnica ou estatística, devendo refletir preferências sociais".

Um dos indicadores sintéticos mais conhecidos é o Índice de Desenvolvimento Humano - IDH, criado pelo Programa das Nações Unidas para o Desenvolvimento (PNUD), no início da década de 1990, que relaciona esperança de vida ao nascer, taxa de analfabetismo, taxa de matrícula combinada e renda per capita. Esses quatro indicadores, distribuídos em três dimensões, têm a mesma importância no índice, que varia de zero a um, e sua combinação gera o IDH de um país em um determinado ano, permitindo a comparação entre os diferentes países em termos do grau de desenvolvimento de suas populações $27,28,29,30$.

Diversos índices similares ao IDH passaram a ser construídos e divulgados por várias instituições e pesquisadores, seguindo sua metodologia de agregação, porém com um número maior de dimensões e indicadores. Em 1998, o próprio PNUD, em conjunto com o Instituto de Pesquisa Econômica Aplicada (IPEA) e a Fundação João Pinheiro, lançou a publicação Desenvolvimento Humano e Condições de Vida: indicadores brasileiros, que, além do cálculo do IDH para o Brasil, unidades da federação e municípios (o chamado IDH Municipal ou IDHM), apresentava também outro índice sintético, denominado Índice de Condições de Vida (ICV), para todos os municípios brasileiros, construído com base em um maior número de dimensões e indicadores básicos ${ }^{27,28,31}$. 
Nessa mesma direção, destaca-se ainda o Índice Paulista de Vulnerabilidade Social - IPVS ${ }^{32}$. Idealizado pela Fundação Sistema Estadual de Análise de Dados SEADE, do governo de São Paulo, o IPVS permite classificar as diferentes áreas geográficas do Estado segundo os recursos da população residente. É composto por dimensões sociais, econômicas e demográficas que permitem classificar o setor censitário em seis grupos de vulnerabilidade social: nenhuma vulnerabilidade, muito baixa, baixa, média, alta e muito alta. A dimensão socioeconômica diz respeito à renda das famílias e ao poder de geração de recursos por seus membros, enquanto a dimensão demográfica está relacionada ao ciclo de vida familiar ${ }^{32}$.

O Índice de Necessidades em Saúde - INS ${ }^{33}$, desenvolvido pela Coordenação de Epidemiologia e Informação (CEInfo) da Secretaria Municipal de Saúde da cidade de São Paulo, tem o propósito de identificar áreas e grupos populacionais a serem priorizados para a oferta de serviços de saúde no Município. As necessidades contempladas no Índice são expressas nas condições demográficas, epidemiológicas e sociais da população residente nos diversos distritos administrativos (DA) da cidade ${ }^{33}$.

Deve-se ressaltar, no entanto, que há muitos questionamentos sobre a forma como são compostos os indicadores sintéticos, relativos principalmente à seleção arbitrária dos indicadores e aos pesos utilizados em sua construção. A maior crítica refere-se ao seu uso para expressar a situação social dos países, cuja diversidade e complexidade dificilmente é captada por índices dessa natureza. Outra crítica diz respeito à utilização dos indicadores sintéticos para o monitoramento de políticas públicas específicas. 
O IDH tem sido objeto de críticas por apresentar deficiências como: a) a seleção arbitrária dos indicadores e dos pesos utilizados na sua criação, não refletindo preferências socais; b) não ser adaptado de modo a ser calculado para cada família, apenas estimado para áreas geográficas e c) dificuldades para agregação em grupos demográficos como negros, idosos etc ${ }^{28}$.

Índices sintéticos como IDH e similares apontam áreas de ação prioritária, mas não identificam problemas específicos. A avaliação do impacto das políticas públicas requer instrumentos ainda mais específicos, que permitam o monitoramento e a comparação de diferentes grupos sociais $27,28,29,30$.

Ao comentar sobre os limites do IDH, Paixão ${ }^{34}$ ressalta que não se pode utilizar um único indicador como instrumento de análise da realidade. Carvalho, Barros e Franco ${ }^{27,} 28$ também comentam as limitações do IDH e seus similares, principalmente no que se refere à ponderação das dimensões e indicadores e o fato de que, por serem estimados apenas para áreas geográficas, não podem ser calculados para famílias. Para tanto, elaboraram o Índice de Desenvolvimento da Família (IDF), que será utilizado neste estudo para criação do índice proposto, intitulado, Índice de Vulnerabilidade da Família a Incapacidades e Dependência (IVF-ID).

A principal vantagem do IDF, no que concerne ao presente estudo, é o fato de que permite flexibilizar tanto a estrutura e como o cálculo em seus diversos domínios, componentes e indicadores. A metodologia desenvolvida para o cálculo do IDF pode ser aplicada quaisquer que sejam os indicadores e pesos selecionados, desde que as regras básicas de construção sejam mantidas. Assim, é possível 
construir um IDF com outros indicadores e pesos, desde que bem fundamentados e validados.

Outros atributos importantes considerados na escolha do IDF foram a desagregabilidade e a agregabilidade. Ou seja, o IDF agrega em primeiro lugar as informações temáticas sobre as famílias, gerando para cada uma delas um índice de desenvolvimento sintético que pode envolver agregações não só de natureza espacial-geográfica, mas também de natureza demográfica e social. Assim, é possível calcular o IDF de numerosos grupos sociais, recortados por gênero, etnia, geração etc. Para tal, entretanto, é necessário que todas as informações venham de uma única fonte, o mais rica e completa possível.

O IDF também pode ser agregado por meio da média ponderada dos índices dos bairros, municípios ou estados. Isso porque a população de referência para o cálculo de todos os indicadores é sempre a mesma família ${ }^{27,28}$.

Entretanto, como o IDF baseia-se em informações coletadas na PNAD, alguns indicadores, como os relacionados às condições de saúde e rede de suporte social, não estão contemplados nesse Índice e serão incluídos no presente estudo, já que constituem indicadores fundamentais para detecção de vulnerabilidade à incapacidade e à dependência.

Najar ${ }^{35}$ também adaptou o IDF com o objetivo de olhar os dados no nível municipal, utilizando como base os dados do Censo Demográfico. Com isso, alguns indicadores do IDF relacionados ao PNAD foram substituídos por outros relacionados ao Censo, como a inclusão do componente de ausência de 
desvantagem física, que contém indicadores de incapacidades visuais, auditivas, de deambulação e pessoas com dependência.

Silva ${ }^{36}$ utilizou o IDF com o objetivo de identificar famílias em situação de vulnerabilidade em uma Unidade Básica da ESF do Distrito Federal. A autora também fez adaptações próprias ao instrumento original e outras sugeridas por Najar ${ }^{35}$.

\subsection{Indicador de vulnerabilidade das famílias a incapacidades e dependência}

No contexto atual de saúde, é relevante a criação de instrumentos válidos e confiáveis que possam, sob o olhar da integralidade, captar a vulnerabilidade das famílias ao aparecimento de pessoas com incapacidades e dependência. Tais instrumentos serão potencialmente úteis no âmbito da ESF, permitindo que a equipes planejem ações de saúde de modo a potencializar os potenciais de fortalecimento das famílias, atenuando o desgaste a que estão expostas.

Nos casos da condição já instalada, esses instrumentos permitirão que as equipes mobilizem os recursos existentes no nível da Atenção Primária ou encaminhem as famílias aos serviços especializados, para que possam ser atendidas em suas necessidades.

Este estudo consiste na criação e validação de um índice para verificar a vulnerabilidade de famílias a incapacidades e dependência. Para tanto, foi feita uma adaptação do IDF desenvolvido por Carvalho, Paes de Barros e Franco ${ }^{27,}{ }^{28}$, com vistas a construir um indicador que sintetize as dimensões de vulnerabilidade a 
incapacidades e dependência e que possa ser aplicado à avaliação da situação de famílias na Atenção Primária.

O propósito não é apenas verificar se há alguém com alguma incapacidade ou dependência no domicílio, mas principalmente identificar famílias em situação que a torna vulneráveis a incapacidades ou dependência.

Algumas condições de saúde, como a presença de doenças crônicas e de idosos entre os membros da família são mais facilmente associáveis ao aparecimento de incapacidades e dependência. Já a associação com condições sociais não é imediatamente perceptível, embora já existam estudos demonstrando associações entre escolaridade e dependência, por exemplo.

Neste estudo, a identificação das condições sociais servirá principalmente para compor o cenário no qual as famílias estão inseridas e com isso avaliar o tipo de suporte, os meios e os recursos de que dispõem. Condições sociais desfavoráveis podem agravar a condição de dependência e demandar maior atenção e cuidados da equipe de saúde.

No que se refere à presença de incapacidades e dependência entre os membros das famílias, há duas situações possíveis: aquelas que já contam com alguém com alguma incapacidade ou dependência (D) e outras que não tenham incapacidade ou dependência entre seus integrantes (I). Porém, como se pretende avaliar a vulnerabilidade das famílias a esses fenômenos, indicadores sociais e de saúde serão usados para caracterizar determinados aspectos da família que podem estar relacionados ao aparecimento ou agravamento desses eventos no futuro. Foram previstas as seguintes situações (QUADRO 2): 
$>$ famílias que tenham alguém com alguma incapacidade ou dependência (D) e que apresentem condições de saúde favoráveis (SAF) ou desfavoráveis (SAD) e condições sociais favoráveis (SOF) ou desfavoráveis (SOD)

$>$ famílias que NÃO tenham alguém com alguma incapacidade ou dependência (I) e que apresentem condições de saúde favoráveis (SAF) ou desfavoráveis (SAD) e sociais favoráveis (SOF) ou desfavoráveis (SOD), conforme demonstrado no quadro a seguir.

Quadro 2 - Combinação entre as condições de saúde e sociais favoráveis e desfavoráveis com famílias dependentes e independentes.

\begin{tabular}{|l|c|c|}
\hline \multirow{2}{*}{ Condições } & \multicolumn{2}{|c|}{ FAMíLIAS } \\
\cline { 2 - 3 } & Dependentes (D) & Independentes (I) \\
\hline Saúde Favoráveis (SAF) & SAFD & SAFI \\
\hline Saúde Desfavoráveis (SAD) & SADD & SADI \\
\hline Sociais Favoráveis (SOF) & SOFD & SOFI \\
\hline Sociais Desfavoráveis (SOD) & SODD & SODI \\
\hline
\end{tabular}

É difícil ordenar tais famílias quanto ao grau de vulnerabilidade a incapacidades e dependência, fenômenos que requerem uma abordagem multidimensional. Só é possível analisar a vulnerabilidade a cada dimensão separadamente. Ou seja, se a família A apresenta determinadas condições sociais e de saúde favoráveis e desfavoráveis em algumas dimensões e a família $B$, em outros, qual delas será mais vulnerável? Neste caso, somente é possível afirmar que a família A apresenta situação melhor em algumas dimensões que a família B e vice-versa. 
Ou ainda, se a família $C$ já possui alguém com alguma incapacidade $e$ dependência entre seus membros, porém apresenta condições sociais e de saúde favoráveis e a família D que não possui pessoas com incapacidades e dependência, porém suas condições sociais e de saúde e sociais são desfavoráveis, qual delas estaria em piores condições?

Nessas situações, há ainda dois aspectos que devem ser considerados: a presença ou não de incapacidades e dependência na família, bem como o seu grau, e as condições que podem favorecer o aparecimento ou que podem agravar a situação pré-existente, o que resulta nas seguintes situações para as famílias dependentes (D):

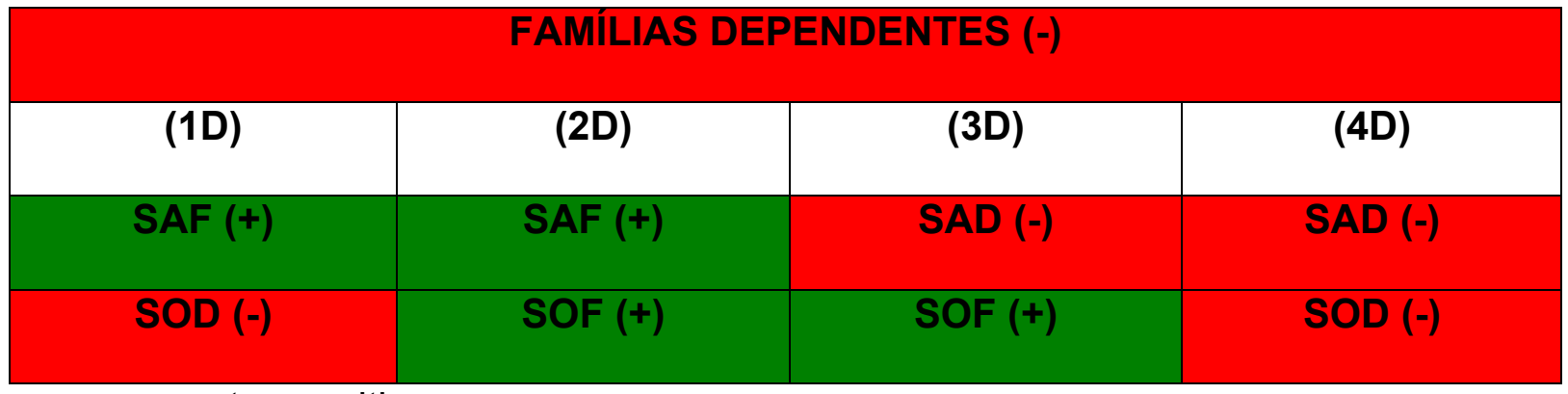

aspectos positivos

aspectos negativos

Em que:

$>$ (1D) - famílias que têm alguém com alguma incapacidade ou dependência (D) e apresenta condições de saúde favoráveis (SAF) e sociais desfavoráveis (SOD).

$>$ (2D) - famílias que têm alguém com alguma incapacidade ou dependência (D) e apresentam condições de saúde favoráveis (SAF) e sociais favoráveis (SOF). 
$>$ (3D) - famílias que têm alguém com alguma incapacidade ou dependência (D) e apresentam condições de saúde desfavoráveis (SAD) e sociais favoráveis (SOF).

$>$ (4D) - famílias que têm alguém com alguma incapacidade ou dependência (D) e apresentam condições de saúde desfavoráveis (SAD) e sociais desfavoráveis (SOD).

Para as famílias independentes (I), podem ser previstas as seguintes situações:

\begin{tabular}{|c|c|c|c|}
\hline \multicolumn{4}{|c|}{ FAMÍLIAS INDEPENDENTES (+) } \\
\hline$(1 \mathrm{I})$ & $(2 \mathrm{I})$ & $(3 \mathrm{I})$ & $(4 \mathrm{I})$ \\
\hline SAF (+) & SAF (+) & SAD (-) & SAD (-) \\
\hline SOD (-) & SOF (+) & SOF (+) & SOD (-) \\
\hline
\end{tabular}

aspectos positivos

aspectos negativos

Em que:

> (11) - famílias que NÃO têm alguém com alguma incapacidade ou dependência (I) e apresentam condições de saúde favoráveis (SAF) e sociais desfavoráveis (SOD).

(2I) - famílias que NÃO têm alguém com alguma incapacidade ou dependência (I) e apresenta condições de saúde favoráveis (SAF) e sociais favoráveis (SOF).

$>$ (3l) - Famílias que NÃO têm alguém com alguma incapacidade ou dependência (I) e apresentam condições de saúde desfavoráveis (SAD) e sociais favoráveis (SOF). 
> (4I) - Famílias que NÃO têm alguém com alguma incapacidade ou dependência (I) e apresentam condições de saúde desfavoráveis (SAD) e sociais desfavoráveis (SOD).

Quanto aos aspectos positivos e negativos de cada situação, são possíveis as seguintes situações:

1. Menor vulnerabilidade (2I): Famílias que NÃO têm alguém com alguma incapacidade ou dependência (I) e apresentam condições de saúde favoráveis (SAF) e sociais favoráveis (SOF).

2. Maior vulnerabilidade (4D): Famílias que têm alguém com alguma incapacidade ou dependência (D) e apresentam condições de saúde desfavoráveis (SAD) e sociais desfavoráveis (SOD).

3. Menor vulnerabilidade entre as famílias que já vivenciam incapacidades e dependência (2D): famílias que têm alguém com alguma incapacidade ou dependência (D) e apresentam condições de saúde favoráveis (SAF) e sociais favoráveis (SOF).

4. Maior vulnerabilidade entre as famílias independentes para incapacidades e dependência (4I): famílias que NÃO têm alguém com alguma incapacidade ou dependência (I) e apresentam condições de saúde desfavoráveis (SAD) e sociais desfavoráveis (SOD).

\section{Melhor condição de saúde entre as famílias com incapacidades e} dependência (1D): famílias que têm alguém com alguma incapacidade ou dependência (D) e apresentam condições de saúde favoráveis (SAF) e sociais desfavoráveis (SOD). 
6. Melhor condição social entre as famílias dependentes (3D): famílias que têm alguém com alguma incapacidade ou dependência (D) e apresentam condições de saúde desfavoráveis (SAD) e sociais favoráveis (SOF).

7. Melhor condição de saúde entre as famílias com alguma incapacidade ou dependência (1I): famílias que têm alguém com alguma incapacidade ou dependência (D) e apresenta condições de saúde favoráveis (SAF) e sociais desfavoráveis (SOD).

8. Melhor condição social entre as famílias independentes (3I): famílias que NÃO têm alguém com alguma incapacidade ou dependência (I) e apresentam condições de saúde desfavoráveis (SAD) e sociais favoráveis (SOF).

$\mathrm{Na}$ proposição do instrumento, a escolha dos indicadores foi baseada em evidências da literatura das condições relacionadas ao aparecimento de incapacidades e dependência e da utilização da técnica Delphi ${ }^{37}$ para consulta a um comitê de especialistas no tema. Para atribuição do número de indicadores, bem como o peso, recorreu-se a testes estatísticos para auxiliar na escolha dos indicadores com maior influência nas dimensões e verificar sua validade quando associado a presença de incapacidades e dependência na família. 


\section{OBJETIVOS}

\subsection{Geral}

Construir e validar um índice de vulnerabilidade de famílias a incapacidades e dependência (IVF-ID).

\subsection{Específicos}

- Adaptar o Índice de Desenvolvimento da Família (IDF) para o desenvolvimento de um índice de vulnerabilidade de famílias a incapacidades e dependência;

- Verificar a validade aparente desse Índice por meio de um comitê de especialistas;

- Desenvolver e validar o Índice utilizando dados de famílias acompanhadas por equipes de saúde da família de uma região do município de São Paulo;

- Validar o Índice em outra região do município de São Paulo, em famílias acompanhadas por equipes de saúde da família. 


\section{MÉTODO}

\subsection{Tipo de pesquisa}

Trata-se de uma pesquisa exploratória, descritiva, transversal, de abordagem quantitativa.

\subsection{Local do estudo}

O estudo foi desenvolvido em duas regiões do município de São Paulo, Sul e Centro-oeste. O Município tem uma área de aproximadamente $1.461 \mathrm{~km}^{2}$ e uma população estimada de 11.253.503 habitantes em 2010. Por sua grandiosidade e complexidade, apresenta divisões político-administrativas para viabilização da gestão e implantação de políticas públicas. Está dividido em 31 subprefeituras (Figura 1) e a Secretaria Municipal de Saúde é composta por cinco Coordenadorias Regionais de Saúde (Figura 2) e 25 Supervisões Técnicas de Saúde. 


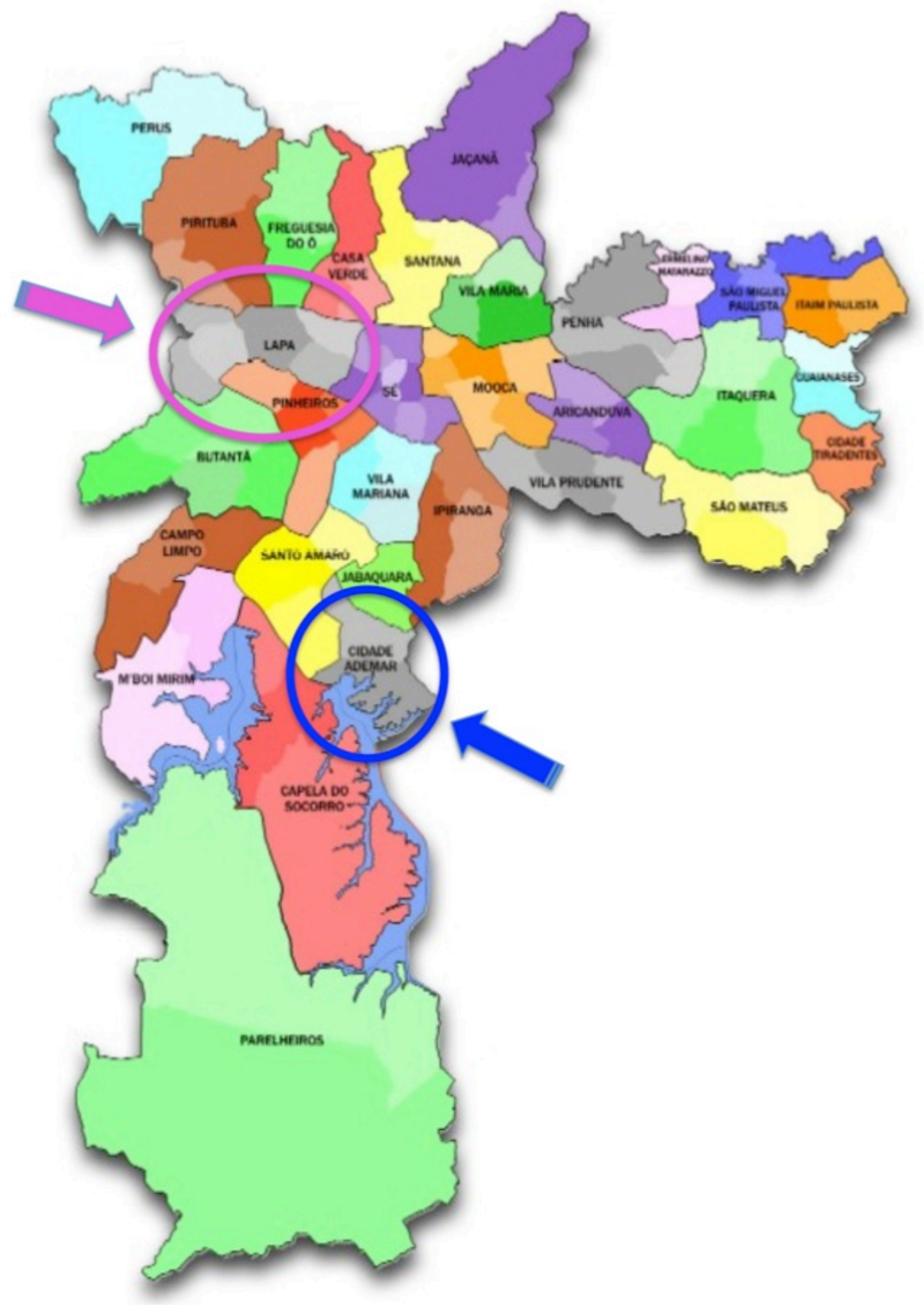

Figura 1 - Mapa das subprefeituras do município de São Paulo. São Paulo, 2010. Fonte: Prefeitura de São Paulo. Disponível em:

http://www.prefeitura.sp.gov.br/cidade/secretarias/subprefeituras/subprefeituras/map a/index.php? $\mathrm{p}=14894$ 


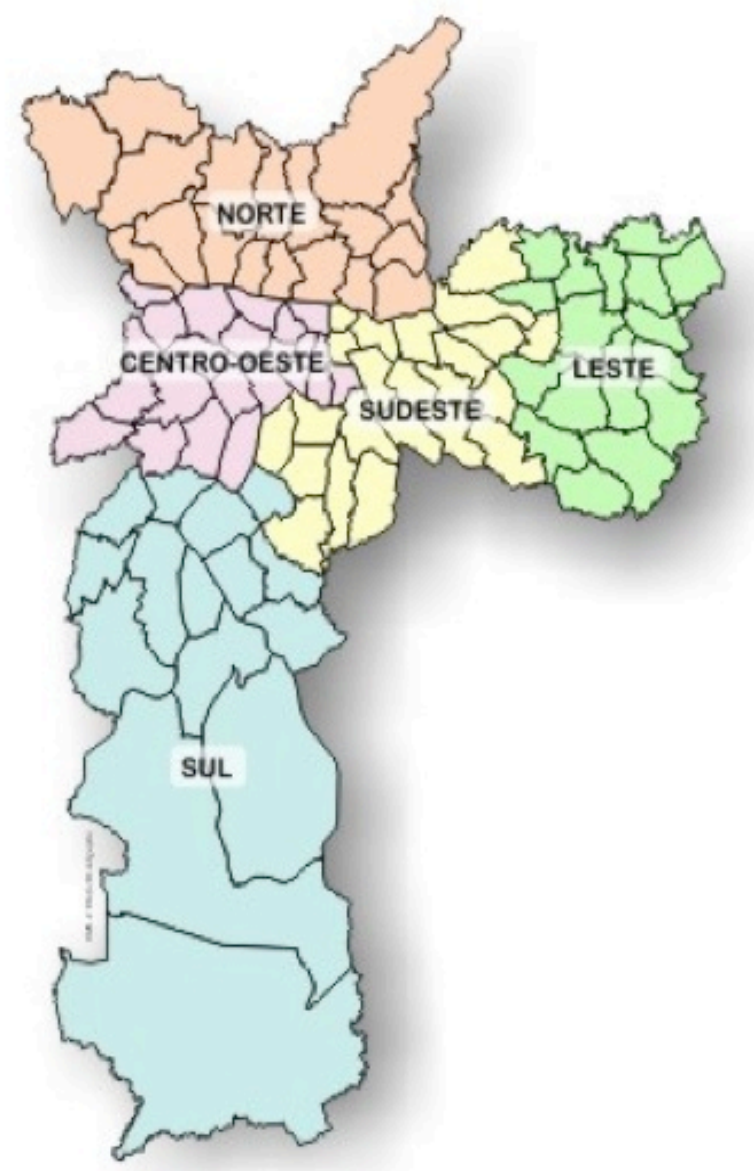

Figura 2 - Mapa das Coordenadorias Regionais de Saúde do município de São Paulo. São Paulo, 2011. Fonte: Prefeitura de São Paulo. Disponível em: http://www.prefeitura.sp.gov.br/cidade/secretarias/saude/organizacao/coordenadoria s_saude/index.php? $p=6541$

Para o desenvolvimento do estudo foram escolhidas Unidades Básicas de Saúde que contam com a Estratégia de Saúde da Família das subprefeituras da Lapa e Cidade Ademar. A subprefeitura da Lapa pertence à Coordenadoria Regional de Saúde Centro-oeste e à Supervisão Técnica de Saúde Lapa/Pinheiros (Figura 3). Já a subprefeitura da Cidade Ademar pertence à Coordenadoria Regional de Saúde Sul e à Supervisão Técnica de Saúde de Santo Amaro/Cidade Ademar (Figura 4). A escolha deveu-se à classificação dessas Subprefeituras em função da vulnerabilidade social. 
A Fundação Sistema Estadual de Análise de Dados - SEADE classificou essas Subprefeituras segundo a vulnerabilidade social, por meio do Índice Paulista de Vulnerabilidade Social (IPVS) ${ }^{38}$. A subprefeitura da Cidade Ademar apresenta um índice de vulnerabilidade muito alta $(17,1 \%)$, superior à média do Município, enquanto a da Lapa apresenta o índice de nenhuma vulnerabilidade $(46,5 \%)$ superior ao do Município $(13,9 \%)^{39}$.

A subprefeitura da Cidade Ademar é composta pelos distritos de Cidade Ademar e Pedreira, abrangendo uma área de $30,6 \mathrm{~km}^{2}$. Dentre seus indicadores socioeconômicos há $71,9 \%$ de domicílios com coleta de esgoto em rede, $24,3 \%$ da população em favelas, $23,4 \%$ dos chefes de família com menos de três anos de estudo e $40,9 \%$ da população com renda familiar inferior a 400 reais ${ }^{40}$.

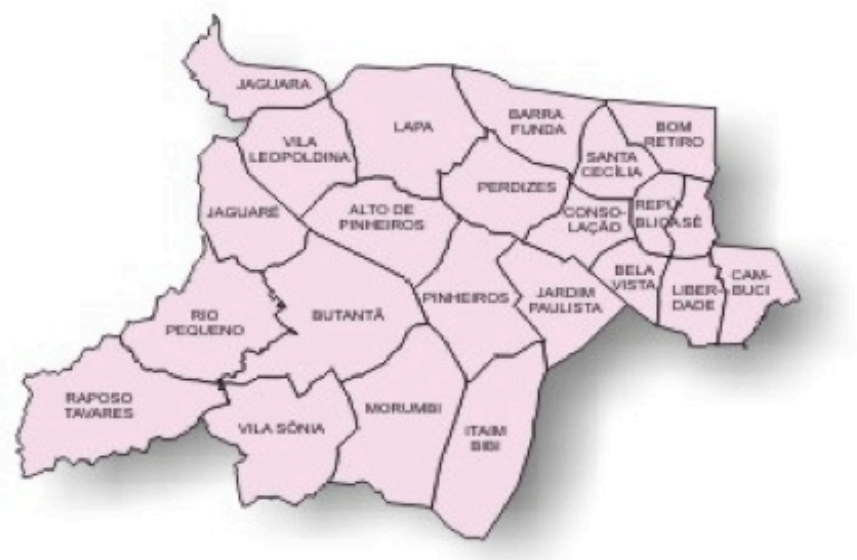

Figura 3 - Mapa das Supervisões Técnicas de Saúde da Coordenadoria Regional Centro-oeste. São Paulo, 2011. Fonte: Prefeitura de São Paulo. Disponível em: http://www.prefeitura.sp.gov.br/cidade/secretarias/saude/organizacao/supervisoes_d e_saude/index.php?p=5406/\#CO 
Na Cidade Ademar, a população vem aumentando nas últimas décadas, com um crescimento de aproximadamente $16 \%$ em 14 anos. A densidade demográfica é de $14.386,79$ habitantes $/ \mathrm{km}^{2}$, a terceira maior do município ${ }^{41}$.

Com relação aos indicadores demográficos, a proporção de crianças (0 a 9 anos) na região Sul, à qual pertence a subprefeitura de Cidade Ademar, é de 16,89\%, 15\% superior à da cidade de São Paulo. Já a proporção de idosos (mais de 60 anos) é baixa $(8,6 \%)$ e o índice de envelhecimento é de $36,3 \%$, sendo $15 \%$ inferior ao índice geral do Município. A taxa bruta de natalidade é igual nas regiões Centro-oeste e Sul (15,2 nascidos vivos/1.000 habitantes). Já a taxa bruta de mortalidade é menor na região Sul (4,65 óbitos/1.000 habitantes) ${ }^{40,42}$.

Em relação aos indicadores epidemiológicos, o coeficiente de mortalidade infantil na região Sul é de 11,1 óbitos/1.000 nascidos vivos. Ainda que a proporção de idosos seja o dobro na região Centro-oeste, o coeficiente de mortalidade padronizado por idade para doença cerebrovascular e diabetes mellitus é maior na região Sul (44,9 óbitos/100.000 habitantes e 15,9 óbitos/100.000 habitantes) ${ }^{40,42}$.

O coeficiente de mortalidade por homicídios também é maior na região Sul (15,5 óbitos/ 100.000 habitantes). Em 2007 e 2008, a Região apresentou os maiores coeficientes do Município (21,5 e 19,4 óbitos/ 100.000 habitantes) e, após uma queda considerável no ano de 2009 , ficou atrás da região Leste ${ }^{40,42}$.

Na região Sul, proporção da população que se vale exclusivamente de serviços do SUS, que não possui plano ou convênio de saúde, é de 59,3\%. 
Também tem a maior proporção de população cadastrada pela ESF $(61,5 \%)$, indicando um acesso diferenciado a esse modelo de atenção à saúde ${ }^{40,42}$. Em 2011 , a Cidade Ademar contava com 50 estabelecimentos de saúde, sendo 23 Unidades Básicas de Saúde ${ }^{40,42}, 11$ das quais com Estratégia Saúde da Família e uma em processo de implantação ${ }^{43}$.

A subprefeitura da Lapa corresponde a uma área de $40,57 \mathrm{~km}^{2}$ da cidade de São Paulo e é composta pelos distritos da Barra Funda, Jaguara, Jaguaré, Lapa, Perdizes e Vila Leopoldina ${ }^{41}$. Apresenta $96,7 \%$ dos domicílios com coleta de esgoto em rede e apenas $8,3 \%$ da população em favelas; somente $8,5 \%$ dos chefes de família com menos de três anos de estudo e $21,5 \%$ da população com renda familiar inferior a 400 reais ${ }^{40,42}$.

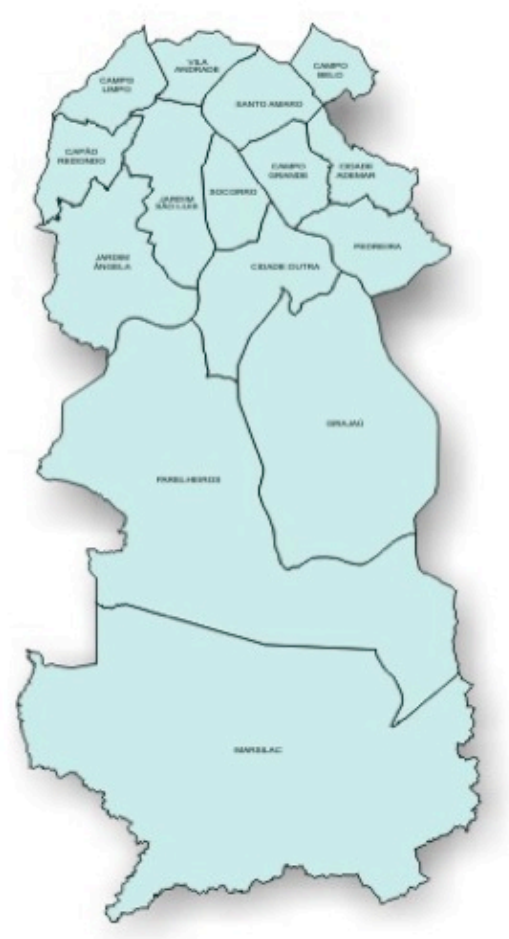

Figura 4 - Mapa das Supervisões Técnicas de Saúde da Coordenadoria Regional Sul. São Paulo, 2011. Fonte: Prefeitura de São Paulo. Disponível em: http://www.prefeitura.sp.gov.br/cidade/secretarias/saude/organizacao/supervisoes_d e_saude/index.php?p=5406/\#CO 
Em 2010, a população correspondia a 305.526 habitantes. Desde 1996 o crescimento populacional é de 7,6\%. A densidade populacional dessa região é a $4^{a}$ menor do município com $6.342,41$ habitantes $/ \mathrm{km}^{241}$.

Com relação aos indicadores demográficos, a proporção de crianças (0 a 9 anos) na região Centro-oeste, onde está localizada a subprefeitura da Lapa, era de $10,98 \%, 15 \%$ inferior à média do município. A proporção de idosos (mais de 60 anos) é a maior do Município (16,5\%). O índice de envelhecimento também é alto $(110,1 \%)$, apresentando valor superior a $15 \%$ do índice geral da cidade de São Paulo ${ }^{40,42}$.

Quanto aos indicadores epidemiológicos, em relação à taxa bruta de natalidade, os valores são semelhantes em todas as regiões do Município, sendo de 15,2 nascidos vivos/1.000 habitantes na região Centro-oeste ${ }^{40,42}$.

Não se verifica a mesma semelhança nas taxas bruta de mortalidade, sendo a da região Centro-oeste a maior do município (8,05 óbitos/1.000 habitantes). 0 coeficiente de mortalidade infantil vem diminuindo ao longo dos anos em todas as regiões do Município de São Paulo, sendo que a região Centro-oeste apresenta o menor índice (8,9 óbitos/ 1.000 nascidos vivos) ${ }^{40,42}$.

O coeficiente de mortalidade padronizado por idade para doença cerebrovascular e diabetes mellitus é de 27,3 óbitos/100.000 habitantes. A proporção de óbitos é de 11,4/100.000 habitantes e o coeficiente de mortalidade por homicídios é de 10,3 óbitos/100.000 habitantes, o menor entre todas as regiões do Município ${ }^{40,42}$. 
A região Centro-oeste é que apresenta a menor proporção da população exclusivamente SUS, que não possui plano ou convênio de saúde (44,5\%). Dentre essa população, 21,7\% é cadastrada pela Estratégia Saúde da Família, valor inferior ao restante do município ${ }^{40,42}$.

Em 2011, a subprefeitura da Lapa contava 35 estabelecimentos de saúde, sendo 13 Unidades Básicas de Saúde ${ }^{40,42}$ e entre essas, três com Estratégia Saúde da Família e uma em processo de implantação.

\subsection{População do estudo}

A população do estudo foi composta pelas famílias atendidas por equipes de Saúde da Família do município de São Paulo nas subprefeituras da Lapa e Cidade Ademar.

Os critérios de inclusão do estudo foram:

- família cadastrada na Unidade;

- $\quad$ presença de algum morador no domicílio no momento da entrevista, capaz de responder pela família;

Os critérios de exclusão do estudo foram:

- $\quad$ estar cadastrado na Unidade, porém não residir com a família no domicílio cadastrado;

- $\quad$ ninguém for encontrado no domicílio, após duas tentativas; 
- famílias consideradas "finais de semana" porque não ficam em casa no horário de funcionamento da Unidade.

\subsubsection{Cálculo da amostra}

Com base na prevalência de vulnerabilidade de $30 \%$, erro de $\pm 10 \%, \alpha=5 \%$ e poder de 80\%, estimou-se que seriam necessárias 138 famílias por Região. Considerando as eventuais perdas, optou-se por dobrar o tamanho da amostra, totalizando 300 famílias sorteadas em cada uma delas.

Para o sorteio da amostra foram obtidos os bancos de cadastro do SIAB do mês de fevereiro de 2011 das Unidades da região da Lapa e de maio de 2011 da região da Cidade Ademar. Isso porque foi solicitado o banco mais atual e em cada região os bancos de dados foram obtidos em tempos diferentes.

No período estudado, na região da Lapa, a UBS Parque da Lapa tinha 5.322 famílias cadastradas, a UBS Vila Jaguara 3.584 famílias e a UBS Vila Piauí 3.502 famílias, totalizando 12.408 famílias cadastradas nas Unidades com ESF.

Na Cidade Ademar o número total de famílias cadastradas era de 55.521 e estavam assim distribuídas dentre as 11 Unidades com ESF: UBS Cidade Júlia (5.208 famílias), UBS Jd. Apurá (3.614 famílias), UBS Jd. Niterói (5.889 famílias),

UBS Jd. São Carlos (4.722 famílias), UBS Jd. São Jorge (5.062 famílias), UBS Laranjeiras (4.488 famílias), UBS Mar Paulista (4.118 famílias), UBS Mata Virgem (5.108 famílias), UBS Vila Aparecida (5.294 famílias), UBS Vila Guacuri (5.012 famílias) e UBS Vila Império II (7.006 famílias). 
As variáveis selecionadas do banco de dados do SIAB foram o número da equipe, o número da microárea, o número de cadastro da família e o número de pessoas na casa. Após a seleção dessas variáveis no banco de dados de cada Unidade, juntou-se o banco de dados de todas as Unidades de cada região e foi feito um sorteio sistemático do cadastro das famílias de cada subprefeitura, fazendo a ordenação da lista de sorteio de acordo com o número da equipe, número da microárea e número de pessoas na casa.

\subsection{Procedimentos}

\subsubsection{Desenvolvimento do Índice}

Na criação do IVF-ID, a escolha dos indicadores baseou-se em evidências na literatura das condições relacionados ao aparecimento de incapacidade e dependência. A técnica Delphi foi usada para consulta a um comitê de especialistas.

Partiu-se do Índice de Desenvolvimento Familiar (IDF) elaborado por Carvalho, Barros e Franco ${ }^{27}$. O IDF utiliza um indicador sintético que é uma regra de escolha para o cálculo do índice, o qual prevê combinações de distintas dimensões, atribuindo pesos a cada uma delas. Avalia o grau de desenvolvimento das famílias por meio de informações disponíveis no questionário básico da Pesquisa Nacional por Amostra de Domicílio (PNAD).

O IDF é composto por seis dimensões, 26 componentes e 48 indicadores que se traduzem em perguntas feitas às famílias que devem responder SIM ou NÃO. O SIM significa algo positivo, indicando maior nível de desenvolvimento ${ }^{27}$. As seis dimensões que compõe o IDF são: 
1. Ausência de vulnerabilidade: situações que aumentam o volume de recursos que uma família necessita para satisfazer necessidades como alimentação e assistência à saúde.

2. Acesso ao conhecimento: meios que as famílias dispõem para satisfazer suas necessidades, avaliado através da escolaridade, qualificação profissional e analfabetismo.

3. Acesso ao trabalho: oportunidades que uma pessoa tem de utilizar sua capacidade produtiva

4. Disponibilidade de recursos: renda familiar per capita, recurso fundamental para aquisição de bens e serviços para satisfação de necessidades;

5. Desenvolvimento Infantil: trata-se de uma meta social para garantir à criança condições para o seu desenvolvimento pleno e

6. Condições habitacionais: que guardam relação com as condições de vida.

A análise da vulnerabilidade social é feita justamente pelos indicadores contidos no IDF, sendo esse um dos principais motivos de escolha da utilização desse Índice, já que está voltado para a avaliação social das famílias. Tais indicadores permitem conhecer as condições de vida e trabalho das famílias. Foram incluídos no IDF alguns indicadores específicos, associados à vulnerabilidade para incapacidades e dependência. A escolha desses indicadores segue o critério de ampla utilização em outros estudos, conforme a revisão da literatura:

1. Relações Sociais: refere-se à rede e ao apoio social das famílias, que influenciam a capacidade funcional, a dependência e a autonomia das pessoas. 
2. Condições de Saúde: conjunto de condições relacionadas que podem estar relacionadas ao surgimento de incapacidade e dependência. Os componentes deste domínio são: doenças crônicas, adesão ao tratamento, medicamentos, internações, quedas, avaliação subjetiva da de saúde, acesso aos serviços de saúde, incapacidade física, capacidade funcional e transtornos mentais.

Assim, o instrumento resultante da adaptação do IDF foi encaminhado aos juízes, para sua apreciação, contendo 8 dimensões, 38 componentes e 95 indicadores.

\subsubsection{Pré-teste}

Com a finalização da adaptação do IDF para a construção do IVF-ID, amplamente debatido com a orientadora de estudo e com membros do grupo de pesquisa, verificou-se a necessidade de submetê-lo a uma avaliação inicial externa, antes do encaminhamento ao corpo de juízes. Para isso, realizamos um pré-teste com uma juíza, enfermeira, professora e com formação em gerontologia e saúde coletiva.

Nesse pré-teste, o instrumento não sofreu qualquer alteração na composição geral, no que se refere aos domínios, componentes e questões. Entretanto, a redação de oito $(5,7 \%)$ itens foi modificada. Na segunda rodada, foram feitas sugestões a respeito de quatro $(2,7 \%)$ itens que, no entanto, foram mantidos para serem avaliados pelos juízes, por meio da técnica Delphi ${ }^{37}$. 


\subsubsection{Validade aparente - o uso da técnica Delphi}

No período de janeiro a julho de 2011 , o novo instrumento foi submetido a um corpo de juízes composto por pesquisadores e profissionais de saúde com expertise na temática que o Índice pretende medir, para que fossem feitas análises em relação à validade aparente. Esta técnica de validação permite avaliar se aparentemente o instrumento mede aquilo que pretende ${ }^{44}$. Embora considerada um teste pouco sofisticado, a validade aparente é imprescindível na construção de um instrumento para que posteriormente possam ser aplicados outros testes de validação.

\section{Técnica Delphi}

Na consulta aos juízes, a técnica Delphi foi utilizada para a obtenção do consenso. No método Delphi, é feita a "consulta um grupo de especialistas através de um questionário, que é repassado continuadas vezes até que seja obtida uma convergência das respostas, um consenso, que representa uma consolidação do julgamento intuitivo do grupo" ${ }^{37}$. Foram realizadas as seguintes etapas:

1. Definição clara do objetivo

2. Formulação do questionário com base na literatura

3. Escolha heterogenia do corpo de juízes.

4. $1^{\mathrm{a}}$ rodada: envio do questionário

5. Tabulação e análise dos dados

6. $2^{\mathrm{a}}$ rodada: apresentação dos resultados da rodada anterior, possibilitando que cada respondente reveja sua posição face à argumentação do grupo, em cada pergunta.

7. Rodada final até atingir um nível satisfatório de convergência. 
Oito juízes foram convidados a participar da pesquisa, porém um recusou, alegando falta de tempo. Outros dois chegaram a assinar o termo de consentimento livre e esclarecido, mas tiveram problemas pessoais e não conseguiram participar da pesquisa. Ao final, cinco juízes participaram do estudo, sendo dois enfermeiros e pesquisadores da área de gerontologia, um enfermeiro e uma médica sanitarista que trabalham na gestão de casos, vinculada a um serviço de assistência domiciliária na Atenção Básica, e uma assistente social e gerontóloga, que atua como docente e pesquisadora.

Adotou-se como nível de concordância entre os juízes pelo menos $80 \%$. Foram realizadas três rodadas de consultas para que o nível de convergência adotado fosse atingido. Em cada rodada, os comentários dos juízes foram tabulados e foi verificada a necessidade de exclusão, inclusão ou ajustes de itens, possibilitando que cada respondente revisse sua posição face à argumentação dos demais. Nessas etapas, o instrumento sofreu modificações, tanto na sua estrutura quanto na forma e no conteúdo. Com isso foi criado um instrumento com indicadores socais e de saúde selecionados para incapacidade e dependência, que resultará na criação do IVF-ID, que está descrito no item 3.4.5.

\subsubsection{Coleta de dados}

O instrumento final foi aplicado a famílias acompanhadas em três Unidades com Estratégia Saúde da Família na região da subprefeitura da Lapa, a saber, UBS Parque da Lapa, UBS Vila Jaguara e UBS Vila Piauí. Na época do sorteio da amostra havia outra Unidade Básica com ESF na região, porém ainda estava em processo de implantação e por isso não compôs o estudo. 
Em todas as Unidades onde se realizou a coleta de dados uma reunião foi agendada previamente com os gerentes e as equipes de saúde para apresentação do estudo e para o agendamento dos dias de coleta com os agentes comunitários de saúde (ACS), que acompanharam todas as entrevistas nos domicílios.

Em alguns casos, os ACS conseguiam avisar previamente as famílias e agendar as entrevistas. Quando isso não foi possível, as famílias eram informadas e convidadas a participar no momento da visita aos domicílios.

Famílias não encontradas na residência, mas que habitualmente poderiam ser encontradas foram visitadas uma segunda vez. Já aquelas que as equipes informavam que só permaneciam em casa nos finais de semana, que não eram encontradas no horário de funcionamento da Unidade ou que dificilmente eram encontradas em casa foram substituídas.

A substituição foi feita pela família residente na casa à esquerda da sorteada e, no caso de recusa, casa vazia ou moradores ausentes, foi feita nova substituição, desta vez pela família residente na casa da direita. Em algumas casas de classe econômica alta, apenas os empregados estavam cadastrados na ESF e não a família que morava no domicílio. Nesses casos, a família também foi substituída.

A coleta de dados foi realizada no período de setembro a novembro de 2011 por três entrevistadores enfermeiros.

\subsubsection{Instrumentos}

Os instrumentos de medida utilizados para o desenvolvimento e validação do IVF-ID foram os seguintes: 
Identificação da família (APÊNDICE I): foram coletados os dados do cadastro da família (identificação da equipe, identificação da microárea e número do cadastro) e as iniciais dos nomes de cada membro da família residente no domicílio, assim como sexo, data de nascimento e idade.

Instrumento com indicadores sociais e de saúde selecionados para incapacidade e dependência (APÊNDICE II):

Após a avaliação do comitê de juízes, o instrumento foi composto por oito dimensões, 38 componente e 103 questões. Dentre os domínios, seis referiam-se a aspectos sociais e foram adaptados do Índice de Desenvolvimento da Família (IDF); os outros dois, Relações Sociais e Condições de Saúde, foram acrescentados neste estudo. O Quadro 3 descreve a composição do instrumento final, em relação a suas dimensões, componente e questões.

Quadro 3 - Composição do instrumento final, segundo domínios, componentes e número de questões. São Paulo, 2011.

\begin{tabular}{|c|c|c|}
\hline DIMENSÕES & COMPONENTES & $\mathbf{N}^{\circ}$ QUESTÕES \\
\hline \multirow{5}{*}{$\begin{array}{l}1 \text { - Vulnerabilidade das } \\
\text { famílias }\end{array}$} & 1 - Fecundidade & 1,2 \\
\hline & $\begin{array}{l}2 \text { - Existência de crianças, } \\
\text { adolescentes e jovens }\end{array}$ & $3,4,5,6$ \\
\hline & 3 - Existência de idosos & $7,8,9,10$ \\
\hline & 4 - Condição econômica & 11,12 \\
\hline & 5 - Ausência de mãe & 13,14 \\
\hline \multirow{3}{*}{$\begin{array}{l}2-\text { Acesso ao } \\
\text { conhecimento }\end{array}$} & $6-$ Analfabetismo & $15,16,17$ \\
\hline & 7 - Escolaridade & 18,19 \\
\hline & 8 - Escolaridade do chefe da família & $20,21,22,23,24$ \\
\hline \multirow[t]{3}{*}{3 - Acesso ao trabalho } & 9 - Disponibilidade de trabalho & 25,26 \\
\hline & 10 - Qualidade do posto de trabalho & 27,28 \\
\hline & 11 - Remuneração & 29,30 \\
\hline \multirow{3}{*}{$\begin{array}{l}4-\text { Disponibilidade de } \\
\text { recursos }\end{array}$} & 12 - Extrema pobreza & 31 \\
\hline & 13 - Pobreza & 32 \\
\hline & $\begin{array}{l}14 \text { - Incapacidade de geração de } \\
\text { renda }\end{array}$ & 33 \\
\hline \multirow{4}{*}{$\begin{array}{l}5-\text { Desenvolvimento } \\
\text { infantil }\end{array}$} & 15 - Trabalho precoce & 34,35 \\
\hline & $16-$ Acesso à escola & $36,37,38$ \\
\hline & 17 - Progresso escolar & $39,40,41$ \\
\hline & 18 - Mortalidade infantil & 42,43 \\
\hline \multirow{3}{*}{$\begin{array}{l}6 \text { - Condições } \\
\text { habitacionais }\end{array}$} & 19 - Propriedade & 44,45 \\
\hline & 20 - Condições de moradia & 46 \\
\hline & 21 - Abrigabilidade & 47,48 \\
\hline
\end{tabular}




\begin{tabular}{|l|l|c|}
\hline & $22-$ Acesso a abastecimento de água & 49 \\
\cline { 2 - 3 } & $23-$ Acesso a saneamento & 50 \\
\cline { 2 - 3 } & $24-$ Acesso a coleta de lixo & 51 \\
\cline { 2 - 3 } & $25-$ Acesso a energia elétrica & 52 \\
\cline { 2 - 3 } & 26 - Acesso a bens duráveis & $53,54,55,56,57,58,59,60,61,62$ \\
\hline \multirow{5}{*}{ 8 - Relações sociais } & 27 - Rede social & $63,64,65,66,67,68,69,70,71$ \\
\cline { 2 - 3 } & 28 - Apoio social & $72,73,74,75,76,77$ \\
\cline { 2 - 3 } & 29 - Doenças crônicas & $78,79,80$ \\
\cline { 2 - 3 } & 30 - Adesão ao tratamento & 81,82 \\
\cline { 2 - 3 } & $31-$ Medicamentos & 83,84 \\
\cline { 2 - 3 } & $32-$ Internações & 85,86 \\
\cline { 2 - 3 } & $33-$ Quedas & 87 \\
\cline { 2 - 3 } & $34-$ Avaliação subjetiva da saúde & 88 \\
\cline { 2 - 3 } & $35-$ Acesso aos serviços de saúde & $89,90,91,92$ \\
\cline { 2 - 3 } & 36 - Incapacidade física & $93,94,95,96$ \\
\cline { 2 - 3 } & $37-$ Capacidade funcional & $97,98,99$ \\
\cline { 2 - 3 } & $38-$ Transtornos mentais & $100,101,102,103$ \\
\hline
\end{tabular}

Todas as questões referem-se sobre a presença de determinada condição na família. As respostas devem ser dadas por algum membro da família capaz responder em nome de toda família. As perguntas são fechadas e o respondente deve dizer apenas SIM ou NÃO. Em algumas questões, as respostas afirmativas indicam a presença de vulnerabilidade e valem 1 ponto, enquanto que as negativas indicam ausência de vulnerabilidade e não pontuam (0 pontos).

Em outras questões, respostas afirmativas indicam ausência de vulnerabilidade ( 0 pontos) e as negativas, presença de vulnerabilidade (1 ponto). Isso ocorre porque a depender da variável analisada, as respostas afirmativas ou negativas indicam condições contrárias de vulnerabilidade.

ÍNDICE DE KATZ: Índex de independência nas atividades de vida diária de Katz (ANEXO I)

O Índice de Independência nas Atividades Básicas de Vida Diária, denominado originalmente de "Index of Activity Daily Living", elaborado por Sidney Katz e 
publicado pela primeira vez em $1963^{45}$, é um dos instrumentos mais usados, nacional e internacionalmente, para avaliar as AVD.

Duarte, Andrade e Lebrão ${ }^{46}$, ao fazer uma revisão sobre a utilização do instrumento, verificaram que é utilizado de diferentes formas, principalmente em relação à classificação da dependência/independência e das atividades envolvidas.

O Índice de Katz avalia a independência no desempenho de seis funções consideradas básicas e biopsicossocialmente integradas, classificando as pessoas como independentes ou dependentes. As funções avaliadas são: banho, vestir-se, ir ao banheiro, transferência, continência e alimentação. Apresenta três categorias de classificação: independente, parcialmente dependente ou totalmente dependente. São considerados independentes às pessoas que desenvolvem qualquer atividade sem supervisão, orientação ou qualquer tipo de auxílio direto. No presente estudo, foi utilizada a classificação original, por meio de letras, como indicado no quadro a seguir:

\begin{tabular}{|c|l|}
\hline $\begin{array}{c}\text { Índice de } \\
\text { AVDs (Katz) }\end{array}$ & \multicolumn{1}{c|}{ Tipo de classificação } \\
\hline A & Independente para todas as atividades. \\
\hline B & Independente para todas as atividades menos uma. \\
\hline C & $\begin{array}{l}\text { Independente para todas as atividades menos banho e mais uma } \\
\text { adicional. }\end{array}$ \\
\hline D & $\begin{array}{l}\text { Independente para todas as atividades menos banho, vestir-se e } \\
\text { mais uma adicional. }\end{array}$ \\
\hline E & $\begin{array}{l}\text { Independente para todas as atividades menos banho, vestir-se, ir ao } \\
\text { banheiro e mais uma adicional. }\end{array}$ \\
\hline F & $\begin{array}{l}\text { Independente para todas as atividades menos banho, vestir-se, ir ao } \\
\text { banheiro, transferência e mais uma adicional. }\end{array}$ \\
\hline G & Dependente para todas as atividades. \\
\hline Outro & $\begin{array}{l}\text { Dependente em pelo menos duas funções, mas que não se } \\
\text { classificasse em C,D,E e F. }\end{array}$ \\
\hline
\end{tabular}

Fonte: Brasil. Ministério da Saúde. Secretaria de Atenção à Saúde. Departamento de Atenção Básica. Envelhecimento e saúde da pessoa idosa; 2006. pág 145. 
Foram consideradas dependentes as famílias que apresentavam algum membro com dependência para, pelo menos, uma das atividades e independentes aquelas que não tinham ninguém dependente para nenhuma das ABVD.

ESCALA DE LAWTON - A Escala de Lawton avalia as atividades instrumentais da vida diária (AIVD) (ANEXO II)

As AIVD exploram um nível mais complexo de funcionalidade, descrevendo as atividades necessárias para adaptação ao ambiente, dando ênfase às atividades comunitárias, sendo mais influenciadas cognitivamente. A independência para o desempenho dessas atividades está diretamente relacionada à capacidade de vida comunitária independente, tais como: (1) utilizar meios de transporte, (2) manipular medicamentos, (3) realizar compras, (4) realizar tarefas domésticas leves e pesadas, (5) utilizar o telefone, (6) preparar refeições, (7) cuidar das próprias finanças ${ }^{47,48}$.

A Escala utilizada nesse estudo é a recomendada pelo Ministério da Saúde no Caderno de Atenção Básica $n^{\circ} 19$ - Saúde do Idoso ${ }^{47}$ que, por sua vez, utilizou a versão publicada por Freitas e Miranda ${ }^{47,48}$ que classifica as pessoas como independentes ou dependentes no desempenho de nove funções. Em cada uma das funções a classificação é: sem ajuda (3 pontos), ajuda parcial (2 pontos) e não consegue (1 ponto). Portanto, a pontuação máxima é de 27 pontos e a mínima, 9 pontos. Quanto maior a pontuação, menor a dependência.

As questões 4 a 7, que se referem a preparar refeições, arrumar a casa, fazer trabalhos manuais domésticos, como pequenos reparos e lavar e passar a roupa, podem ter variações por condições ambientais ou por papéis assumidos durante a vida, como no caso das atividades domésticas. Essa é uma desvantagem da Escala 
e alguns autores sugerem que essas questões sejam adaptadas para outras atividades como subir escadas ou cuidar do jardim ou até mesmo recomendam a redução da Escala, excluindo essas questões.

No presente estudo, as questões não foram substituídas e nem excluídas, procurou-se captar a necessidade de ajuda, independente da prática ou habilidade. As famílias que porventura tivessem crianças dependentes, a Escala de Lawton não seria aplicada, apenas o índice de Katz.

\subsection{Análise estatística}

\subsubsection{Desenvolvimento dos indicadores}

Nesta etapa foi utilizada a amostra da Lapa. A caracterização dos membros das famílias foi feita pela estatística descritiva (número e porcentagem, média, desvio padrão, mediana, mínima e máxima). Foi utilizado o teste de KolmogorovSmirnov para avaliar a adesão à distribuição normal das variáveis quantitativas. Como diversas variáveis não apresentaram distribuição normal, foram utilizados testes não paramétricos. A comparação das médias de idade entre a população estudada das UBS da região da Lapa foi feita pelo teste de Kruskal-Wallis.

Realizou-se uma análise fatorial exploratória para verificar em quantos e quais seriam os componentes do IVF-ID. A análise fatorial foi feita utilizando KMO $>1$, rotação varimax e coeficiente de correlação $>0,40$. A partir daí foram calculados os índices baseado na soma das variáveis definidas em cada fator. Após o cálculo dos índices, utilizou-se o coeficiente alpha de Cronbach para análise de sua consistência interna. 
A validação dos fatores em relação à dependência foi feita por meio das validades discriminante e concorrente. $\mathrm{Na}$ análise da validade discriminante foi feita a comparação das médias dos indicadores, analisando famílias com e sem dependentes. Para essa definição, foram aplicados o Índice de Katz e a Escala de Lawton em todos os membros da família. Foram consideradas com dependência famílias que obtiveram qualquer classificação, exceto a letra $A$ (independência para todas as atividades), no Katz e pontuação menor do que 27, na Escala de Lawton. Nesta análise, utilizou-se o teste de Mann-Whitney.

$\mathrm{Na}$ análise da validade concorrente, calculou-se o coeficiente de correlação de Spearman entre os indicadores e os escores do Katz e Lawton. Após esta análise, três indicadores foram validados. Dois validaram somente em relação à Escala de Lawton e o terceiro validou com ambas as escalas, Katz e Lawton.

Diante desse resultado, decidiu-se agrupar os três indicadores e verificar sua consistência interna através do coeficiente alpha de Cronbach e realizar os testes de validade concorrente e discriminante, como descritos anteriormente. O agrupamento desses três indicadores também foi validado para as escalas de Katz e Lawton.

Foi escolhido um ponto de corte para vulnerabilidade, por meio da curva ROC, tanto para o indicador que isoladamente apresentou melhor desempenho nos testes de validade (validou para ambas as Escalas, Katz e Lawton) quanto para o agrupamento dos três indicadores.

A classificação das famílias, segundo a presença de vulnerabilidade, através o IVF-ID, foi feita através da análise descritiva (número e porcentagem). 


\subsubsection{Validação na Cidade Ademar}

A caracterização das famílias também foi feita por meio de estatística descritiva (número e porcentagem, média, desvio padrão, mediana, mínima e máxima) e o Índice construído na região da Lapa foi aplicado na população da Cidade Ademar. Foi realizada a estatística descritiva (número e porcentagem) do IVF-ID.

Utilizou-se o coeficiente alpha de Cronbach para análise da consistência interna do IVF-ID.

A validação do IVF-ID em relação à dependência foi feita através da validade discriminante e concorrente, igualmente a realizada na região da Lapa. Utilizou-se o teste qui-quadrado para comparação das vulnerabilidades, segundo o IVF-ID, entre as populações da Lapa e Cidade Ademar. O nível de significância adotado para este estudo foi de $p<0,005$. O tratamento dos dados foi feito utilizando-se o Software SPSS 15.0 (Statistical Package for the Social Sciences).

\subsection{Aspectos ético-legais}

O estudo obteve aprovação dos Comitês de Ética da Escola de Enfermagem (n 960/2010-CEP/EEUSP) (ANEXO III) e da Secretaria Municipal de Saúde de São Paulo ( $n^{\circ}$ 410/10-CEP/SMS) (ANEXO IV). Também foram obtidas autorizações da Organização Social Santa Catarina (OS-ACSC), Fundação Faculdade de Medicina da Universidade de São Paulo (FFMUSP) e Supervisão Técnica de Saúde LapaPinheiros, responsáveis pelo gerenciamento das Unidades das regiões da Cidade Ademar, Butantã e Lapa, respectivamente. 
Após contato inicial com as equipes de saúde da família de cada UBS para apresentação da pesquisa e agendamento prévio das visitas, as entrevistas foram realizadas no domicílio das famílias, sempre acompanhadas por um agente comunitário de saúde.

Os participantes foram informados dos objetivos da pesquisa e da confidencialidade dos dados, nos termos da Resolução 196/96, e assinaram o termo de consentimento livre e esclarecido (ANEXO V) manifestando sua anuência. 


\section{RESULTADOS}

\subsection{Avaliação dos juízes - técnica Delphi}

Após duas rodadas de avaliação dos juízes, cinco itens foram transferidos do componente "escolaridade" para um novo componente, intitulado "escolaridade do chefe da família". Foram acrescentadas cinco questões no componente "acesso a bens duráveis", quatro no componente "rede social" e três no "apoio social". Outros quatro itens foram excluídos do componente "capacidade funcional".

Como se pode observar na tabela 1, após o índice ser submetido ao comitê de expertos, houve nove acréscimos ao instrumento (um componente e oito questões), de modo que o Índice passou a ser composto por oito dimensões, 38 componentes e 103 questões. Muitas sugestões dos juízes na primeira rodada foram acordadas entre os juízes na segunda rodada e na rodada final.

Tabela 1 - Distribuição em números da composição geral do Índice, segundo dimensões, componentes e questões, na $1^{\mathrm{a}}$ e $2^{\mathrm{a}}$ rodadas São Paulo, 2011.

\begin{tabular}{lcc}
\hline Composição do Índice & $\mathbf{1}^{\mathbf{a}}$ rodada & $\mathbf{2}^{\mathbf{a}}$ rodada \\
\cline { 2 - 3 } & $\mathbf{N}$ & $\mathbf{N}$ \\
\hline Total de dimensões & 8 & 8 \\
Total de componentes & 37 & 38 \\
Total de questões & 95 & 103 \\
Total de itens no instrumento & 140 & 149 \\
\hline
\end{tabular}

A seguir, serão apresentados os itens que tiveram menos de $80 \%$ de concordância entre os juízes. 


\section{$1^{a}$ RODADA}

Frente às justificativas dos juízes para excluir ou manter com ajustes, os itens do instrumento foram classificadas quanto à forma ou conteúdo. No total, foram feitas 92 sugestões, $49(53,3 \%)$ relacionadas ao conteúdo e 43 (46,7\%) à forma. Dos 140 itens avaliados, entre dimensões, componentes e questões, apenas 17 $(12,1 \%)$ tiveram um nível de concordância menor do que $80 \%$, sendo quatro $(23,5 \%)$ relacionados à forma e $13(76,5 \%)$, ao conteúdo (Tabelas 2 e 3).

Na tabela 2 que reúne os itens discordantes em relação à forma diziam respeito aos componentes "trabalho precoce", "medicamentos", "avaliação subjetiva da saúde" e "transtornos mentais". Todos apresentaram $60 \%$ de concordância.

Tabela 2 - Distribuição dos itens do Índice com porcentagem de concordância menor de $\mathbf{8 0} \%$, entre os juízes, relacionado à forma, na $1^{\mathrm{a}}$ rodada. São Paulo, 2011.

\begin{tabular}{|c|c|c|c|c|c|c|c|c|c|}
\hline \multirow{2}{*}{$\begin{array}{l}\text { ITEM } \\
\text { Neste domicílio há: }\end{array}$} & \multicolumn{2}{|c|}{$\underset{1}{J U I Z}$} & \multicolumn{2}{|c|}{$\begin{array}{c}\text { JUIZ } \\
2\end{array}$} & \multicolumn{2}{|c|}{$\begin{array}{c}\text { JUIZ } \\
3\end{array}$} & $\begin{array}{c}\text { JUIZ } \\
4\end{array}$ & $\begin{array}{c}\text { JUIZ } \\
5\end{array}$ & \multirow[t]{2}{*}{$\begin{array}{c}\text { Concordância } \\
(\%)\end{array}$} \\
\hline & $E$ & A & $E$ & A & $E$ & $\mathbf{A}$ & E $\quad A$ & $E$ & \\
\hline $\begin{array}{l}\text { Q35 - Alguma criança com menos } \\
\text { de } 16 \text { anos trabalhando? }\end{array}$ & & $x$ & & $X$ & & & & & 60 \\
\hline $\begin{array}{l}\text { Q72 - Algum membro da família que } \\
\text { faz uso de } 5 \text { medicamentos ou } \\
\text { mais? }\end{array}$ & & $x$ & & $X$ & & & & & 60 \\
\hline $\begin{array}{l}\text { Q76 - Alguém com saúde ruim ou } \\
\text { muito ruim? }\end{array}$ & & & & $x$ & & $X$ & & & 60 \\
\hline $\begin{array}{l}\text { Q92 - Alguém com transtornos } \\
\text { mentais psiquiátricos? (depressão, } \\
\text { suicídio, transtorno de ansiedade, } \\
\text { transtorno obsessivo- compulsivo, } \\
\text { esquizofrenia, psicose, transtorno } \\
\text { bipolar)? }\end{array}$ & & $x$ & & $x$ & & & & & 60 \\
\hline
\end{tabular}

Na questão 35 ("Neste domicílio há alguma criança com menos de 16 anos trabalhando?"), cada juiz apontou para um aspecto diferente. 
Um deles sugeriu que se perguntasse se havia alguma criança entre 14 e 16 anos trabalhando, visto que na pergunta anterior já verificava se havia alguma criança com 14 anos ou menos trabalhando. A maioria dos juízes chamou a atenção para a aparente repetição das questões também nos componentes "existência de crianças, adolescentes e jovens", "existência de idosos", "remuneração", "acesso à escola" e "doenças crônicas".

Foi esclarecido que no Índice, tal como no IDF, os itens propositalmente são apresentados de maneira "repetitiva" (em cascata), uma alternativa a atribuir mais peso a determinados componentes. Dessa forma, todos os itens têm o mesmo peso, o que facilita o cálculo dos escores e permite que os mais vulneráveis pontuem mais que os menos vulneráveis.

Por exemplo, uma criança com 14 anos ou menos que trabalha pontuará duas vezes, enquanto a maior de 14 anos pontuará apenas uma vez. Outra sugestão nessa questão foi incluir o termo "com remuneração", para que ficasse claro que a pergunta dizia respeito ao trabalho remunerado.

Na questão 72 ("Algum membro da família faz uso de 5 medicamentos ou mais?"), os juízes observaram que faltavam informações na pergunta para captar o conceito de polifarmácia. Para isso, sugeriram acrescentar os termos "uso contínuo" e "de forma simultânea".

Já a questão 76, que fazia uma avalição subjetiva da saúde na família, estava mal formulada e os juízes sugeriram alteração da redação para "há alguém no domicílio que considera a própria saúde como ruim ou muito ruim?”. 
$\mathrm{Na}$ questão 92 ["Neste domicílio há alguém com transtornos mentais psiquiátricos? (depressão, suicídio, transtorno de ansiedade, transtorno obsessivocompulsivo, esquizofrenia, psicose, transtorno bipolar)?"] um dos juízes sugeriu alterar a forma da pergunta, não inserindo os exemplos entre parênteses e sim os incluindo na pergunta. Outro solicitou a substituição do termo "suicídio" por "tentativa de suicídio".

As discordâncias dos juízes referiram-se majoritariamente ao conteúdo das questões, como mostra a tabela 3.

Tabela 3 - Distribuição dos itens do Índice com porcentagem de concordância menor de $\mathbf{8 0} \%$ entre os juízes, relacionada ao conteúdo, na $1^{\text {a }}$ rodada. São Paulo, 2011.

\begin{tabular}{|c|c|c|c|c|c|c|c|c|c|c|}
\hline \multirow{2}{*}{$\begin{array}{r}\text { ITEM } \\
\text { Neste domicílio há: }\end{array}$} & \multicolumn{2}{|c|}{ JUIZ 1} & \multicolumn{2}{|c|}{ JUIZ 2} & \multicolumn{2}{|c|}{ JUIZ 3} & \multicolumn{2}{|c|}{ JUIZ 4} & JUIZ 5 & \multirow{2}{*}{$\begin{array}{c}\text { Concordância } \\
(\%)\end{array}$} \\
\hline & $E$ & $\bar{A}$ & $E$ & $\mathbf{A}$ & $E$ & $\mathbf{A}$ & $E$ & $\mathbf{A}$ & $E$ & \\
\hline $\begin{array}{l}\text { Q58 - Parentes que moram } \\
\text { próximo? }\end{array}$ & & $x$ & & $X$ & & & & & & 60 \\
\hline $\begin{array}{l}\text { Q59 - Amigos que moram } \\
\text { próximo? }\end{array}$ & & $x$ & & $x$ & & & & & & 60 \\
\hline $\begin{array}{l}\text { Q61 - A família recebe visitas de } \\
\text { familiares pelo menos uma vez } \\
\text { por semana? }\end{array}$ & & $x$ & & $x$ & & & & & & 60 \\
\hline $\begin{array}{l}\text { Q62- A família recebe visitas de } \\
\text { amigos/vizinhos pelo menos uma } \\
\text { vez por semana? }\end{array}$ & & $X$ & & $x$ & & & & & & 60 \\
\hline $\begin{array}{l}\text { Q63 - Alguém que não tem com } \\
\text { quem contar, caso necessite? }\end{array}$ & & $x$ & & $X$ & & & & $X$ & & 40 \\
\hline $\begin{array}{l}\text { Q64 - Alguém que não tem ajuda } \\
\text { se ficar acamado permanente ou } \\
\text { dependente para as tarefas do } \\
\text { dia-a-dia? }\end{array}$ & & $x$ & & $x$ & & $x$ & & $x$ & & 20 \\
\hline $\begin{array}{l}\text { Q65 - Alguém que não tem } \\
\text { ninguém para levar a consultas } \\
\text { ou serviços de saúde, caso } \\
\text { necessite? }\end{array}$ & & $X$ & & $x$ & & $x$ & & $x$ & & 20 \\
\hline $\begin{array}{l}\text { Q76 - Alguém com saúde ruim ou } \\
\text { muito ruim? }\end{array}$ & & $x$ & & & & & & $x$ & & 60 \\
\hline $\begin{array}{l}\text { Q79 - Alguém que precisa de } \\
\text { transporte para ir ao Serviço de } \\
\text { Saúde? }\end{array}$ & & $x$ & & $x$ & & & & & & 60 \\
\hline
\end{tabular}


Q85 - Alguém que apresenta vestir-se, controle de eliminação intestinal e vesical, deambulação, e transferências (Atividades Básicas da Vida Diária - ABVD)?

Q86 - Alguém que apresenta dificuldades graves na alimentação, higiene pessoal, vestir-se, controle de eliminação intestinal e vesical, deambulação

e transferências (Atividades

Básicas da Vida Diária- ABVD)?

Q89 - Alguém que apresenta alguma dificuldade em atividades como limpar a casa, cuidar da roupa, da comida, usar equipamentos domésticos, fazer compras, usar transporte pessoal ou público, controlar a própria medicação e finanças?

(Atividades Instrumentais da Vida Diária - AIVD)?

Q90 - Alguém que apresenta dificuldades graves para realizar atividades como limpar a casa, cuidar da roupa, da comida, usar equipamentos domésticos, fazer compras, usar transporte pessoal ou público, controlar a própria medicação e finanças?

(Atividades Instrumentais da Vida Diária - AIVD)?

$E$ - excluir $A$ - ajustar

No componente "rede social" (Q58 e Q59), um dos juízes sugeriu que fossem incluídas as definições de "familiares", "amigos" e "morar próximo".

Assim, foi acrescido ao instrumento o conceito ampliado de família, compreendido como "pessoas consideradas da família, com ou sem laços de consanguinidade"(8). Amigos foram definidos como "pessoas com quem mantém relações de amizade" e morar próximo foi considerado "a ponto de ser possível ir a pé", já que o objetivo da questão é avaliar a rede social que pode ser ativada facilmente em caso de necessidade. 
Ainda nesse componente, foi sugerido incluir mais duas categorias na frequência das visitas entre familiares e amigos: ao menos uma vez ao mês e ao menos uma vez ao ano.

Foi feita a inclusão, já que a rede social refere-se predominantemente a aspectos quantitativos do grupo de pessoas com as quais o indivíduo mantém contato ou alguma forma de vínculo social ${ }^{49}$.

Um dos componentes mais polêmicos e com baixa concordância entre os juízes foi o "apoio social". Algumas perguntas foram consideradas muito subjetivas, como por exemplo, "Neste domicílio há alguém que não tem com quem contar, caso necessite?". Um dos juízes argumentou que só é possível saber ser temos com quem contar no momento que precisamos de ajuda. Ainda assim, a questão foi mantida, pois o Índice procurará rastrear a vulnerabilidade das famílias ao surgimento de incapacidade e dependência e essa questão permitiria identificar casos evidentes de falta de apoio. Por outro lado, como as questões estavam muito genéricas optou-se por desmembrá-las nos tipos de apoio mais relacionados à incapacidade e dependência, como a de reforço ou emocional, instrumental ou material, afetiva e interação positiva ${ }^{49,50}$.

O componente da avaliação subjetiva da saúde recebeu correções quanto à forma e ao conteúdo. Um dos juízes questionou a veracidade da resposta e sobre influência do estado emocional. Estudos têm demonstrado que a autoavaliação da saúde é um importante determinante de piores condições de saúde, inclusive dependência. 
Com relação ao acesso ao serviço de saúde, a questão 79 foi criticada pelos juízes, que consideraram que o fato de necessitar de transporte para ir ao serviço não necessariamente significa dificuldade de acesso. A intenção era verificar se havia serviços de saúde próximos à residência da família. Para contemplar esse aspecto, a questão foi modificada para "Nesse domicílio há alguém que não consegue ir a pé ao serviço de saúde?".

A capacidade funcional foi avaliada por meio das questões que verificavam se havia alguém na residência com alguma dificuldade ou com dificuldade para realizar sem ajuda qualquer ABVD e AIVD (Q85 e Q86; Q89 e Q90). Os juízes questionaram como avaliar se a dificuldade era grave sem utilizar um instrumento específico de medida.

Um deles sugeriu que as questões fossem retiradas e substituídas por uma única: "Neste domicílio há alguma pessoa que, sem ajuda, não realiza qualquer das atividades...". Essa foi a opção adotada, visto que o instrumento não procurará realizar avaliações individuais aprofundadas e sim rastrear situações de vulnerabilidade na família.

\section{$2^{a} R O D A D A$}

$\mathrm{Na} 2^{\mathrm{a}}$ rodada, os juízes fizeram 26 sugestões, sete $(26,9 \%)$ relacionadas ao conteúdo e 19 , à forma $(73,1 \%)$. Dos 149 itens avaliados, somente quatro $(2,7 \%)$ apresentaram nível de concordância menor do que $80 \%$, sendo três relacionadas ao conteúdo e um, à forma. 
Foi possível perceber que a construção dos itens em cascata ainda não havia ficado clara para alguns juízes, que novamente sugeriram modificar as questões 34 e 35 para que as idades não se repetissem. Assim, foi necessário esclarecer uma vez mais que essa construção era intencional.

Novamente a questão da polifarmácia não obteve concordância entre os juízes, pois, o termo "de uso contínuo", mencionado na rodada anterior, foi sugerido acrescentar o termo "medicamentos diferentes". Com isso, o conceito de polifarmácia ficou plenamente contemplado na questão (Neste domicílio há alguma pessoa que faz uso contínuo de 5 ou mais medicamentos diferentes ao mesmo tempo"?).

Tabela 4 - Distribuição dos itens do Índice com porcentagem de concordância menor de $\mathbf{8 0 \%}$ entre os juízes, relacionada à forma, na $\mathbf{2}^{\mathrm{a}}$ rodada. São Paulo, 2011.

\begin{tabular}{|c|c|c|c|c|c|c|c|c|c|c|c|}
\hline \multirow{2}{*}{$\begin{array}{c}\text { ITEM } \\
\text { Neste domicílio há: }\end{array}$} & \multicolumn{2}{|c|}{ JUIZ 1} & \multicolumn{2}{|c|}{ JUIZ 2} & \multicolumn{2}{|c|}{ JUIZ 3} & \multicolumn{2}{|c|}{ JUIZ 4} & \multicolumn{2}{|c|}{ JUIZ 5} & \multirow{2}{*}{$\begin{array}{c}\text { Concordância } \\
\text { (\%) }\end{array}$} \\
\hline & $E$ & A & $E$ & A & $E$ & A & $E$ & A & $E$ & A & \\
\hline $\begin{array}{l}\text { Q34 - Alguma criança com } \\
\text { menos de } 14 \text { anos trabalhando } \\
\text { com remuneração? }\end{array}$ & & & & $X$ & & & & & & $x$ & 60 \\
\hline $\begin{array}{l}\text { Q35 - Alguma criança com } \\
\text { menos de } 16 \text { anos trabalhando } \\
\text { com remuneração? }\end{array}$ & & & & $X$ & & & & & & $x$ & 60 \\
\hline $\begin{array}{l}\text { Q72 - Algum membro da família } \\
\text { que faz uso de } 5 \text { medicamentos } \\
\text { ou mais ao mesmo tempo? }\end{array}$ & & & & $X$ & & & & $x$ & & & 60 \\
\hline
\end{tabular}

A questão sobre o componente "acesso aos serviços de saúde", modificada na rodada anterior, não obteve o consenso entre os juízes. Foi observado que da forma como estava elaborada a pergunta, a resposta indicaria a possível incapacidade funcional de um membro da família para ir a pé ao serviço de saúde. 
No entanto, a intenção era verificar a distância do domicílio ao serviço de saúde como dificultador do acesso, o que já estava contemplado no item posterior ("Serviços de saúde, muito utilizados pela família, são distantes da residência, a ponto de não se conseguir ir a pé?").

Um dos juízes sugeriu acrescentar uma questão para abordar outro aspecto da acessibilidade, a impossibilidade de utilizar o transporte coletivo público para ir ao serviço de saúde, o que foi aceito pelos autores e pelo consenso final.

Tabela 5 - Distribuição dos itens do Índice com porcentagem de concordância menor de $80 \%$ entre os juízes, relacionada ao conteúdo, na $2^{a}$ rodada. São Paulo, 2011.

\begin{tabular}{|c|c|c|c|c|c|c|c|c|c|c|c|}
\hline \multirow{2}{*}{ ITEM } & \multicolumn{2}{|c|}{ JUIZ 1} & \multicolumn{2}{|c|}{ JUIZ 2} & \multicolumn{2}{|c|}{ JUIZ 3} & \multicolumn{2}{|c|}{ JUIZ 4} & \multicolumn{2}{|c|}{ JUIZ 5} & \multirow{2}{*}{$\begin{array}{c}\text { Concordânci } \\
\text { a } \\
(\%)\end{array}$} \\
\hline & $E$ & A & $E$ & A & $E$ & A & $E$ & A & $E$ & A & \\
\hline $\begin{array}{l}\text { Q91 - Alguém que não } \\
\text { consegue ir a pé ao Serviço } \\
\text { de Saúde? }\end{array}$ & & & & $x$ & & & & & & $X$ & 60 \\
\hline
\end{tabular}

Os itens que não obtiveram $80 \%$ de consenso na segunda rodada foram modificados e novamente enviados aos juízes para uma rodada final, em que todos concordaram com as correções. Com isso, todos os itens alcançaram nível de concordância acima de 80\%.

\section{OBSERVAÇÕES COMPLEMENTARES DOS JUÍZES}

Inúmeras outras sugestões e observações feitas pelos juízes na $1^{a}$ e $2^{a}$ rodadas foram consideradas na construção do Índice, porém, como não apresentaram menos de $80 \%$ de concordância entre os juízes, não entraram na apresentação dos resultados através da técnica Delphi. 


\section{$1^{a}$ RODADA}

$\mathrm{Na}$ questão que aborda se há idosos de 60 anos ou mais que moram sozinhos no domicílio, um juiz observou que aos 60 anos morar sozinho pode indicar uma boa condição de saúde, diferentemente do caso de um idoso de 80 anos. Ainda que a hipótese seja plausível, como interessa captar situações de vulnerabilidade, face a um evento inesperado, como um queda, por exemplo, o idoso que more sozinho estará mais vulnerável e sujeito a incapacidade e dependência.

No componente "dependência econômica", relacionado à existência no domicílio de casais e moradores com idade superior à idade ativa, um dos juízes argumentou que não conseguia perceber a questão da dependência em relação à pergunta da existência de casais. Assim, o título do componente foi modificado para "condição econômica".

No componente "escolaridade" foram acrescentadas questões sobre a escolaridade do chefe da família, pois um dos juízes chamou atenção para a necessidade de distinguir os dois aspectos: de um lado, está sendo analisada a baixa escolaridade e, de outro, seu impacto na organização da dinâmica familiar. Assim, o Índice foi acrescido de um componente relacionado à escolaridade do chefe da família. Por solicitação de um dos juízes, incluiu-se a definição para "chefe da família", ou seja, pessoa reconhecida pelos demais moradores como responsável pelo domicílio.

A questão sobre se "mais da metade das pessoas em idade ativa (10 anos ou mais) trabalha com remuneração" suscitou muita polêmica entre os juízes, pois o trabalho antes dos 16 anos é considerado trabalho infantil, ilegal no Brasil. 
Entretanto, que essa é a idade ativa considerada em todos os inquéritos populacionais, uma vez que, lamentavelmente, o trabalho infantil ainda é uma realidade no País.

Após a sugestão de um juiz, a questão sobre se "há alguém trabalhando mais do que 10 horas/dia (semana de 5 dias de trabalho)?" foi modificada para "há alguém trabalhando mais do que 50 horas/ semana?", isso porque podem existir situações em que as pessoas trabalham mais de 10 horas seguidas (em um plantão, por exemplo), sem, contudo, ultrapassar 40 horas semanais.

Nas questões referentes à renda per capita, cujo propósito é verificar se as famílias encontram-se abaixo da linha da pobreza ou da extrema pobreza, os juízes alertaram para que a resposta não fosse solicitada em reais, mas em frações do salário mínimo vigente, o que permitirá manter o instrumento adequado para aplicação a qualquer tempo, independentemente das variações do salário mínimo.

Outra questão levantada pelos juízes foi a inclusão da faixa etária de 0 a 6 anos no componente "acesso à escola", argumentando que a falta de acesso à escola nessa faixa etária poderia não ser um problema tão grande como a partir dos 7 anos. No Brasil, a educação infantil, primeira etapa da educação básica, é oferecida em creches, para crianças de até três anos, e em pré-escola, para crianças de 4 a 6 anos. Por isso, essa faixa etária está incluída na educação básica, daí a decisão de mantê-la no componente "acesso à escola".

No componente "acesso a bens duráveis", foi sugerido por um juiz seguir os mesmos itens do censo 2010. A substituição foi considerada pertinente por ter itens mais atuais e completos. 
Ainda na primeira rodada, os itens que fazem parte da vulnerabilidade relacionada à saúde também sofreram modificações em decorrência da análise feita pelos juízes.

Com relação ao componente "adesão ao tratamento", havia uma questão assim formulada: "Neste domicílio há alguém que não segue o tratamento medicamentoso?". Um dos juízes observou que a pergunta poderia induzir a resposta.

Assim, foi modificada para "Neste domicílio há alguém com doença crônica que tem dificuldade em seguir o tratamento medicamentoso por motivos pessoais ou dificuldade de acesso aos medicamentos?"

O componente que aborda a queda em idosos foi questionado por um juiz, informando que, em geral, $40 \%$ dos idosos caem uma vez ao ano, mas sem gravidade ou complicação. Por isso sugeriu acrescentar internação por queda. Entretanto, a queda, mesmo que não tenha gerado internação, já indica uma situação de alerta no cuidado ao idoso e situação de maior vulnerabilidade.

Com relação aos transtornos mentais, foi sugerido definir "demência", haja vista a grande confusão referente ao termo. A sugestão foi aceita e incluída a definição de demência como sendo uma síndrome clínica que ocasiona perturbações na memória, atenção, aprendizado, pensamento, orientação, compreensão, julgamento acompanhado por deterioração do controle emocional e comportamento social. Outra observação foi feita em relação ao termo deficiência mental, sugerindo que fosse alterado para deficiência intelectual, termo mais atual. 


\section{$2^{\mathrm{a}} \mathrm{RODADA}$}

Na segunda rodada, o componente "condição econômica", cujo título havia sido modificado na rodada anterior, foi considerado inadequado por um dos juízes. No IDF original, esse componente recebe a denominação "dependência econômica". Considera que, quando o número de crianças ou idosos é elevado em relação ao número de adultos, a família pode estar vulnerável, pois muitos dependem da renda de poucos. Outro aspecto que é levado em conta é a presença de ambos os cônjuges que, tal como o trabalho de pessoas em idade ativa, tem impacto econômico sobre a família. De fato, tanto "dependência econômica" como "condição econômica" são termos que apresentam alguma inadequação, porém não se encontrou outro termo que pudesse substituí-lo.

Foi novamente questionada a idade ativa a partir dos 10 anos de idade. $\mathrm{Na}$ questão "mais da metade das pessoas em idade ativa exerce trabalho remunerado?" um dos juízes sugeriu manter a pergunta considerando o disposto pela Previdência Social para trabalhadores formais (16 anos e mais) e a idade de 10 anos ficaria somente no componente "trabalho precoce". Como esse componente não procurar avaliar o trabalho infantil, mas o trabalho de pessoas em idade ativa que pode contribuir para o sustento da família, a sugestão foi aceita e a idade ativa foi modificada para 16 anos e mais, por entender que uma família que conta com alguém de 10 anos para contribuir para a renda familiar não pode ser considerada menos vulnerável apenas pelo número de pessoas que contribuem para a renda.

Ao modificar os itens do "acesso a bens duráveis", introduzindo os itens utilizados no censo $2010^{51}$, um dos juízes questionou a retirada fogão da lista. De 
fato, não foi possível encontrar uma justificativa para a exclusão do fogão, que é um item importante, e decidiu-se incluí-lo.

Também se agregou em um único item a motocicleta e o automóvel, por considerar que uma família que não tenha motocicleta não pode pontuar mais e ser considerada mais vulnerável que uma família que tenha automóvel e motocicleta.

Já nos componentes que fazem parte da vulnerabilidade à saúde, o componente "apoio social" novamente suscitou questionamentos a respeito da veracidade das respostas. Um juiz observou que, dentro de um arranjo domiciliar que não é unipessoal (morar sozinho), não se poderia responder "honestamente" que um membro da casa não pode contar com o outro. Argumentou que, em arranjos múltiplos, todas as respostas possivelmente seriam "não", exemplificando que, se em uma casa residem um casal de idosos com uma filha de meia idade e duas crianças, seria possível admitir que qualquer um deles não teria com quem contar, caso fosse necessário. Para o juiz, a palavra "alguém" atrapalharia muito, já que normalmente a pergunta é específica para cada membro da família em relação à dificuldade e ao recebimento de ajuda.

Ainda sim, em se tratando de um instrumento de rastreio, considerou-se que as questões são sensíveis para captar os casos mais evidentes, atingindo o objetivo de avaliação, no nível de aprofundamento proposto para o Índice. Por se tratar de um instrumento que avalia a família, interessa saber se ao menos um dos membros não tem com quem contar, caso precise.

Por fim, foi sugerido definir o termo "demência senil", por não ser adequado para exemplificar os tipos de demências. Isso nos fez optar por "demência vascular". 


\subsection{Aplicação do Índice na região da Lapa}

\subsubsection{Caracterização dos membros das famílias entrevistadas}

$\mathrm{Na}$ região da Lapa, o número de pessoas pertencentes às famílias entrevistadas foi semelhante nas três Unidades. Na UBS Vila Jaguara, o número de pessoas foi cerca de $6 \%$ inferior ao das outras duas Unidades (234 pessoas), embora o número de famílias entrevistadas tenha sido o mesmo da UBS Parque da Lapa, o que sugere que as famílias na região da Vila Jaguara são menores.

As idades médias foram 33,2 anos, 40,2 anos e 43,8 anos, respectivamente, nas UBS Parque da Lapa, Vila Jaguara e Vila Piauí. Nas famílias da UBS Parque da Lapa a idade média foi menor que nas demais (teste de Kruskal-Wallis $p<0,001$ ).

Tabela 6 - Número e porcentagem de membros das famílias entrevistadas, na região da Lapa, segundo a Unidade Básica de Saúde. São Paulo, 2011.

\begin{tabular}{ccc}
\hline Unidade Básica de Saúde & $\mathbf{N}$ & $\mathbf{\%}$ \\
\hline Parque da Lapa & 277 & 34,8 \\
Vila Jaguará & 234 & 29,4 \\
Vila Piauí & 286 & 35,9 \\
\hline Total & 797 & 100,0 \\
\hline
\end{tabular}

Observou-se um número maior de mulheres $(54,6 \%)$ nas famílias entrevistadas, representando quase $10 \%$ a mais que o número de homens $(45,4 \%)$.

Tabela 7 - Número e porcentagem dos membros das famílias entrevistadas, na região da Lapa, segundo o sexo. São Paulo, 2011.

\begin{tabular}{ccc}
\hline Sexo & $\mathbf{N}$ & \% \\
\hline Feminino & 435 & 54,6 \\
Masculino & 362 & 45,4 \\
\hline Total & 797 & 100,0 \\
\hline
\end{tabular}


Houve predomínio de adultos de 18 a 59 anos $(54,0 \%)$ e porcentagens semelhantes de crianças, adolescentes e jovens $(23,2 \%)$ e idosos acima de 60 anos $(22,8 \%)$. A idade média foi de 39,06 anos e a idade máxima foi de 93 anos.

Tabela 8 - Número e porcentagem de membros das famílias entrevistadas, na região da Lapa, segundo a faixa etária. São Paulo, 2011.

\begin{tabular}{ccc}
\hline Faixa etária & $\mathbf{N}$ & $\mathbf{\%}$ \\
\hline$<2$ anos & 15 & 1,9 \\
$2-9$ anos & 87 & 10,9 \\
$10-14$ anos & 44 & 5,5 \\
$15-17$ anos & 39 & 4,9 \\
$18-59$ anos & 430 & 54,0 \\
$60-69$ anos & 78 & 9,8 \\
$70-79$ anos & 64 & 8,0 \\
80 anos e mais & 40 & 5,0 \\
\hline Total & 797 & 100,0
\end{tabular}

A pontuação média da amostra no índice de Katz foi de apenas 0,10 , indicando independência para as atividades básicas da vida diária (AVD), tendo em vista que a pontuação zero significa ser independente para todas as atividades. Entretanto, pontuação máxima (12), dependente para todas as atividades, foi alcançada. A média de pontuação na escala de Lawton também foi alta $(26,47)$ indicando independência para as AIVD.

Tabela 9 - Estatística descritiva dos membros das famílias entrevistadas, na região da Lapa, segundo o número de pessoas, idade, pontuação total do Índice de Katz e pontuação total da Escala de Lawton. São Paulo, 2011.

\begin{tabular}{cccc}
\hline Variável & Média $(\mathbf{d p})$ & Min-máx & Mediana \\
\hline Idade & $39,06(23,85)$ & $0-93$ & 37,00 \\
Pontuação total Katz & $0,10(0,80)$ & $0-12$ & 0,00 \\
Pontuação total Lawton & $26,47(2,23)$ & $9-27$ & 27,00 \\
\hline
\end{tabular}


A grande maioria não apresentava dependência para as AVD (97,0\%). Treze pessoas $(1,6 \%)$ apresentavam dependência apenas para uma atividade, como é o caso de mulheres com perdas urinárias ocasionais. Quatro eram dependentes em pelo menos duas funções, que não se classificavam nas demais letras do Índice de Katz, como, por exemplo, dependente para se vestir e continência. Apenas duas $(0,3 \%)$ foram classificadas em "G", por serem totalmente dependentes para as ABVD.

Tabela 10 - Número e porcentagem dos membros das famílias entrevistadas, na região da Lapa, segundo o Índice de independência nas atividades básicas da vida diária, Katz. São Paulo, 2011.

\begin{tabular}{ccc}
\hline Índice de Katz & $\mathbf{N}$ & $\%$ \\
\hline A & 773 & 97,0 \\
B & 13 & 1,6 \\
C & 1 & 0,1 \\
D & 2 & 0,3 \\
E & 0 & 0 \\
F & 2 & 0,3 \\
G & 2 & 0,3 \\
Outro & 4 & 0,5 \\
\hline Total & 797 & 100,0
\end{tabular}

A amostra foi dividida entre pessoas totalmente independentes e outras com alguma dependência, parcial ou total, para ABVD e AIVD. Mais de $90 \%$ da amostra era totalmente independente (97\% no Katz e 92,2\% no Lawton) (Tabelas 11 e 12).

Tabela 11 - Número e porcentagem dos membros das famílias entrevistadas, na região da Lapa, segundo a presença de alguma dependência para as atividades básicas da vida diária. São Paulo, 2011.

\begin{tabular}{ccc}
\hline Dependência (Índice de KATZ) & $\mathbf{N}$ & $\mathbf{\%}$ \\
\hline Totalmente independente & 773 & 97,0 \\
Alguma dependência & 24 & 3,0 \\
\hline Total & 797 & 100,0 \\
\hline
\end{tabular}


Tabela 12 - Número e porcentagem dos membros das famílias entrevistadas, segundo a presença de alguma dependência para as atividades instrumentais da vida diária. São Paulo, 2011.

\begin{tabular}{ccc}
\hline Dependência (Escala de LAWTON) & $\mathbf{N}$ & $\mathbf{\%}$ \\
\hline Totalmente independente & 735 & 92,2 \\
Alguma dependência & 62 & 7,8 \\
\hline Total & 797 & 100,0 \\
\hline
\end{tabular}

\subsubsection{Caracterização das famílias entrevistadas}

O número de famílias entrevistadas foi uniforme nas três Unidades, sendo exatamente igual nas UBS Parque da Lapa e Vila Jaguara (78 famílias) e maior na UBS Vila Piauí (92 famílias).

Tabela 13 - Número e porcentagem das famílias entrevistadas, na região da Lapa, segundo a Unidade Básica de Saúde. São Paulo, 2011.

\begin{tabular}{ccc}
\hline UBS & $\mathbf{N}$ & $\mathbf{\%}$ \\
\hline Parque da Lapa & 78 & 31,5 \\
Vila Jaguará & 78 & 31,5 \\
Vila Piauí & 92 & 37,1 \\
\hline Total & 248 & 100,0 \\
\hline
\end{tabular}

O número médio de pessoas por domicílio foi 3,21. A média da pontuação no índice de Katz foi 0,13 , ou seja, em poucas famílias havia pessoas com dependência. Da mesma forma, para dependência nas AIVD, a média foi de 26,30 pontos, indicando pouca dependência para essas atividades.

Tabela 14 - Estatística descritiva das famílias entrevistadas, na região da Lapa, segundo o número de pessoas na casa, média familiar da pontuação no Índice de Katz e média familiar da pontuação na Escala de Lawton. São Paulo, 2011.

\begin{tabular}{cccc}
\hline Variável & Média (dp) & Mín-máx & Mediana \\
\hline Número de pessoas na casa & $3,21(1,56)$ & $1-10$ & 3,00 \\
Média pontuação Katz & $0,13(0,60)$ & $0-6$ & 0,00 \\
Média pontuação Lawton & $26,30(1,73)$ & $17,5-27$ & 27,00 \\
\hline
\end{tabular}


A maioria das famílias entrevistadas (56\%) tinha entre dois e três membros, seguidas pelas famílias de até quatro pessoas $(16,1 \%)$. Também é importante destacar o número de pessoas que viviam sós, representando $9,7 \%$ do total da amostra.

Tabela 15 - Número e porcentagem das famílias entrevistadas, na região da Lapa, segundo o número de pessoas na casa. São Paulo, 2011.

\begin{tabular}{cccc}
\hline Número de pessoas na casa & $\mathbf{N}$ & $\mathbf{\%}$ \\
\hline 1 & 24 & 9,7 \\
2 & 66 & 26,6 \\
3 & 73 & 29,4 \\
4 & 40 & 16,1 \\
5 & 24 & 9,7 \\
6 & 9 & 3,6 \\
7 & 10 & 4,0 \\
8 & 1 & 0,4 \\
10 & 1 & 0,4 \\
\hline Total & 248 & 100,0 \\
\hline
\end{tabular}

Pouco menos de $10 \%$ das famílias entrevistadas tinha pelo menos um membro com alguma dependência, parcial ou total, para uma ou mais AVD.

Tabela 16 - Número e porcentagem das famílias entrevistadas, na região da Lapa, segundo a presença de dependência para as atividades básicas da vida diária entre algum membro da família. São Paulo, 2011.

\begin{tabular}{ccc}
\hline Dependência & $\mathbf{N}$ & $\mathbf{\%}$ \\
\hline Não existe pessoa com dependência & 225 & 90,7 \\
Pelo menos 1 pessoa tem dependência & 23 & 9,3 \\
\hline Total & 248 & 100,0 \\
\hline
\end{tabular}

Em relação às AIVD, aproximadamente um quarto da amostra apresentava alguma dependência $(22,2 \%)$, parcial ou total, para uma ou mais atividades instrumentais. 
Tabela 17 - Número e porcentagem das famílias entrevistadas, na região da Lapa, segundo a presença de dependência para as atividades instrumentais da vida diária entre algum membro da família. São Paulo, 2011.

\begin{tabular}{ccc}
\hline Dependência & $\mathbf{N}$ & $\mathbf{\%}$ \\
\hline Não existe pessoa com dependência & 193 & 77,8 \\
Pelo menos 1 pessoa tem dependência & 55 & 22,2 \\
\hline Total & 248 & 100,0 \\
\hline
\end{tabular}

\subsubsection{Descrição do IVF-ID}

Apresenta-se a seguir a descrição da aplicação do instrumento. Alguns itens obtiveram um número de respostas inferior a 10 , o que indica que retratam condições encontradas em menos de 10 famílias, tais como: mulheres que tiveram filhos no último ano, crianças menores de um ano, renda familiar na linha da extrema pobreza, maior parte da renda familiar advinda de transferências, crianças com menos de 16 anos exercendo trabalho remunerado, crianças de 0 a 17 anos fora da escola, crianças de até 14 anos com mais de dois anos de atraso escolar, crianças de 10 a 17 nos analfabeto, casas que não são feitas de material de construção permanente, casas que não tem abastecimento de água, esgoto sanitário, coleta de lixo, televisão, geladeira e fogão.

Em poucos domicílios havia alguém com deficiência física, imobilizado ou acamado, com demência ou deficiência intelectual. Não foi encontrado nenhum domicílio com crianças com mãe falecida, com menores de 14 anos que exerciam trabalho remunerado e domicílios sem banheiro próprio ou sem iluminação elétrica. 
Tabela 18 - Número e porcentagem de respostas de valor 0 ou 1. São Paulo, 2011.

\begin{tabular}{|c|c|c|c|c|}
\hline \multirow[t]{2}{*}{ Questão } & \multicolumn{2}{|c|}{0} & \multicolumn{2}{|c|}{1} \\
\hline & $\mathbf{N}$ & $\%$ & $\mathbf{N}$ & $\%$ \\
\hline 1. Alguma mulher que teve filho nascido vivo nos últimos 12 meses? & 242 & 97,6 & 6 & 2,4 \\
\hline 2. Alguma mulher que teve filho nascido vivo nos últimos 24 meses? & 235 & 94,8 & 13 & 5,2 \\
\hline 3. Alguma criança menor de um ano? & 240 & 96,8 & 8 & 5,2 \\
\hline 4. Alguma criança até 10 anos? & 174 & 70,2 & 74 & 29,8 \\
\hline 5. Alguma criança ou adolescente até 14 anos? & 163 & 65,7 & 85 & 34,3 \\
\hline 6. Alguma criança, adolescente ou jovem até 17 anos? & 152 & 61,3 & 96 & 38,7 \\
\hline 7. Algum idoso (60 anos ou mais)? & 124 & 50,0 & 124 & 50,0 \\
\hline 8 , Algum idoso com 80 anos ou mais? & 214 & 86,3 & 34 & 13,7 \\
\hline 9. Apenas um morador no domicílio e é idoso ( 60 anos ou mais)? & 230 & 92,7 & 18 & 7,3 \\
\hline 10. Apenas moradores idosos (60 anos ou mais)? & 206 & 83,1 & 42 & 16,9 \\
\hline 11. Pessoas vivendo maritalmente (casais)? & 158 & 63,7 & 90 & 36,3 \\
\hline $\begin{array}{l}\text { 12. Mais da metade dos moradores com mais de } 10 \text { anos de idade (idade } \\
\text { ativa)? }\end{array}$ & 233 & 94,0 & 15 & 6,0 \\
\hline 13. Crianças cuja mãe tenha falecido? & 248 & 100,0 & - & - \\
\hline 14. C & 234 & 94,4 & 14 & 5,6 \\
\hline 15. A & 223 & 89,9 & 25 & 10,1 \\
\hline $\begin{array}{l}\text { 16. Algum adulto com dificuldade para ler e escrever (analfabeto } \\
\text { funcional)? }\end{array}$ & 202 & 81,5 & 46 & 18,5 \\
\hline menos um adulto com ensino fundamental completo? & 195 & 78,6 & 53 & 21,4 \\
\hline 18. & 155 & 62,5 & 93 & 37,5 \\
\hline 19. A & 69 & 27,8 & 179 & 72,2 \\
\hline & 234 & 94,4 & 14 & 5,6 \\
\hline 21 . & 225 & 90,7 & 23 & 9,3 \\
\hline 22. & 140 & 56,5 & 108 & 43,5 \\
\hline 23.7 & 85 & 34,3 & 163 & 65,7 \\
\hline 24. Tem & 29 & 11,7 & 219 & 88,3 \\
\hline $\begin{array}{l}\text { 25. Mais da metade das pessoas em idade ativa exerce trabalho } \\
\text { remunerado? }\end{array}$ & 119 & 48,0 & 129 & 52,0 \\
\hline a pessoa trabalha há mais de seis meses no emprego atual? & 185 & 74,6 & 63 & 25,4 \\
\hline 27. & 149 & 60,1 & 99 & 39,9 \\
\hline 28. Algun & 170 & 68,5 & 78 & 31,5 \\
\hline $\begin{array}{l}\text { 29. Alguma pessoa trabalhando com rendimento superior a } 1 \text { salário } \\
\text { mínimo? }(\mathrm{R} \$ 545,00)\end{array}$ & 209 & 84,3 & 39 & 15,7 \\
\hline $\begin{array}{l}\text { 30. Alguma pessoa trabalhando com rendimento superior a } 2 \text { salários } \\
\text { mínimos? }(R \$ 1.090,00)\end{array}$ & 136 & 54,8 & 112 & 45,2 \\
\hline Imiliar é inferior a $1 / 4$ do salário mínimo vigente por pessoa? & 242 & 97,6 & 6 & 2,4 \\
\hline & 230 & 92,7 & 18 & 7,3 \\
\hline $\begin{array}{l}\text { 33. A maior parte (mais de } 50 \% \text { ) da renda familiar advém de } \\
\text { transferências? }\end{array}$ & 240 & 96,8 & 8 & 3,2 \\
\hline $\begin{array}{l}\text { 34. Alguma criança com menos de } 14 \text { anos exercendo trabalho } \\
\text { remunerado? }\end{array}$ & 248 & 100,0 & - & - \\
\hline $\begin{array}{l}\text { 35. Alguma criança com menos de } 16 \text { anos exercendo trabalho } \\
\text { remunerado? }\end{array}$ & 246 & 99,2 & 2 & 0,8 \\
\hline & 239 & 96,4 & 9 & 3,6 \\
\hline & 246 & 99,2 & 2 & 0,8 \\
\hline a de 7 a 17 anos fora da escola? & 243 & 98,0 & 5 & 2,0 \\
\hline $\begin{array}{l}\text { 39. Alguma criança de até } 14 \text { anos com mais de dois anos de atraso } \\
\text { escolar? }\end{array}$ & 240 & 96,8 & 8 & 3,2 \\
\hline eto? & 247 & 99,6 & 1 & 0,4 \\
\hline 41. A & 247 & 99,6 & 1 & 0,4 \\
\hline & 220 & 88,7 & 28 & 11,3 \\
\hline a mãe cujo filho tenha morrido com menos de um ano? & 227 & 91,5 & 21 & 8,5 \\
\hline 44. Próprio? & 197 & 79,4 & 51 & 20,6 \\
\hline 45. Próprio em terreno próprio? & 170 & 68,5 & 78 & 31,5 \\
\hline $\begin{array}{l}\text { 46. O número total de moradores dividido pelo número de dormitórios é } \\
\text { maior que dois? }\end{array}$ & 191 & 77,0 & 57 & 23,0 \\
\hline 47. É feito de material de construção permanente? & 241 & 97,2 & 7 & 2,8 \\
\hline
\end{tabular}




\begin{tabular}{|c|c|c|c|c|}
\hline 48. Tem banheiro próprio? & 248 & 100,0 & - & - \\
\hline 49. Abastecimento de água da rede pública? & 246 & 99,2 & 2 & 0,8 \\
\hline 50. Esgoto sanitário (rede geral ou fossa séptica)? & 247 & 99,6 & 1 & 0,4 \\
\hline 51. Acesso regular a serviço de coleta de lixo? & 247 & 99,6 & 1 & 0,4 \\
\hline 52. Iluminação elétrica? & 248 & 100,0 & - & - \\
\hline 53. Rádio (inclusive integrado a outro tipo de aparelho)? & 22 & 89,5 & 26 & 10,5 \\
\hline 54. Televisão? & 244 & 98,4 & 4 & 1,6 \\
\hline 55. Máquina de lavar roupa (não considerar tanquinho)? & 210 & 84,7 & 38 & 15,3 \\
\hline 56. Geladeira? & 247 & 99,6 & 1 & 0,4 \\
\hline 57. Fogão? & 246 & 99,2 & 2 & 0,8 \\
\hline 58. Telefone celular? & 220 & 88,7 & 28 & 11,3 \\
\hline 59. Telefone fixo? & 199 & 80,2 & 49 & 19,8 \\
\hline 60. Microcomputador? & 146 & 58,9 & 102 & 41,1 \\
\hline 61. Microcomputador com acesso a internet? & 129 & 52,0 & 119 & 48,0 \\
\hline 62. Motocicleta ou automóvel para uso particular? & 129 & 52,0 & 119 & 48,0 \\
\hline $\begin{array}{l}\text { 63. Familiares que moram próximos (a ponto de ser possível ir a pé) e que } \\
\text { mantém contato? }\end{array}$ & 172 & 69,4 & 76 & 30,6 \\
\hline $\begin{array}{l}\text { 64. Amigos que moram próximos (a ponto de ir a pé) e que mantém } \\
\text { contato? }\end{array}$ & 193 & 77,8 & 55 & 22,2 \\
\hline $\begin{array}{l}\text { 65. Alguma pessoa que participa de associações, clubes, igrejas, grupos } \\
\text { ou trabalho voluntário não remunerado? }\end{array}$ & 101 & 40,7 & 147 & 59,3 \\
\hline 66. Visitas de familiares pelo menos uma vez por semana? & 140 & 56,5 & 108 & 43,5 \\
\hline liares pelo $n$ & 198 & 79,8 & 50 & 20,2 \\
\hline le familiares pelo me & 229 & 92,3 & 19 & 7,7 \\
\hline pelo $\mathrm{m}$ & 85 & 34,3 & 163 & 65,7 \\
\hline 70. Visita & 162 & 65,3 & 86 & 34,7 \\
\hline 71. Visitas de amigos pelo menos uma vez ao ano? & 198 & 79,8 & 50 & 20,2 \\
\hline $\begin{array}{l}\text { 72. Alguma pessoa que não tem com quem contar, caso necessite de } \\
\text { ajuda para realizar tarefas domésticas como fazer a comida e limpar a } \\
\text { casa? }\end{array}$ & 197 & 79,4 & 51 & 20,6 \\
\hline $\begin{array}{l}\text { 73. Alguma pessoa que não tem com quem contar, caso necessite de } \\
\text { ajuda com bens materiais? }\end{array}$ & 197 & 79,4 & 51 & 20,6 \\
\hline $\begin{array}{l}\text { 74. Alguma pessoa que não tem com quem contar, caso necessite de } \\
\text { dinheiro ou ajuda financeira? }\end{array}$ & 184 & 74,2 & 64 & 25,8 \\
\hline $\begin{array}{l}\text { 75. Alguma pessoa que não tem com quem contar, caso necessite de } \\
\text { companhia? }\end{array}$ & 211 & 85,1 & 37 & 14,9 \\
\hline $\begin{array}{l}\text { 76. Alguma pessoa que não tem com quem contar, caso necessite } \\
\text { receber cuidados de saúde? }\end{array}$ & 213 & 85,9 & 35 & 14,1 \\
\hline $\begin{array}{l}\text { 77. Alguma pessoa que não tem com quem contar para acompanhá-lo, } \\
\text { caso necessite sair de casa (para consultas, fazer compras, passear...)? }\end{array}$ & 224 & 90,3 & 24 & 9,7 \\
\hline pessoa com pelo menos uma doença crônica? & 53 & 21,4 & 195 & 78,6 \\
\hline essoa com pelo menos duas doenças crônicas? & 144 & 58,1 & 104 & 41,9 \\
\hline 80. Algu & 195 & 78,6 & 53 & 21,4 \\
\hline $\begin{array}{l}\text { 81. Alguma pessoa com doença crônica que tem dificuldades em seguir o } \\
\text { tratamento medicamentoso, por motivos pessoais ou por dificuldade de } \\
\text { acesso aos medicamentos? }\end{array}$ & 216 & 87,1 & 32 & 12,9 \\
\hline $\begin{array}{l}\text { 82. Alguma pessoa com doença crônica que tem dificuldades em seguir o } \\
\text { tratamento não-medicamentoso, como fazer atividade física, seguir uma } \\
\text { dieta recomendada, parar de fumar? }\end{array}$ & 167 & 67,3 & 81 & 32,7 \\
\hline 83. Alguma pessoa que faz uso de medicamento contínuo? & 82 & 33,1 & 166 & 66,9 \\
\hline $\begin{array}{l}\text { 84. Alguma pessoa que faz uso contínuo de } 5 \text { ou mais medicamentos } \\
\text { diferentes ao mesmo tempo? (polifarmácia) }\end{array}$ & 183 & 73,8 & 65 & 26,2 \\
\hline 85. Alguma pessoa foi internada nos últimos 12 meses (exceto parto)? & 194 & 78,2 & 54 & 21,8 \\
\hline $\begin{array}{l}\text { 86. Alguma pessoa foi internada por doença crônica descompensada, nos } \\
\text { últimos } 12 \text { meses? }\end{array}$ & 233 & 94,0 & 15 & 6,0 \\
\hline 87. Algum idoso sofreu queda nos últimos 12 meses? & 210 & 84,7 & 38 & 15,3 \\
\hline 88. Alguma pessoa que consider & 207 & 83,5 & 41 & 16,5 \\
\hline 89. Alguma pessoa com dificuldade para utilizar os serviços de saúde? & 180 & 72,6 & 68 & 27,4 \\
\hline $\begin{array}{l}\text { 90. Alguma pessoa que não conseguiu agendar consultas, exames ou } \\
\text { tratamentos nos últimos } 12 \text { meses? }\end{array}$ & 194 & 78,2 & 54 & 21,8 \\
\hline
\end{tabular}




\begin{tabular}{|c|c|c|c|c|}
\hline $\begin{array}{l}\text { 91. Alguma pessoa que não consegue ir de transporte público coletivo ao } \\
\text { serviço de saúde? }\end{array}$ & 216 & 87,1 & 32 & 12,9 \\
\hline $\begin{array}{l}\text { 92. Serviços de saúde, muito utilizados, que são distantes da residência, a } \\
\text { ponto de não se conseguir ir a pé? }\end{array}$ & 147 & 59,3 & 101 & 40,7 \\
\hline $\begin{array}{l}\text { 93. Alguma pessoa com incapacidade visual? (considerar pessoa incapaz, } \\
\text { com grande dificuldade permanente ou alguma dificuldade permanente de } \\
\text { enxergar mesmo com uso de óculos ou lentes de contato) }\end{array}$ & 226 & 91,1 & 22 & 8,9 \\
\hline $\begin{array}{l}\text { 94. Alguma pessoa com incapacidade auditiva? (considerar pessoa } \\
\text { incapaz, com grande dificuldade permanente ou alguma dificuldade } \\
\text { permanente de ouvir mesmo com uso de aparelho auditivo) }\end{array}$ & 221 & 89,1 & 27 & 10,9 \\
\hline $\begin{array}{l}\text { 95. Alguma pessoa com incapacidade para se movimentar? (considerar } \\
\text { pessoa incapaz, com grande dificuldade permanente ou alguma } \\
\text { dificuldade permanente de caminhar mesmo com uso de prótese, bengala } \\
\text { ou aparelho auxiliar) }\end{array}$ & 233 & 94,0 & 15 & 6,0 \\
\hline $\begin{array}{l}\text { 96. Alguma pessoa com deficiência física? (considerar tetraplegia, } \\
\text { paraplegia, hemiplegia, falta de membro ou parte dele) }\end{array}$ & 242 & 97,6 & 6 & 2,4 \\
\hline $\begin{array}{l}\text { 97. Alguma pessoa que, sem ajuda, não realiza qualquer das seguintes } \\
\text { atividades: alimentação, higiene pessoal, vestir-se, controle de eliminação } \\
\text { intestinal e vesical, deambulação e transferências? (Atividades Básicas da } \\
\text { Vida Diária - ABVD)? }\end{array}$ & 236 & 95,2 & 12 & 4,8 \\
\hline nobilizada/acamada permanentemente? & 244 & 98,4 & 4 & 1,6 \\
\hline $\begin{array}{l}\text { 99. Alguma pessoa que, sem ajuda, não consegue realizar nenhuma das } \\
\text { seguintes atividades: limpar a casa, cuidar da roupa, da comida, usar } \\
\text { equipamentos domésticos, fazer compras, usar transporte pessoal ou } \\
\text { público, controlar a própria medicação e finanças? (Atividades } \\
\text { Instrumentais da Vida Diária - AIVD) }\end{array}$ & 225 & 90,7 & 23 & 9,3 \\
\hline $\begin{array}{l}\text { 100. Alguma pessoa com transtornos psiquiátricos como depressão ou } \\
\text { tentativa de suicídio ou transtorno de ansiedade ou transtorno obsessivo- } \\
\text { compulsivo ou esquizofrenia ou psicose ou transtorno bipolar? }\end{array}$ & 183 & 73,8 & 65 & 26,2 \\
\hline $\begin{array}{l}\text { 101. Alguma pessoa com demência, como por exemplo, Alzheimer, } \\
\text { demência vascular? }\end{array}$ & 242 & 97,6 & 6 & 2,4 \\
\hline & & & 29 & \\
\hline 103. Alguma pessoa com deficiência intelectual? & 244 & 98,4 & 4 & 1,6 \\
\hline
\end{tabular}

\subsubsection{Análise fatorial do IVF-ID para definição dos indicadores}

A análise fatorial exploratória definiu sete componentes com 40,0\% de explicação da variância total acumulada. A Tabela 19 reúne todas as questões que entraram nos resultados da análise fatorial e seus respectivos valores de correlação.

Das 103 questões do instrumento original, permaneceram 56 questões.

Observa-se que a dimensão 5, intitulado 'desenvolvimento infantil', composto por quatro componentes (trabalho precoce, acesso à escola, progresso escolar e mortalidade infantil), não apareceu na análise fatorial. 
Outros 12 componentes não apareceram na análise: condições econômicas, ausência de mãe, qualidade do posto de trabalho, extrema pobreza, incapacidade de geração de renda, abrigabilidade, acesso a abastecimento de água, saneamento, coleta de lixo e energia elétrica, internações e transtornos mentais.

As questões 7, 10, 26, 29, 32 e 79 apareceram em mais de um fator, sendo necessário definir em qual deveriam permanecer. Para isso, foram agrupadas nos sete fatores resultantes da análise fatorial, para análise posterior.

Tabela 19 - Descrição dos fatores dos resultados da análise fatorial (após a rotação varimax). São Paulo, 2011.

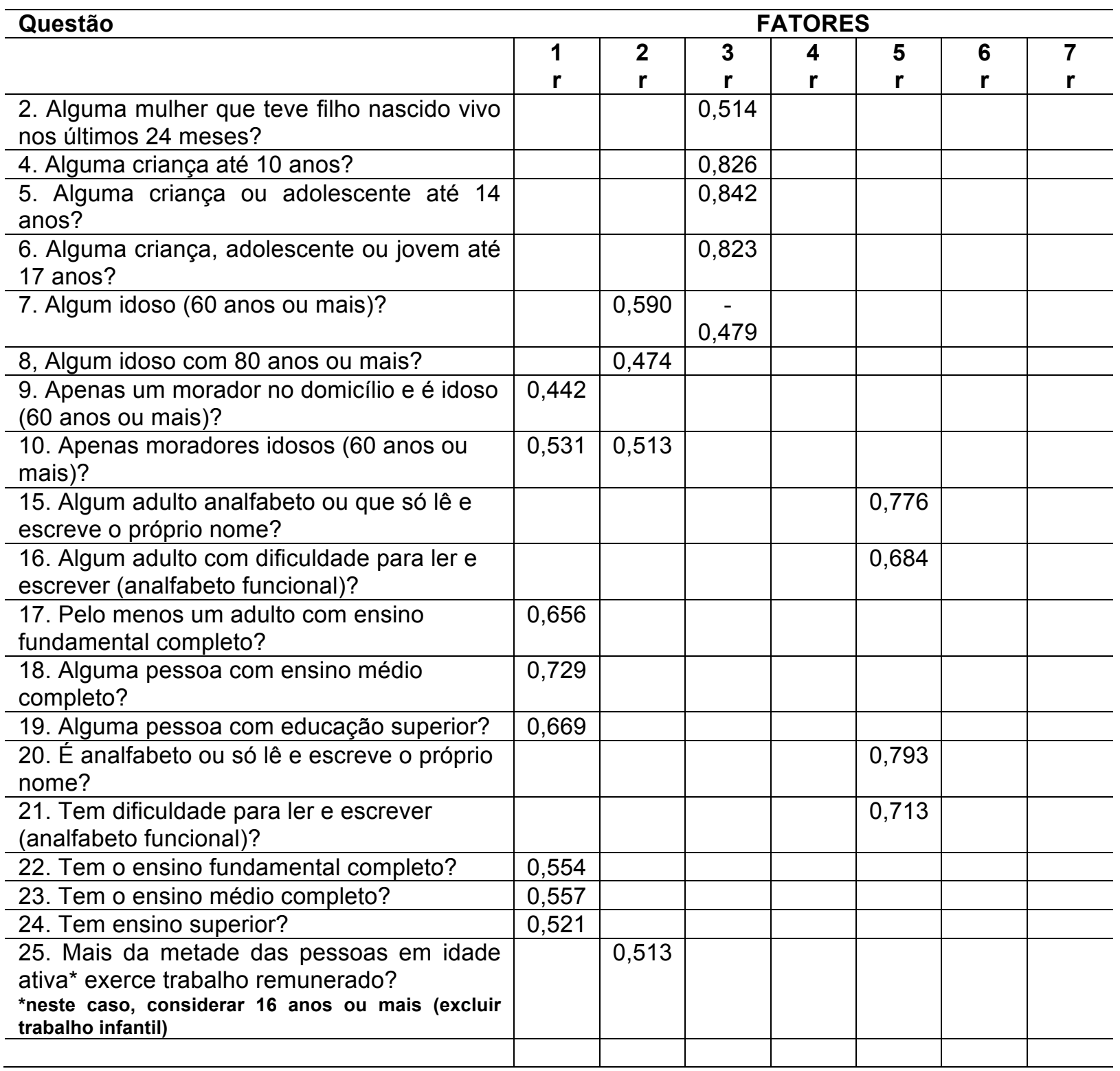




\begin{tabular}{|c|c|c|c|c|c|c|c|}
\hline $\begin{array}{l}\text { 26. Alguma pessoa trabalha há mais de seis } \\
\text { meses no emprego atual? }\end{array}$ & 0,499 & 0,505 & & & & & \\
\hline $\begin{array}{l}\text { 29. Alguma pessoa trabalhando com } \\
\text { rendimento superior a } 1 \text { salário mínimo? ( } R \$ \\
545,00)\end{array}$ & 0,459 & 0,439 & & & & & \\
\hline $\begin{array}{l}\text { 30. Alguma pessoa trabalhando com } \\
\text { rendimento superior a } 2 \text { salários mínimos? } \\
(\mathrm{R} \$ 1.090,00)\end{array}$ & 0,589 & & & & & & \\
\hline $\begin{array}{l}\text { 32. A renda familiar é de } 1 / 4 \text { até } 1 / 2 \text { salário } \\
\text { mínimo por pessoa* } \\
\text { *Salário Mínimo em } 2011=R \$ 545,00 ; 1 / 2=R \$ 272,50, \\
1 / 4=R \$ 136,25-\text { Instituto de Pesquisa Econômicas } \\
\text { Aplicadas - IPEA }\end{array}$ & & & 0,454 & & 0,403 & & \\
\hline 45. Próprio em terreno próprio? & & $\begin{array}{c}- \\
0,409\end{array}$ & & & & & \\
\hline $\begin{array}{l}\text { 46. O número total de moradores dividido } \\
\text { pelo número de dormitórios é maior que } \\
\text { dois? }\end{array}$ & & & 0,604 & & & & \\
\hline 58. Telefone celular? & 0,454 & & & & & & \\
\hline 60. Microcomputador? & 0,805 & & & & & & \\
\hline 61. Microcomputador com acesso a internet? & 0,765 & & & & & & \\
\hline $\begin{array}{l}\text { 62. Motocicleta ou automóvel para uso } \\
\text { particular? }\end{array}$ & 0,512 & & & & & & \\
\hline $\begin{array}{l}\text { 64. Amigos }{ }^{2} \text { que moram próximos (a ponto } \\
\text { de ir a pé) e que mantém contato? }\end{array}$ & & & & & & 0,585 & \\
\hline $\begin{array}{l}\text { 66. Visitas de familiares pelo menos uma vez } \\
\text { por semana? }\end{array}$ & & & & & & 0,504 & \\
\hline $\begin{array}{l}\text { 67. Visitas de familiares pelo menos uma vez } \\
\text { ao mês? }\end{array}$ & & & & & & 0,549 & \\
\hline $\begin{array}{l}\text { 68. Visitas de familiares pelo menos uma vez } \\
\text { ao ano? }\end{array}$ & & & & & & 0,426 & \\
\hline $\begin{array}{l}\text { 69. Visitas de amigos pelo menos uma vez } \\
\text { por semana? }\end{array}$ & & & & & & 0,523 & \\
\hline $\begin{array}{l}\text { 70. Visitas de amigos pelo menos uma vez } \\
\text { por mês? }\end{array}$ & & & & & & 0,668 & \\
\hline $\begin{array}{l}\text { 71. Visitas de amigos pelo menos uma vez } \\
\text { ao ano? }\end{array}$ & & & & & & 0,592 & \\
\hline $\begin{array}{l}\text { 72. Alguma pessoa que não tem com quem } \\
\text { contar, caso necessite de ajuda para realizar } \\
\text { tarefas domésticas como fazer a comida e } \\
\text { limpar a casa? }\end{array}$ & & & & 0,746 & & & \\
\hline $\begin{array}{l}\text { 73. Alguma pessoa que não tem com quem } \\
\text { contar, caso necessite de ajuda com bens } \\
\text { materiais? }\end{array}$ & & & & 0,664 & & & \\
\hline $\begin{array}{l}\text { 74. Alguma pessoa que não tem com quem } \\
\text { contar, caso necessite de dinheiro ou ajuda } \\
\text { financeira? }\end{array}$ & & & & 0,663 & & & \\
\hline $\begin{array}{l}\text { 75. Alguma pessoa que não tem com quem } \\
\text { contar, caso necessite de companhia? }\end{array}$ & & & & 0,758 & & & \\
\hline $\begin{array}{l}\text { 76. Alguma pessoa que não tem com quem } \\
\text { contar, caso necessite receber cuidados de } \\
\text { saúde? }\end{array}$ & & & & 0,820 & & & \\
\hline $\begin{array}{l}\text { 77. Alguma pessoa que não tem com quem } \\
\text { contar para acompanhá-lo, caso necessite } \\
\text { sair de casa (para consultas, fazer compras, } \\
\text { passear...)? }\end{array}$ & & & & 0,758 & & & \\
\hline $\begin{array}{l}\text { 78. Alguma pessoa com pelo menos uma } \\
\text { doença crônica }{ }^{3} \text { ? }\end{array}$ & & & & & & & 0,453 \\
\hline $\begin{array}{l}\text { 79. Alguma pessoa com pelo menos duas } \\
\text { doenças crônicas }{ }^{3} \text { ? }\end{array}$ & & 0,441 & & & & & 0,465 \\
\hline
\end{tabular}




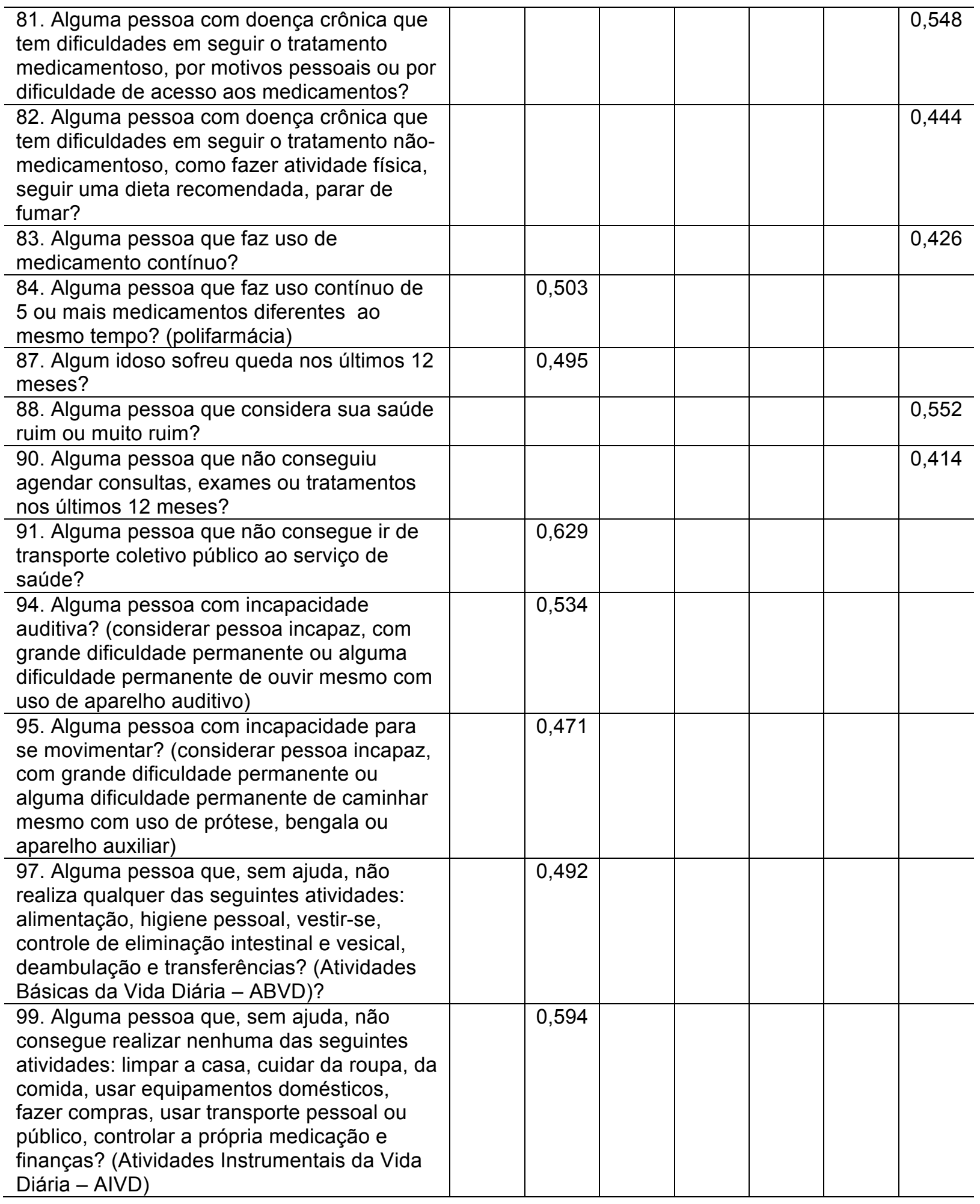

Pode-se observar no fator 1 que, em geral, as questões relacionadas referem-se à melhores condições de vida, como acesso à educação, maior tempo no emprego atual, rendimento superior a um e dois salários mínimos, ter telefone celular, ter computador e com acesso a internet e ter moto ou carro. 
É interessante destacar que o fato do domicílio ser habitado por apenas moradores idosos, vivendo só ou não, relacionou-se a outros itens que indicam melhores condições de vida. Porém, como a questão 10 também apareceu no fator 2, juntamente com outras referentes ao envelhecimento, optou-se retirá-la do fator 1 , mantendo-a no fator 2.

Com isso, a questão 9, também referente à presença de moradores idosos no domicílio, ficou fora de contexto no fator 1 e, portanto, decidiu-se eliminá-la, pois já estava de certa forma contemplada no fator 2 . Além disso, a questão 9 foi a que apresentou a mais baixa correlação nesse fator $(r=0,442)$.

Tabela 20 - Descrição do fator 1. São Paulo, 2011.

\begin{tabular}{lr}
\hline Questão & $\mathbf{r}$ \\
\hline 9. Apenas um morador no domicílio e é idoso (60 anos ou mais)? & 0,442 \\
10. Apenas moradores idosos ( 60 anos ou mais)? & 0,531 \\
$\begin{array}{l}\text { 17. Pelo menos um adulto com ensino fundamental completo? } \\
\text { 18. Alguma pessoa com ensino médio completo? }\end{array}$ & 0,656 \\
19. Alguma pessoa com educação superior? & 0,729 \\
22. Chefe da família com ensino fundamental completo? & 0,669 \\
23. Chefe da família com ensino médio completo? & 0,554 \\
24. Chefe da família com ensino superior? & 0,557 \\
26. Alguma pessoa trabalha há mais de seis meses no emprego atual? & 0,521 \\
29. Alguma pessoa trabalhando com rendimento superior a 1 salário mínimo? (R\$ 545,00) & 0,499 \\
30. Alguma pessoa trabalhando com rendimento superior a 2 salários mínimos? (R\$ $\$, 459$ \\
1.090,00) & 0,589 \\
58. Telefone celular? & 0,454 \\
60. Microcomputador? & 0,805 \\
61. Microcomputador com acesso a internet? & 0,765 \\
62. Motocicleta ou automóvel para uso particular? & 0,512 \\
\hline
\end{tabular}

No fator 2 (Tabela 20), a questão sobre a existência de idosos na casa correlacionou-se com outros itens relativos ao processo de envelhecimento e às incapacidades e dependência. 
As questões sobre se mais da metade das pessoas em idade ativa exerciam trabalho remunerado, trabalhavam por mais de seis meses no emprego atual e tinham rendimento superior a um salário mínimo também se relacionaram a esse fator.

Os demais itens fazem parte da dimensão condições de saúde e estão relacionados ao processo de envelhecimento, como é o caso da presença de pelo menos duas doenças crônicas, uso de polifarmácia, ocorrência de quedas em idosos, não conseguir utilizar o transporte público para ir ao serviço de saúde, presença de incapacidade auditiva, incapacidade para se movimentar e dependência para alguma atividade básica ou instrumental da vida diária.

Como ter domicílio próprio em terreno próprio teve correlação negativa, optou-se por retirá-lo do fator 2. Também foram retiradas as questões 26 e 29, já contempladas no fator 1 , e a 79 , presente no fator 7 , que se referem a condições crônicas.

A questão 25 também foi retirada por pertencer ao componente ‘disponibilidade de trabalho' no instrumento original e não estar de acordo com as demais questões agrupadas neste fator.

Tabela 21 - Descrição do fator 2. São Paulo, 2011.

\begin{tabular}{lc}
\hline Questão & $\mathbf{r}$ \\
\hline 7. Algum idoso (60 anos ou mais)? & 0,590 \\
8. Algum idoso com 80 anos ou mais? & 0,474 \\
10. Apenas moradores idosos (60 anos ou mais)? & 0,513 \\
25. Mais da metade das pessoas em idade ativa* exerce trabalho remunerado? & 0,513 \\
*neste caso, considerar 16 anos ou mais (excluir trabalho infantil) & \\
26. Alguma pessoa trabalha há mais de seis meses no emprego atual? & 0,505 \\
29. Alguma pessoa trabalhando com rendimento superior a 1 salário mínimo? (R\$ 545,00) & 0,439 \\
45. Próprio em terreno próprio? & $-0,409$
\end{tabular}


84. Alguma pessoa que faz uso contínuo de 5 ou mais medicamentos diferentes ao mesmo $\quad 0,503$ tempo? (polifarmácia)

87. Algum idoso sofreu queda nos últimos 12 meses?

91. Alguma pessoa que não consegue ir de transporte coletivo público ao serviço de saúde? $\quad 0,629$

94. Alguma pessoa com incapacidade auditiva? (considerar pessoa incapaz, com grande $\quad 0,534$ dificuldade permanente ou alguma dificuldade permanente de ouvir mesmo com uso de aparelho auditivo)

95. Alguma pessoa com incapacidade para se movimentar? (considerar pessoa incapaz, com grande dificuldade permanente ou alguma dificuldade permanente de caminhar mesmo com uso de prótese, bengala ou aparelho auxiliar)

97. Alguma pessoa que, sem ajuda, não realiza qualquer das seguintes atividades: alimentação, higiene pessoal, vestir-se, controle de eliminação intestinal e vesical, deambulação e transferências? (Atividades Básicas da Vida Diária - ABVD)?

99. Alguma pessoa que, sem ajuda, não consegue realizar nenhuma das seguintes atividades: limpar a casa, cuidar da roupa, da comida, usar equipamentos domésticos, fazer compras, usar transporte pessoal ou público, controlar a própria medicação e finanças? (Atividades Instrumentais da Vida Diária - AIVD)

No fator 3, correlacionaram-se as questões que verificavam a presença de crianças, idosos, famílias com renda na linha da pobreza e condição de moradia $\left(\mathrm{n}^{\circ}\right.$ de dormitórios divido pelo número total de moradores do domicílio).

Optou-se por retirar os itens 7 e 32 por já estarem contemplados em outros fatores e por apresentarem baixa correlação. A questão 7 , relativa à existência de idosos, permaneceu no fator 2, que reuniu as questões referentes ao envelhecimento. Já a questão 32 , sobre a renda familiar na linha da pobreza, foi mantida no fator 5 , que também verifica o analfabetismo.

Tabela 22 - Descrição do fator 3. São Paulo, 2011.

\begin{tabular}{|c|c|}
\hline Questão & $\mathbf{r}$ \\
\hline 2. Alguma mulher que teve filho nascido vivo nos últimos 24 meses? & 0,514 \\
\hline 4. Alguma criança até 10 anos? & 0,826 \\
\hline 5. Alguma criança ou adolescente até 14 anos? & 0,842 \\
\hline 6. Alguma criança, adolescente ou jovem até 17 anos? & 0,823 \\
\hline 7. Algum idoso (60 anos ou mais)? & $-0,479$ \\
\hline $\begin{array}{l}\text { 32. A renda familiar é de } 1 / 4 \text { até } 1 / 2 \text { salário mínimo por pessoa*? } \\
\text { *Salário Mínimo em } 2011=R \$ 545,00 ; 1 / 2=R \$ 272,50,1 / 4=R \$ 136,25 \text { - Instituto de Pesquisa } \\
\text { Econômicas Aplicadas - IPEA } \\
\text { 46. O número total de moradores dividido pelo número de dormitórios é maior que dois? }\end{array}$ & 0,454 \\
\hline
\end{tabular}


O fator 4 foi mantido na íntegra, correlacionando todas as questões referentes ao apoio social.

Tabela 23 - Descrição do fator 4. São Paulo, 2011.

\begin{tabular}{lc}
\hline Questão & $\mathbf{r}$ \\
\hline $\begin{array}{l}\text { 72. Alguma pessoa que não tem com quem contar, caso necessite de ajuda para realizar } \\
\text { tarefas domésticas como fazer a comida e limpar a casa? }\end{array}$ & 0,746 \\
$\begin{array}{l}\text { 73. Alguma pessoa que não tem com quem contar, caso necessite de ajuda com bens } \\
\text { materiais? }\end{array}$ & 0,664 \\
$\begin{array}{l}\text { 74. Alguma pessoa que não tem com quem contar, caso necessite de dinheiro ou ajuda } \\
\text { financeira? }\end{array}$ & 0,663 \\
$\begin{array}{l}\text { 75. Alguma pessoa que não tem com quem contar, caso necessite de companhia? } \\
\text { 76. Alguma pessoa que não tem com quem contar, caso necessite receber cuidados de }\end{array}$ & 0,758 \\
saúde? & 0,820 \\
$\begin{array}{l}\text { 77. Alguma pessoa que não tem com quem contar para acompanhá-lo, caso necessite sair } \\
\text { de casa (para consultas, fazer compras, passear...)? }\end{array}$ & 0,758
\end{tabular}

A presença de algum adulto analfabeto no domicílio, o analfabetismo entre os chefes de família e a renda familiar na linha da pobreza correlacionaram-se no fator

5.

Tabela 24 - Descrição do fator 5. São Paulo, 2011.

\begin{tabular}{|c|c|}
\hline Questão & $r$ \\
\hline 15. Algum adulto analfabeto ou que só lê e escreve o próprio nome? & 0,776 \\
\hline 16. Algum adulto com dificuldade para ler e escrever (analfabeto funcional)? & 0,684 \\
\hline 20. O chefe da família é analfabeto ou só lê e escreve o próprio nome? & 0,793 \\
\hline 21. O chefe da família tem dificuldade para ler e escrever (analfabeto funcional)? & 0,713 \\
\hline $\begin{array}{l}\text { 32. A renda familiar é de } 1 / 4 \text { até } 1 / 2 \text { salário mínimo por pessoa*? } \\
\text { *Salário Mínimo em } 2011=R \$ 545,00 ; 1 / 2=R \$ 272,50,1 / 4=R \$ 136,25-\text { IPEA }\end{array}$ & 0,403 \\
\hline
\end{tabular}

As questões 66 a 71, relacionadas à frequência de contatos com familiares e amigos, foram correlacionadas no fator 6, das 'Relações Sociais', tal como no instrumento original. As demais questões desse componente que estavam presentes no instrumento original, referentes a morar próximo de familiares e amigos e participar de atividade social, não se correlacionaram nesse fator. 
Tabela 25 - Descrição do fator 6. São Paulo, 2011.

\begin{tabular}{lc}
\hline Questão & $\mathbf{r}$ \\
\hline 64. Amigos que moram próximos (a ponto de ir a pé) e que mantém contato? & 0,585 \\
66. Visitas de familiares pelo menos uma vez por semana? & 0,504 \\
67. Visitas de familiares pelo menos uma vez ao mês? & 0,549 \\
68. Visitas de familiares pelo menos uma vez ao ano? & 0,426 \\
69. Visitas de amigos pelo menos uma vez por semana? & 0,523 \\
70. Visitas de amigos pelo menos uma vez por mês? & 0,668 \\
71. Visitas de amigos pelo menos uma vez ao ano? & 0,592
\end{tabular}

O fator 7 agrupou as questões associadas a presença de doenças crônicas, adesão ao tratamento medicamentoso e não medicamentoso, uso de medicamentos contínuos, autoavaliação negativa de saúde e dificuldade de acesso no agendamento de consultas, exames ou tratamentos.

Tabela 26 - Descrição do fator 7. São Paulo, 2011.

\begin{tabular}{lc}
\hline Questão & $\mathbf{r}$ \\
\hline 78. Alguma pessoa com pelo menos uma doença crônica? & 0,453 \\
79. Alguma pessoa com pelo menos duas doenças crônicas? & 0,465 \\
$\begin{array}{l}\text { 81. Alguma pessoa com doença crônica que tem dificuldades em seguir o tratamento } \\
\text { medicamentoso, por motivos pessoais ou por dificuldade de acesso aos medicamentos? }\end{array}$ & 0,548 \\
$\begin{array}{l}\text { 82. Alguma pessoa com doença crônica que tem dificuldades em seguir o tratamento não- } \\
\text { medicamentoso, como fazer atividade física, seguir dieta recomendada ou parar de fumar? }\end{array}$ & 0,444 \\
$\begin{array}{l}\text { 83. Alguma pessoa que faz uso de medicamento contínuo? } \\
\text { 88. Alguma pessoa que considera sua saúde ruim ou muito ruim? }\end{array}$ & 0,426 \\
$\begin{array}{l}\text { 90. Alguma pessoa que não conseguiu agendar consultas, exames ou tratamentos nos } \\
\text { últimos 12 meses? }\end{array}$ & 0,552 \\
& 0,414 \\
\hline
\end{tabular}

O instrumento resultante totalizou 53 questões distribuídas em sete fatores. A distribuição do número de questões entre os fatores, bem como as dimensões e componentes originais ao quais pertenciam aparecem no quadro 4 , que permite observar as correlações e os possíveis agrupamentos entre os sete fatores. 
Verifica-se que o fator 1 representa condições sociais favoráveis. Já os fatores 3 e 5 representam condições sociais desfavoráveis, por isso, decidiu-se criar outro fator que é a soma desses dois $(3+5)$, que chamaremos de fator 35 . Da mesma forma, os fatores 2 e 7 relacionam-se a condições de saúde e a existência de idosos, portanto, também decidiu-se criar o fator 27 , resultante da soma desses dois fatores. Os outros dois fatores restantes, 4 e 6, também podem ser agrupados, pois referem-se às relações sociais (rede e apoio social) e serão chamados de fator 46. Com isso, foram considerados quatro fatores, a saber:

Fator 1: Condições sociais favoráveis (Fator 1)

Fator 35: Condições sociais desfavoráveis (Fatores 3 e 5)

Fator 27: Condições de saúde e existência de idosos (Fatores 2 e 7)

Fator 46: Relações sociais (Fatores 4 e 6)

Quadro 4 - Número de questões dos fatores e dimensões e componentes aos quais pertenciam no Índice original.

\begin{tabular}{|c|c|c|c|}
\hline Fatores & $\begin{array}{l}\text { Número de } \\
\text { questões }\end{array}$ & $\begin{array}{l}\text { DIMENSÕES ao } \\
\text { quais pertenciam }\end{array}$ & $\begin{array}{c}\text { COMPONENTES } \\
\text { aos quais } \\
\text { pertenciam }\end{array}$ \\
\hline 1 & 13 & $\begin{array}{c}2 \text { - Acesso ao } \\
\text { conhecimento } \\
3 \text { - Acesso ao trabalho } \\
4 \text { - Condições } \\
\text { habitacionais }\end{array}$ & $\begin{array}{c}\text { Analfabetismo; } \\
\text { escolaridade; } \\
\text { escolaridade do chefe } \\
\text { de família; } \\
\text { disponibilidade de } \\
\text { trabalho; remuneração; } \\
\text { acesso a bens duráveis }\end{array}$ \\
\hline 2 & 10 & $\begin{array}{c}1 \text { - Vulnerabilidade das } \\
\text { famílias } \\
4 \text { - Condições de } \\
\text { saúde }\end{array}$ & $\begin{array}{l}\text { Existência de idosos; } \\
\text { medicamentos; } \\
\text { quedas; acesso aos } \\
\text { serviços de saúde; } \\
\text { incapacidade física; } \\
\text { capacidade funcional }\end{array}$ \\
\hline 3 & 5 & $\begin{array}{c}\text { 1- Vulnerabilidade das } \\
\text { famílias } \\
3 \text { - Condições } \\
\text { habitacionais }\end{array}$ & $\begin{array}{c}\text { Fecundidade; } \\
\text { existência de crianças, } \\
\text { adolescentes e jovens; } \\
\text { condições de moradia }\end{array}$ \\
\hline 4 & 6 & 7 - Relações sociais & Apoio social \\
\hline 5 & 5 & $2-$ Acesso ao & Analfabetismo; \\
\hline
\end{tabular}




\begin{tabular}{|c|c|c|c|}
\hline & & $\begin{array}{c}\text { conhecimento } \\
\text { 3-Acesso ao trabalho }\end{array}$ & $\begin{array}{c}\text { escolaridade do chefe } \\
\text { da família; pobreza }\end{array}$ \\
\hline 6 & 7 & 7 - Relações sociais & Rede social \\
\hline 7 & 7 & $8-$ Condições de \\
saúde & $\begin{array}{c}\text { Doenças crônicas; } \\
\text { adesão ao tratamento; } \\
\text { medicamentos; } \\
\text { avaliação subjetiva da } \\
\text { saúde; acesso aos } \\
\text { serviços de saúde }\end{array}$ \\
\hline TOTAL & 53 & - & - \\
\hline
\end{tabular}

Apresenta-se seguir as análises descritivas dos sete fatores originais e dos três novos, resultantes dos agrupamentos de dois fatores (27, 35, e 46).

\subsubsection{Descrição dos indicadores}

A Tabela 27 permite observar que a consistência interna dos fatores, mesmo agrupados, pode ser considerada boa, pois o alfa é igual ou superior a 0,68 , exceto quando agrupado todos os fatores, o valor de alfa é muito baixo $(0,37)$, portanto o total dos fatores, não entrará nas análises de validade.

Tabela 27 - Estatística descritiva do IVF-ID. São Paulo, 2011.

\begin{tabular}{ccccc}
\hline Fatores & Alpha de cronbach & Média $(\mathbf{d p})$ & Mediana & Mín-máx \\
\hline 1 & 0,88 & $5,63(3,71)$ & 5,00 & $0-13$ \\
2 & 0,80 & $1,66(2,10)$ & 1,00 & $0-9$ \\
3 & 0,86 & $1,31(1,70)$ & 0,00 & $0-9$ \\
4 & 0,85 & $1,06(1,72)$ & 0,00 & $0-6$ \\
5 & 0,80 & $0,51(1,11)$ & 0,00 & $0-5$ \\
6 & 0,69 & $1,92(1,61)$ & 2,00 & $0-6$ \\
7 & 0,68 & $2,71(1,75)$ & 3,00 & $0-7$ \\
27 & 0,80 & $4,38(3,22)$ & 4,00 & $0-14$ \\
35 & 0,79 & $1,82(2,15)$ & 1,00 & $0-9$ \\
46 & 0,77 & $2,98(2,59)$ & 2,00 & $0-12$ \\
Total & 0,37 & $16,40(7,48)$ & 16,00 & $1-34$ \\
$(1+2+3+4+5+6+7)$ & & & & \\
\hline
\end{tabular}




\subsubsection{Validação dos indicadores em relação à dependência por meio da validade discriminante}

Os fatores 2 e 7, bem como sua combinação (27), foram capazes de discriminar famílias com e sem pessoas com dependência para as AVD. As médias desses fatores foram sempre superiores nas famílias em que havia pessoas com dependência $(p<0,001)$, como mostra a Tabela 28 .

Tabela 28 - Estatística descritiva dos indicadores do IVF-ID, segundo a presença de dependência para as atividades básicas da vida diária do Índice de Katz. São Paulo, 2011.

\begin{tabular}{cccccc}
\hline Fatores & \multicolumn{5}{c}{ Presença de dependência (KATZ) } \\
\cline { 2 - 6 } & \multicolumn{2}{c}{$\begin{array}{c}\text { Não existe pessoa com } \\
\text { dependência na família }\end{array}$} & $\begin{array}{c}\text { Há pelo menos uma pessoa com } \\
\text { dependência para AVD }\end{array}$ \\
\cline { 2 - 6 } & Média & Dp & Média & Dp & p\# \\
\hline 1 & 5,54 & 3,64 & 6,52 & 4,34 & 0,294 \\
2 & 1,34 & 1,75 & 4,83 & 2,66 & $<0,001^{*}$ \\
3 & 1,36 & 1,72 & 0,78 & 1,38 & 0,130 \\
4 & 1,10 & 1,74 & 0,61 & 1,50 & 0,056 \\
5 & 0,47 & 1,04 & 0,91 & 1,65 & 0,306 \\
6 & 1,90 & 1,59 & 2,09 & 1,83 & 0,741 \\
7 & 2,60 & 1,77 & 3,83 & 1,19 & $0,001^{*}$ \\
27 & 3,94 & 2,92 & 8,65 & 2,93 & $<0,001^{*}$ \\
35 & 1,83 & 2,12 & 1,70 & 2,48 & 0,506 \\
46 & 3,00 & 2,56 & 2,70 & 2,95 & 0,321 \\
\hline
\end{tabular}

\# Teste de Mann-Whitney

* diferença estatisticamente significativa $(p<0,05)$

Para as atividades instrumentais da vida diária, verificou-se um número maior de fatores capazes de discriminar famílias com e sem pessoas com dependência. Os fatores 1, 2, 7 e 27 apresentaram médias superiores nas famílias com pessoas com dependência $(p<0,001)$. Já os fatores 3 e 35 apresentaram média superiores nas famílias sem pessoas com dependência. 
Tabela 29 - Estatística descritiva dos fatores do IVF-ID, segundo a presença de dependência para as atividades instrumentais da vida diária da Escala de Lawton. São Paulo, 2011.

\begin{tabular}{|c|c|c|c|c|c|}
\hline \multirow[t]{3}{*}{ Fatores } & \multicolumn{4}{|c|}{ Presença de dependência (LAWTON) } & \multirow[t]{3}{*}{ p\# } \\
\hline & \multicolumn{2}{|c|}{$\begin{array}{l}\text { Não existe pessoa com } \\
\text { dependência na família }\end{array}$} & \multicolumn{2}{|c|}{$\begin{array}{l}\text { Há pelo menos uma pessoa com } \\
\text { dependência para AIVD }\end{array}$} & \\
\hline & Média & Dp & Média & Dp & \\
\hline 1 & 5,31 & 3,61 & 6,76 & 3,89 & $0,010^{*}$ \\
\hline 2 & 0,91 & 1,24 & 4,31 & 2,36 & $<0,001^{*}$ \\
\hline 3 & 1,54 & 1,76 & 0,51 & 1,15 & $<0,001^{*}$ \\
\hline 4 & 1,07 & 1,73 & 1,02 & 1,71 & 0,985 \\
\hline 5 & 0,45 & 1,06 & 0,73 & 1,27 & 0,066 \\
\hline 6 & 1,92 & 1,53 & 1,93 & 1,86 & 0,686 \\
\hline 7 & 2,41 & 1,79 & 3,76 & 1,14 & $<0,001^{*}$ \\
\hline 27 & 3,32 & 2,56 & 8,07 & 2,48 & $<0,001^{*}$ \\
\hline 35 & 1,98 & 2,21 & 1,24 & 1,84 & $0,020^{*}$ \\
\hline 46 & 2,98 & 2,54 & 2,95 & 2,80 & 0,637 \\
\hline
\end{tabular}

\subsubsection{Validação dos indicadores em relação à dependência por meio da validade concorrente}

A Tabela 30 mostra a correlação dos fatores do IVF-ID com as pontuações do índice de Katz e da escala de Lawton, por meio da correlação de Spearman. Observa-se que o fator 1 apresenta correlação negativa estatisticamente significativa com a Escala de Lawton $(r=-0,18 ; p=0,005)$, indicando que, quanto maior a pontuação média no fator 1 (maior vulnerabilidade), menor a pontuação média na Escala (maior dependência). $O$ fator 2 apresentou correlação estatisticamente significativa nos dois instrumentos.

Também em relação ao Índice de Katz a correlação foi positiva $(r=0,40$; $p=0,000$ ), indicando que, quanto maior a pontuação no fator 2 (maior vulnerabilidade), maior a pontuação no Índice (maior dependência). Na Escala de Lawton, a correlação foi negativa, portanto, quanto maior a pontuação do fator 2 (maior vulnerabilidade), menor a pontuação na Escala (maior dependência). 
O fator 3 obteve correlação estatisticamente significativa com a Escala de Lawton ( $r=0,28 ; p=0,000)$, indicando que, quanto maior a pontuação do fator 3 (maior vulnerabilidade), maior a pontuação na Escala (menor dependência).

O fator 7 obteve correlação estatisticamente significativa no Índice de Katz $(r=0,21 ; p=0,001)$ e na Escala de Lawton ( $r=-0,32 ; p=0,000)$, indicando que, quanto maior a pontuação do fator 7 (maior vulnerabilidade), maior a pontuação no Índice de Katz (maior dependência) e quanto maior pontuação do fator (maior vulnerabilidade), menor a pontuação na Escala de Lawton (maior dependência).

O fator 27 também obteve correlação positiva estatisticamente significativa com Katz $(r=0,37 ; p=0,000)$ e negativa com Lawton $(r=-0,59 ; p=0,000)$.

Finalmente, o fator 35 apresentou correlação estatisticamente significativa com a Escala de Lawton ( $r=0,16 ; p=0,013)$, indicando que quanto maior a pontuação do fator (maior vulnerabilidade), maior a pontuação na Escala (menor dependência).

Tabela 30 - Coeficientes de correlação de Spearman $\left(r_{\mathrm{sp}}\right)$ entre os indicadores do IVF-ID e a média de pontuação familiar do Katz e Lawton. São Paulo, 2011.

\begin{tabular}{ccc}
\hline Fatores & $\begin{array}{c}\text { Média de Pontuação Katz } \\
\mathbf{r}_{\mathbf{s p}}(\mathbf{p})\end{array}$ & $\begin{array}{c}\text { Média de Pontuação Lawton } \\
\mathbf{r}_{\mathbf{s p}}(\mathbf{p})\end{array}$ \\
\hline 1 & $0,08(0,220)$ & $-0,18^{* *}(0,005)$ \\
2 & $0,40^{* *}(0,000)$ & $-0,62^{* *}(0,000)$ \\
3 & $-0,10(0,108)$ & $0,28^{* *}(0,000)$ \\
4 & $-0,12(0,060)$ & $0,02(0,784)$ \\
5 & $0,06(0,315)$ & $-0,13(0,050)$ \\
6 & $0,02(0,736)$ & $0,01(0,907)$ \\
7 & $0,21^{* *}(0,001)$ & $-0,32^{* *}(0,000)$ \\
27 & $0,37^{* *}(0,000)$ & $-0,59^{* *}(0,000)$ \\
35 & $-0,05(0,449)$ & $0,16^{*}(0,013)$ \\
46 & $-0,06(0,330)$ & $0,03(0,668)$ \\
\hline
\end{tabular}

${ }^{*}$ correlação estatisticamente significativa $(p<0,05)$

Pelo exposto, verifica-se que os fatores 2,7 e 27 foram validados com boa consistência interna, em relação ao Índice de Katz e à Escala de Lawton, enquanto os fatores 1, 3 e 35 validaram apenas em relação à Escala de Lawton. 
O fator 27 foi o que apresentou melhor desempenho em relação aos demais, porque correlacionou-se significativamente com ambas as escalas, Katz e Lawton, enquanto os fatores 1 e 35 correlacionam-se significativamente apenas com a Escala de Lawton.

No entanto, como todos se correlacionaram com a Escala de Lawton, procurou-se avaliar esses três fatores conjuntamente $(1+27+35)$. Encontrou-se um alpha de Cronbach de 0,82 , pontuação média de 11,83 com desvio padrão de 5,73, mediana de 11,0 e mínima de 0 e máxima de 25 pontos.

$\mathrm{Na}$ análise da validade discriminante, o fator $1+27+35$ foi capaz de discriminar famílias com e sem pessoas com dependência para as ABVD (Katz) e AIVD (Lawton). As médias desses fatores foram sempre superiores nas famílias com pessoas com dependência (respectivamente 16,87x11,31; $p<0,001$ e 16,07 x 10,62; $p<0,001)$.

Na validade concorrente, o fator $1+27+35$ apresentou correlação positiva com o Índice de Katz $(r=0,27 ; p<0,001)$, indicando que quanto maior a pontuação no fator (maior vulnerabilidade), maior a pontuação no Índice (maior dependência) e apresentou correlação negativa com a Escala de Lawton ( $r=-0,39 ; p<0,001)$, indicando que quanto maior a pontuação no fator (maior vulnerabilidade), menor a pontuação na Escala (maior dependência).

A análise pode ser feita de duas formas: uma delas é através do Índice, que passará a ser designado IVF-ID Total, composto pelo agrupamento de três fatores $(1+27+35)$, em que os fatores 1 e 35 referem-se às condições sociais (CSO) e o fator 27, às condições de saúde (CSA). Pode-se ainda analisar separadamente o 
fator 27 que avalia as condições de saúde e que doravante será designado Dimensão CSA. Com isso, o IVF-ID será estruturado da seguinte forma: IVF-ID Total= Dimensão CSA + Dimensão CSO, conforme mostra o quadro 5, a seguir:

Quadro 5 - Dimensões e componentes do IVF-ID Total.

\begin{tabular}{|l|l|}
\hline \multicolumn{2}{|c|}{ IVF-ID Total } \\
\hline Dimensões & Componentes \\
\hline Condições de Saúde (CSA) & $\begin{array}{l}\text { Envelhecimento, incapacidades e } \\
\text { dependência }\end{array}$ \\
\cline { 2 - 2 } & Doenças crônicas \\
\hline Condições Sociais (CSO) & Condições de vida favoráveis \\
\cline { 2 - 2 } & Condições de vida desfavoráveis \\
\hline
\end{tabular}

Assim, o instrumento final será composto por duas dimensões, quatro componentes e 40 indicadores (APÊNDICE III). As opções de resposta continuam sendo SIM ou NÃO, sendo que se a resposta representar maior vulnerabilidade a pontuação será 1 e, nos casos de menor vulnerabilidade, a pontuação será zero. Apenas no componente Condições sociais favoráveis, as respostas afirmativas indicam menor vulnerabilidade e a resposta SIM vale um ponto. Nos demais, as respostas afirmativas indicam maior vulnerabilidade e a pontuação é um para SIM e zero para NÃO.

\subsubsection{Definição dos pontos de corte para o IVF-ID TOTAL e para a Dimensão CSA}

Para o IVF-ID Total e para a Dimensão CSA, quanto maior o valor pior a condição. No entanto, seria interessante ter pontos de corte para classificar a família como vulnerável ou não, tanto pelo IVF-ID Total quanto pela Dimensão CSA. O quadro 6 apresenta esse esquema. 
Quadro 6 - Classificação da vulnerabilidade das famílias, segundo o IVF-ID Total e a Dimensão CSA.

\begin{tabular}{|c|c|c|}
\hline IVF-ID TOTAL & \multicolumn{2}{|c|}{ DIMENSÃO CSA } \\
\hline CSO) & NÃO & SIM \\
\hline NÃO & $\begin{array}{l}\text { Família não } \\
\text { vulnerável }\end{array}$ & $\begin{array}{l}\text { Família vulnerável nas } \\
\text { condições de saúde (CSA) }\end{array}$ \\
\hline SIM & $\begin{array}{l}\text { Família vulnerável } \\
\text { nas condições } \\
\text { sociais (CSO) }\end{array}$ & $\begin{array}{l}\text { Família mais vulnerável } \\
\qquad(\text { CSA+CSO) }\end{array}$ \\
\hline
\end{tabular}

Para a definição do ponto de corte do IVF-ID Total foi utilizada a curva ROC, construída com base na Escala de Lawton. A curva ROC obteve área=0,764 $(p<0,001)$ e o ponto de corte 10 revelou sensibilidade de 0,84 e especificidade de 0,53. Assim, definiu-se como família vulnerável para incapacidades e dependência aquela com 11 ou mais pontos no IVF-ID Total.

Em relação Dimensão CSA, a curva ROC obteve área de 0,904 $(p<0,001)$ e o ponto de corte 5 revelou sensibilidade de 0,95 e especificidade de 0,76. Assim, definiu-se como família vulnerável para incapacidades e dependência aquela com 5 ou mais pontos nesta Dimensão.

Verifica-se, portanto, um ponto de corte para o Índice total e outro para a Dimensão CSA. Se a família for considerada vulnerável pela pontuação do IVF-ID Total, mas não vulnerável pelo ponto de corte da Dimensão CSA, pode-se considerar que essa família é mais vulnerável sob os aspectos sociais e não de saúde. Da mesma forma, famílias que não forem consideradas vulneráveis pelo ponto de corte do IVF-ID Total, mas o forem pelo ponto de corte da Dimensão CSA, serão consideradas vulneráveis às condições de saúde e não vulneráveis às condições sociais. Famílias consideradas não vulneráveis serão aquelas que 
estarão abaixo do ponto de corte tanto no IVF-ID Total como na Dimensão CSA. E por sua vez, as famílias consideradas mais vulneráveis serão as que pontuarem acima do ponto de corte tanto no IVF-ID Total quanto na Dimensão CSA. Assim, pode ser representado, conforme Figura 1, a seguir: 


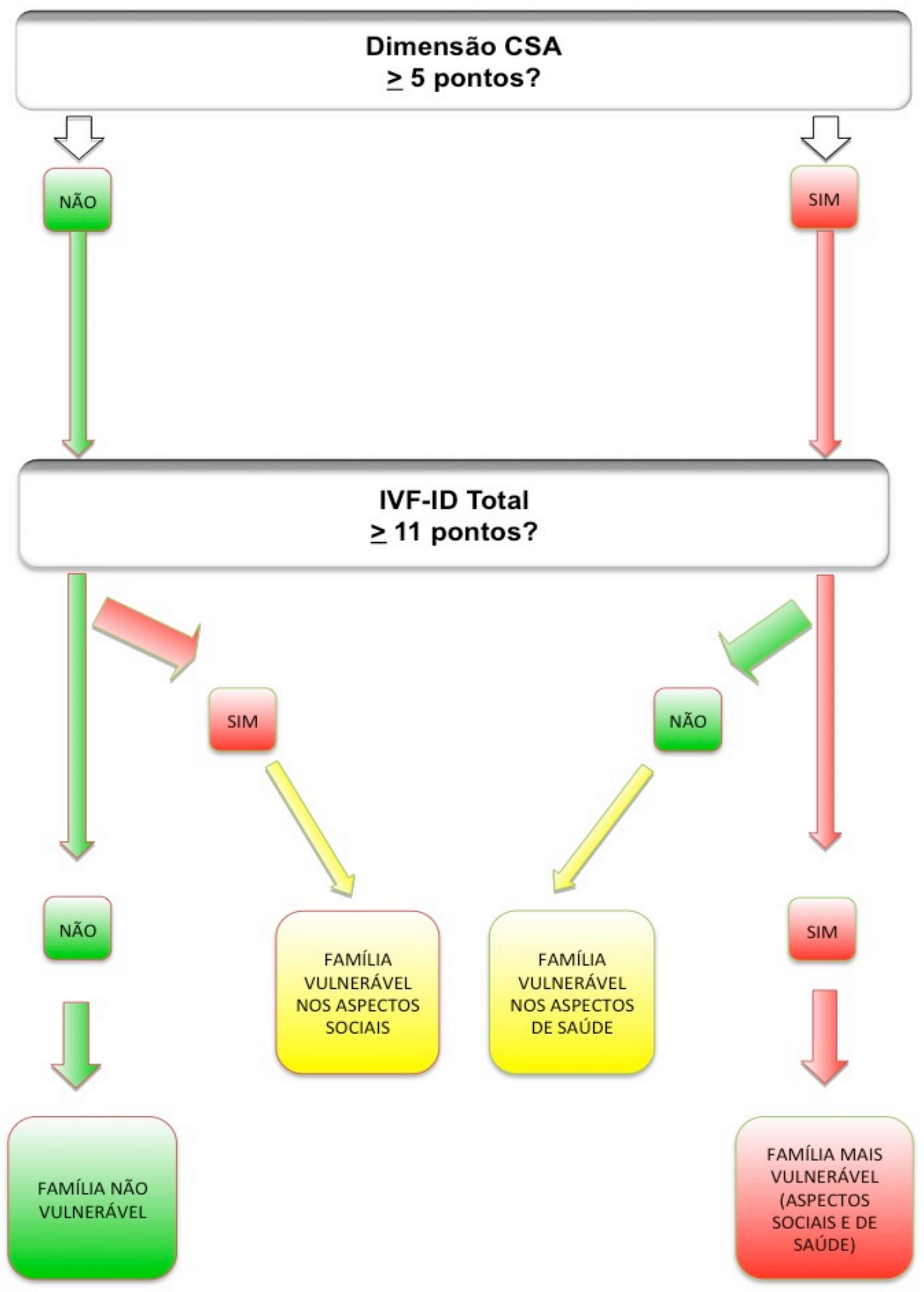

Figura 5 - Representação, em fluxograma, da avaliação e classificação das famílias através da aplicação do IVF-ID total e da dimensão CSA. 


\subsubsection{Classificação das famílias da região da Lapa, segundo o IVF-ID}

Utilizando os pontos de corte e o esquema definidos acima, verificou-se a distribuição das famílias quanto à vulnerabilidade relacionada ao IVF-ID Total e à Dimensão CSA (Tabela 31).

Das 248 famílias entrevistadas, 136 (54,8\%) apresentaram-se vulneráveis para incapacidades e dependência segundo o IVF-ID Total. Dessas, 96 (38,7\%) apresentaram-se vulneráveis na Dimensão CSA, o que leva a considerá-las as famílias mais vulneráveis, pois o são tanto nas condições sociais quanto de saúde (CSO + CSA). As 40 famílias restantes $(16,1 \%)$ não são vulneráveis quando avaliadas somente na Dimensão CSA, o que indica que são mais vulneráveis socialmente (CSO) que nos aspectos relacionados à saúde (CSA).

Por outro lado, 112 famílias $(45,2 \%)$ não foram consideradas vulneráveis no IVF-ID Total (CSO+CSA), mas apresentaram vulnerabilidade na Dimensão CSA, o que indica que não são vulneráveis socialmente (CSO).

E, por fim, 90 famílias (36,3\%) não foram classificadas como vulneráveis nem pelo IVF-ID Total e nem pela Dimensão CSA, sendo, portanto, famílias não vulneráveis para incapacidades e dependência. 
Tabela 31 - Distribuição das famílias segundo a presença de vulnerabilidade, na Lapa. São Paulo, 2011.

\begin{tabular}{l|cc|c}
\hline \multirow{2}{*}{$\begin{array}{l}\text { IVF-ID Total } \\
\text { (CSO + CSA) }\end{array}$} & \multicolumn{3}{|c}{ Dimensão CSA } \\
\cline { 2 - 4 } & $\begin{array}{c}\text { Não vulnerável } \\
\text { pontos) } \\
\mathbf{N}(\%)\end{array}$ & $\begin{array}{c}\text { Vulnerável (5 } \\
\text { pontos e +) } \\
\mathbf{N}(\%)\end{array}$ & $\begin{array}{c}\text { Total } \\
\mathbf{N}(\%)\end{array}$ \\
\hline $\begin{array}{l}\text { Não vulnerável (0-10 } \\
\text { pontos) }\end{array}$ & $90(36,3)$ & $22(8,9)$ & 112 \\
$\begin{array}{l}\text { Vulnerável (11 pontos } \\
\text { e +) }\end{array}$ & $40(16,1)$ & $(45,2)$ \\
\hline Total & $130(52,4)$ & $136(38,7)$ & $154,8)$ \\
\hline
\end{tabular}

\subsection{Validação do IVF-ID em outra população}

O instrumento foi aplicado na região da Cidade Ademar com o mesmo número de famílias entrevistadas (248 famílias). A região da Cidade Ademar foi eleita para validação do índice por ser uma região que apresenta características distintas da região da Lapa, no que se refere às condições sociais (IPVS abaixo da média do município) e ao perfil demográfico (menos idosos). Com isso, verificou-se se o índice é válido para retratar realidades sociais e de saúde consideradas distintas. A seguir serão demonstrados os resultados de caracterização das famílias e também a validação do IVF-ID, na região da Cidade Ademar. 


\subsubsection{Caracterização dos membros das famílias entrevistadas}

Observa-se, na Tabela 32, um predomínio de mulheres nas famílias entrevistadas, representando $(52,1 \%)$.

Tabela 32 - Número e porcentagem dos membros das famílias entrevistadas, segundo o sexo. São Paulo, 2011.

\begin{tabular}{ccc}
\hline Sexo & N & $\%$ \\
\hline Feminino & 490 & 52,1 \\
Masculino & 450 & 47,9 \\
\hline Total & 940 & 100,0 \\
\hline
\end{tabular}

Em relação à faixa etária, verifica-se que a maior parte das pessoas estão na faixa de 18 a 59 anos (58,9\%), seguido pelas crianças, adolescentes e jovens $(29,9 \%)$ e idosos $(11,2 \%)$ (Tabela 33$)$.

Tabela 33 - Número e porcentagem de membros das famílias entrevistadas, segundo a faixa etária. São Paulo, 2011.

\begin{tabular}{ccc}
\hline Faixa etária & $\mathbf{N}$ & $\%$ \\
\hline$<2$ anos & 30 & 3,2 \\
$2-9$ anos & 108 & 11,5 \\
$10-14$ anos & 94 & 10,0 \\
$15-17$ anos & 49 & 5,2 \\
$18-59$ anos & 554 & 58,9 \\
$60-69$ anos & 66 & 7,0 \\
$70-79$ anos & 27 & 2,9 \\
80 anos e mais & 12 & 1,3 \\
\hline Total & 940 & 100,0
\end{tabular}

A idade média encontrada foi de 31,63 anos e mediana de 28 anos, sendo uma amostra composta por adultos mais jovens. A idade máxima encontrada foi de 
89 anos. A média de pontuação no Índice de Katz foi de apenas 0,03 e de 26,72 na Escala de Lawton, indicando pessoas independentes para as AVD (Tabela 34).

Tabela 34 - Estatística descritiva dos membros das famílias entrevistadas, segundo o número de pessoas, idade, pontuação total do Katz e pontuação total do Lawton. São Paulo, 2011.

\begin{tabular}{cccc}
\hline Variável & Média $(\mathbf{d p})$ & Min-máx & Mediana \\
\hline Idade & $31,63(20,35)$ & $0-89$ & 28,00 \\
Pontuação total Katz & $0,03(0,54)$ & $0-12$ & 0,00 \\
Pontuação total Lawton & $26,72(1,73)$ & $9-27$ & 27,00 \\
\hline
\end{tabular}

Foram encontradas apenas cinco pessoas com alguma dependência para as ABVD, sendo apenas uma totalmente dependente (Tabela 35).

Tabela 35 - Número e porcentagem dos membros das famílias entrevistadas, segundo o Índice de independência nas atividades básicas da vida diária, Katz. São Paulo, 2011.

\begin{tabular}{ccc}
\hline Índice de Katz & $\mathbf{N}$ & $\%$ \\
\hline A & 935 & 99,5 \\
B & 1 & 0,1 \\
C & 1 & 0,1 \\
D & 1 & 0,1 \\
E & 0 & 0 \\
F & 1 & 0,1 \\
G & 1 & 0,1 \\
Outro & 0 & 0 \\
\hline Total & 940 & 100,0
\end{tabular}

Mais de $90 \%$ da amostra era totalmente independente. Somente foram encontradas 34 pessoas com alguma dependência (3,6\%) para as AIVD (Tabela 36). 
Tabela 36 - Número e porcentagem dos membros das famílias entrevistadas, segundo a presença de alguma dependência para as atividades básicas da vida diária. São Paulo, 2011.

\begin{tabular}{lcccc}
\hline \multirow{2}{*}{ Dependência } & \multicolumn{2}{c}{ KATZ } & \multicolumn{2}{c}{ LAWTON } \\
\cline { 2 - 5 } & $\mathbf{N}$ & $\mathbf{N}$ & $\mathbf{N}$ & $\%$ \\
\hline Totalmente independente & 935 & 99,5 & 906 & 96,4 \\
Alguma dependência & 5 & 0,5 & 34 & 3,6 \\
\hline Total & 940 & 100,0 & 940 & 100,0 \\
\hline
\end{tabular}

\subsubsection{Caracterização das famílias entrevistadas}

A média do número de pessoas na casa foi de 3,79 pessoas, sendo encontradas famílias com até 11 pessoas. A média da pontuação familiar no Índice de Katz foi de 0,03 e, na Escala de Lawton, 26,67, indicando poucas pessoas com dependência para as AVD (Tabela 37).

Tabela 37 - Estatística descritiva das famílias entrevistadas, segundo o número de pessoas na casa, média familiar da pontuação no Índice de Katz e média familiar da pontuação na Escala de Lawton. São Paulo, 2011.

\begin{tabular}{cccc}
\hline Variável & Média (dp) & Min-máx & Mediana \\
\hline Número de pessoas na casa & $3,79(1,68)$ & $1-11$ & 4,00 \\
Média pontuação Katz & $0,03(0,31)$ & $0-4$ & 0,00 \\
Média pontuação Lawton & $26,67(1,24)$ & $16,5-27$ & 27,00 \\
\hline
\end{tabular}

O número de famílias entrevistadas em cada UBS da Cidade Ademar, variou de 15 a 32 famílias, de acordo com o tamanho da área de abrangência de cada UBS, do sorteio aleatório e do número de perdas (Tabela 38). 
Tabela 38 - Número e porcentagem das famílias entrevistadas, segundo a Unidade Básica de Saúde, na região da Cidade Ademar. São Paulo, 2011.

\begin{tabular}{ccc}
\hline UBS & N & $\%$ \\
\hline Cidade Júlia & 28 & 11,3 \\
Jardim Apurá & 16 & 6,5 \\
Jardim Laranjeiras & 19 & 7,7 \\
Jardim Niterói & 22 & 8,9 \\
Jardim São Jorge & 28 & 11,3 \\
Mar Paulista & 21 & 8,5 \\
Mata Virgem & 20 & 8,1 \\
São Carlos & 15 & 6,0 \\
Vila Guacuri & 29 & 11,7 \\
Vila Aparecida & 18 & 7,3 \\
Vila Império & 32 & 12,9 \\
\hline Total & 248 & 100,0
\end{tabular}

A distribuição do número de pessoas na casa se concentrou entre 3 e 4 pessoas, representando $49,2 \%$ da amostra (Tabela 39 ).

Tabela 39 - Número e porcentagem das famílias entrevistadas, segundo o número de pessoas na casa, na região da Cidade Ademar. São Paulo, 2011.

\begin{tabular}{cccc}
\hline Número de pessoas na casa & $\mathbf{N}$ & $\%$ \\
\hline 1 & 12 & 4,8 \\
2 & 42 & 16,9 \\
3 & 66 & 26,6 \\
4 & 56 & 22,6 \\
5 & 38 & 15,3 \\
6 & 20 & 8,1 \\
7 & 6 & 2,4 \\
8 & 5 & 2,0 \\
9 & 1 & 0,4 \\
10 & 1 & 0,4 \\
11 & 1 & 0,4 \\
\hline Total & 248 & 100,0 \\
\hline
\end{tabular}


Encontrou-se um número baixo de pessoas com alguma dependência (5 pessoas), segundo Katz, portanto, em $98 \%$ das famílias não havia pessoas com dependência para as atividades básicas da vida diária (Tabela 40).

Tabela 40 - Número e porcentagem das famílias entrevistadas, segundo a presença de dependência para as atividades básicas da vida diária entre algum membro da família, na região da Cidade Ademar. São Paulo, 2011.

\begin{tabular}{ccc}
\hline Dependência para AVD & N & $\%$ \\
\hline Não existe pessoa com dependência & 243 & 98,0 \\
Pelo menos 1 pessoa apresenta dependência & 5 & 2,0 \\
\hline Total & 248 & 100,0 \\
\hline
\end{tabular}

Entretanto, houve um número maior de famílias $(11,7 \%)$ cujos integrantes apresentavam alguma dependência para as AIVD, segundo a Escala de Lawton (Tabela 41).

Tabela 41 - Número e porcentagem das famílias entrevistadas, segundo a presença de dependência para as atividades instrumentais da vida diária entre algum membro da família, na região da Cidade Ademar. São Paulo, 2011.

\begin{tabular}{ccc}
\hline Dependência para AIVD & N & $\mathbf{\%}$ \\
\hline Não existe pessoa com dependência & 219 & 88,3 \\
Pelo menos 1 pessoa apresenta dependência & 29 & 11,7 \\
\hline Total & 248 & 100,0 \\
\hline
\end{tabular}

\subsubsection{Descrição do IVF-ID}

Apresenta-se a seguir a descrição do IVF-ID quando aplicado na região da Cidade Ademar. Observa-se o baixo número de famílias com idosos com mais de 80 anos e com pessoas com incapacidades para se movimentar e que não realizavam as ABVD sem ajuda (inferior a 10 famílias). Destaca-se também o elevado número de famílias com crianças, adolescentes ou jovens (58,5\%) (Tabela 42). 
Tabela 42 - Número e porcentagem da frequência de respostas das questões que compõe o IVF-ID, na região da Cidade Ademar. São Paulo, 2011.

\section{Dimensão: CONDIÇÕES DE SAÚDE}

Componente: Envelhecimento, incapacidades e dependência

Neste domicílio há:

1. Algum idoso (60 anos ou mais)?

2. Algum idoso com 80 anos ou mais?

3. Apenas moradores idosos (60 anos ou mais)?

4. Alguma pessoa que faz uso contínuo de 5 ou mais medicamentos diferentes ao mesmo tempo? (polifarmácia)

5. Algum idoso sofreu queda nos últimos 12 meses?

6. Alguma pessoa que não consegue ir de transporte coletivo público ao serviço de saúde?

7. Alguma pessoa com incapacidade auditiva? (considerar pessoa incapaz, com grande dificuldade permanente ou alguma dificuldade permanente de ouvir mesmo com uso de aparelho auditivo)

8. Alguma pessoa com incapacidade para se movimentar? (considerar pessoa incapaz, com grande dificuldade permanente ou alguma dificuldade permanente de caminhar mesmo com uso de prótese, bengala ou aparelho auxiliar)

9. Alguma pessoa que, sem ajuda, não realiza qualquer das seguintes atividades: alimentação, higiene pessoal, vestir-se, controle de eliminação intestinal e vesical, deambulação e transferências? (Atividades Básicas da Vida Diária - ABVD)? 10. Alguma pessoa que, sem ajuda, não consegue realizar nenhuma das seguintes atividades: limpar a casa, cuidar da roupa, da comida, usar equipamentos domésticos, fazer compras, usar transporte pessoal ou público, controlar a própria medicação e finanças? (Atividades Instrumentais da Vida Diária - AIVD)

\section{Componente: Doenças crônicas}

Neste domicílio há:

11. Alguma pessoa com pelo menos uma doença crônica?

12. Alguma pessoa com pelo menos duas doenças crônicas?

13. Alguma pessoa com doença crônica que tem dificuldades em seguir o tratamento medicamentoso, por motivos pessoais ou por dificuldade de acesso aos medicamentos?

14. Alguma pessoa com doença crônica que tem dificuldades em seguir o tratamento não-medicamentoso, como fazer atividade física, seguir uma dieta recomendada, parar de fumar?

15. Alguma pessoa que faz uso de medicamento contínuo?

16. Alguma pessoa que considera sua saúde ruim ou muito ruim?

17. Alguma pessoa que não conseguiu agendar consultas, exames ou tratamentos nos últimos 12 meses?

Dimensão: CONDIÇÕES SOCIAIS

Componente: Condições sociais favoráveis

Neste domicílio há:

\begin{tabular}{|c|c|c|c|}
\hline \multicolumn{2}{|c|}{ NÃO } & \multicolumn{2}{|c|}{ SIM } \\
\hline $\mathrm{N}$ & $\%$ & $\mathrm{~N}$ & $\%$ \\
\hline 172 & 69,4 & 76 & 30,6 \\
\hline 239 & 96,4 & 9 & 3,6 \\
\hline 233 & 94,0 & 15 & 6,0 \\
\hline 218 & 87,9 & 30 & 12,1 \\
\hline 229 & 92,3 & 19 & 7,7 \\
\hline 235 & 94,8 & 13 & 5,2 \\
\hline 232 & 93,5 & 16 & 6,5 \\
\hline 241 & 97,2 & 7 & 2,8 \\
\hline 243 & 98,0 & 5 & 2,0 \\
\hline 236 & 95,2 & 12 & 4,8 \\
\hline & & & \\
\hline & & & \\
\hline & & & \\
\hline
\end{tabular}

\begin{tabular}{c|c|c|c|c}
\multirow{2}{*}{} & \multicolumn{2}{|c|}{ NÃO } & \multicolumn{2}{c}{ SIM } \\
\cline { 2 - 5 } & $\mathrm{N}$ & $\%$ & $\mathrm{~N}$ & $\%$ \\
\hline & 72 & 29,0 & 176 & 71,0 \\
\hline & 171 & 69,0 & 77 & 31,0 \\
\hline & 214 & 86,3 & 34 & 13,7 \\
& & & & \\
\hline & 197 & 79,4 & 51 & 20,6 \\
& 87 & 35,1 & 161 & 64,9 \\
\hline & 192 & 77,4 & 56 & 22,6 \\
\hline & 193 & 77,8 & 55 & 22,2 \\
\hline
\end{tabular}

\begin{tabular}{|l|l|l|l|}
\multicolumn{2}{c|}{ NÃO } & \multicolumn{2}{c}{ SIM } \\
\hline $\mathrm{N}$ & $\%$ & $\mathrm{~N}$ & $\%$ \\
\hline
\end{tabular}




\begin{tabular}{l|c|c|c|c}
\hline 18. Pelo menos um adulto com ensino fundamental completo? & 44 & 17,7 & 204 & 82,3 \\
\hline $\begin{array}{l}\text { 19. Alguma pessoa com ensino médio completo? } \\
\text { 20. Alguma pessoa com educação superior? }\end{array}$ & 96 & 38,7 & 152 & 61,3 \\
\hline 21. O chefe da família com ensino fundamental completo? & 122 & 86,3 & 34 & 13,7 \\
\hline 22. O chefe da família com o ensino médio completo? & 171 & 69,0 & 126 & 50,8 \\
\hline 23. O chefe da família com ensino superior? & 236 & 95,2 & 12 & 41,0 \\
\hline $\begin{array}{l}\text { 24. Alguma pessoa trabalha há mais de seis meses no emprego } \\
\text { atual? }\end{array}$ & 61 & 24,6 & 187 & 75,4 \\
\hline $\begin{array}{l}\text { 25. Alguma pessoa trabalhando com rendimento superior a } 1 \\
\text { salário mínimo? (R } \$ 545,00)\end{array}$ & 34 & 13,7 & 214 & 86,3 \\
\hline $\begin{array}{l}\text { 26. Alguma pessoa trabalhando com rendimento superior a } 2 \\
\text { salários mínimos? (R } \$ 1.090,00)\end{array}$ & 127 & 51,2 & 121 & 48,8 \\
\hline 27. Telefone celular? & 12 & 4,8 & 236 & 95,2 \\
\hline 28. Microcomputador? & 102 & 41,1 & 146 & 58,9 \\
\hline 29. Microcomputador com acesso a internet? & 122 & 49,2 & 126 & 50,8 \\
\hline 30. Motocicleta ou automóvel para uso particular? & 128 & 51,6 & 120 & 48,4 \\
\hline
\end{tabular}

Componente: Condições sociais desfavoráveis

Neste domicílio há:

31. Alguma mulher que teve filho nascido vivo nos últimos 24 meses?

32. Alguma criança até 10 anos?

33. Alguma criança ou adolescente até 14 anos?

34. Alguma criança, adolescente ou jovem até 17 anos?

35. O número total de moradores dividido pelo número de dormitórios é maior que dois?

36. Algum adulto analfabeto ou que só lê e escreve o próprio nome?

37. Algum adulto com dificuldade para ler e escrever (analfabeto funcional)?

38. É analfabeto ou só lê e escreve o próprio nome?

39. Tem dificuldade para ler e escrever (analfabeto funcional)?

40. A renda familiar é de $1 / 4$ até $1 / 2$ salário mínimo por pessoa*?

*Salário Mínimo em 2011= R\$ 545,00; $1 / 2=\mathbf{R} \$ 272,50,1 / 4=R \$$

136,25 - Instituto de Pesquisa Econômicas Aplicadas - IPEA

\begin{tabular}{c|c|c|c}
\multicolumn{2}{c|}{ NÃO } & \multicolumn{2}{c}{ SIM } \\
$\mathrm{N}$ & $\%$ & $\mathrm{~N}$ & $\%$ \\
\hline 219 & 88,3 & 29 & 11,7 \\
& & & \\
141 & 56,9 & 107 & 43,1 \\
114 & 46,0 & 134 & 54,0 \\
103 & 41,5 & 145 & 58,5 \\
171 & 69,0 & 77 & 31,0 \\
& & & \\
\hline 06 & 83,1 & 42 & 16,9 \\
& & & \\
187 & 75,4 & 61 & 24,6 \\
& & & \\
\hline 220 & 88,7 & 28 & 11,3 \\
213 & 85,9 & 35 & 14,1 \\
205 & 82,7 & 43 & 17,3 \\
& & & \\
\hline
\end{tabular}

A Tabela 43 indica que o IVF-ID apresenta boa consistência interna, tanto na Dimensão CSA quanto no IVF-ID Total (0,73 e 0,78, respectivamente). Observa-se que a média da pontuação na Dimensão CSA é menor que o ponto de corte $(\geq 5$ pontos) para famílias vulneráveis, já a média de pontuação do IVF-ID Total apresenta-se acima do ponto de corte ( $\geq 11$ pontos) para famílias vulneráveis. 
Tabela 43 - Estatística descritiva do IVF-ID. São Paulo, 2011.

\begin{tabular}{ccccc}
\hline IVF-ID & Alpha de cronbach & Média (dp) & Mediana & Mín-máx \\
\hline Dimensão CSA & 0,73 & $3,27(2,52)$ & 3,00 & $0-11$ \\
IVF-ID Total & 0,78 & $12,02(5,03)$ & 12,00 & $1-25$ \\
\hline
\end{tabular}

\subsubsection{Validação dos indicadores em relação à dependência por meio da validade discriminante}

A Dimensão CSA foi capaz de discriminar famílias com e sem pessoas com dependência, segundo o Índice Katz, cuja média foi superior nas famílias em que havia pessoas com dependência $(p<0,05)$. Já o IVF-ID Total não apresentou capacidade discriminante. Porém, é importante lembrar o baixo número de pessoas com dependência para as ABVD na amostra, podendo interferir no poder do resultado (Tabela 44).

Tabela 44 - Estatística descritiva dos componentes do IVF-ID, segundo a presença de dependência para as atividades básicas da vida diária do Índice de Katz. São Paulo, 2011.

\begin{tabular}{lccccc}
\hline \multirow{2}{*}{ IVF-ID } & \multicolumn{5}{c}{ Presença de dependência (KATZ) } \\
\cline { 2 - 6 } & \multicolumn{2}{c}{$\begin{array}{c}\text { Não existe pessoa com } \\
\text { dependência na família }\end{array}$} & $\begin{array}{c}\text { Há pelo menos uma pessoa com } \\
\text { dependência para AVD }\end{array}$ \\
\cline { 2 - 6 } & Média & dp & Média & Dp & p\# \\
\hline Dimensão CSA & 3,19 & 2,45 & 7,20 & 2,95 & $0,006^{*}$ \\
IVF-ID Total & 11,96 & 5,04 & 15,20 & 3,83 & 0,177 \\
\hline $\begin{array}{l}\text { \# Teste de Mann-Whitney } \\
\text { * diferença estatisticamente significativa }(p<0,05)\end{array}$ & & & \\
\end{tabular}

Para a Escala de Lawton, a Dimensão CSA e o IVF-ID Total foram capazes de discriminar as famílias com e sem pessoas com dependência $(p<0,001)$ (Tabela 45). 
Tabela 45 - Estatística descritiva dos componentes do IVF-ID, segundo a presença de dependência para as atividades instrumentais da vida diária da Escala de Lawton. São Paulo, 2011.

\begin{tabular}{lccccc}
\hline \multirow{2}{*}{ IVF-ID } & \multicolumn{3}{c}{ Presença de dependência (LAWTON) } & p\# \\
\cline { 2 - 5 } & \multicolumn{2}{c}{$\begin{array}{l}\text { Não existe pessoa com } \\
\text { dependência na família }\end{array}$} & $\begin{array}{c}\text { Há pelo menos uma pessoa com } \\
\text { dependência para AIVD }\end{array}$ & \\
\cline { 2 - 5 } & Média & $\mathbf{d p}$ & Média & Dp & \\
\hline Dimensão CSA & 2,82 & 2,16 & 6,72 & 2,42 & $<0,001^{*}$ \\
IVF-ID Total & 11,42 & 4,83 & 16,59 & 4,17 & $<0,001^{*}$ \\
\hline $\begin{array}{l}\text { \# Teste de Mann-Whitney } \\
\text { * diferença estatisticamente significativa }(p<0,05)\end{array}$ & & &
\end{tabular}

\subsubsection{Validação dos indicadores em relação à dependência por meio da validade concorrente}

Em relação ao Índice de Katz, observa-se na Tabela 46 que a Dimensão CSA apresenta correlação estatisticamente significativa $(r=0,18 ; p=0,005)$, indicando que quanto maior sua pontuação média (maior vulnerabilidade), maior a pontuação média do Katz (maior dependência). É importante destacar o baixo número de pessoas dependentes para ABVD na amostra, na avaliação desse dado.

Já para a Escala de Lawton, observa-se correlação negativa estatisticamente significativa entre a Dimensão CSA e o IVF-ID Total, indicando que quanto maior sua pontuação média (maior vulnerabilidade), menor a pontuação média no Lawton (maior dependência).

Tabela 46 - Coeficientes de correlação de Spearman $\left(r_{\mathrm{sp}}\right)$ entre os componentes do IVF-ID e a média de pontuação familiar do Katz e Lawton. São Paulo, 2011.

\begin{tabular}{ccc}
\hline IVF-ID & Média de Pontuação Katz & Média de Pontuação Lawton \\
& $\mathbf{r}_{\mathrm{sp}}(\mathbf{p})$ & $\mathbf{r}_{\mathrm{sp}}(\mathbf{p})$ \\
\hline Dimensão CSA & $0,18^{\star \star}(0,005)$ & $-0,44^{* \star}(0,000)$ \\
IVF-ID Total & $0,09(0,174)$ & $-0,32^{\star *}(0,000)$ \\
\hline
\end{tabular}

* correlação estatisticamente significativa $(p<0,05)$ 
Diante do exposto, conclui-se que o Índice proposto para avaliar a vulnerabilidade de famílias a incapacidades e dependência mostrou-se confiável e válido ao ser aplicado em duas populações com vulnerabilidade social e perfis demográficos distintos.

\subsubsection{Classificação das famílias da região da Cidade Ademar, segundo o IVF- ID}

A Tabela 47 demonstra a distribuição das famílias quanto à vulnerabilidade relacionada ao IVF-ID total e a Dimensão CSA do IVF-ID.

Verifica-se que das 248 famílias entrevistadas, $144(58,1 \%)$ apresentaram-se vulneráveis para incapacidades e dependência segundo o IVF-ID total. Dessas, 64 $(25,8 \%)$ apresentaram vulnerabilidade na Dimensão CSA, podendo ser consideradas as famílias mais vulneráveis, pois o são tanto nas condições sociais quanto nas de saúde (CSO + CSA).

Havia 80 famílias $(32,3 \%)$ que não se mostraram vulneráveis quando avaliadas somente na Dimensão CSA, o que indica que são mais vulneráveis socialmente (CSO) que nos aspectos relacionados à saúde (CSA).

Quatorze famílias $(5,6 \%)$ restantes não foram consideradas vulneráveis no IVF-ID Total, mas se mostraram vulneráveis na Dimensão CSA, o que indica que não são vulneráveis socialmente (CSO). E, por fim, 90 famílias (36,3\%) não foram classificadas como vulneráveis nem pelo IVF-ID Total e nem pela Dimensão CSA, sendo, portanto, famílias não vulneráveis para incapacidades e dependência. 
Tabela 47 - Distribuição das famílias segundo a presença de vulnerabilidade, na Cidade Ademar. São Paulo, 2011.

\begin{tabular}{|c|c|c|c|}
\hline \multirow{2}{*}{$\begin{array}{c}\text { IVF-ID } \\
\text { Total } \\
\text { (CSA+CSO) }\end{array}$} & \multicolumn{3}{|c|}{ Dimensão CSA } \\
\hline & $\begin{array}{c}\text { Não vulnerável (0-4 } \\
\text { pontos) } \\
\mathrm{N}(\%)\end{array}$ & $\begin{array}{c}\text { Vulnerável (5 } \\
\text { pontos e +) } \\
N(\%)\end{array}$ & $\begin{array}{l}\text { Total } \\
\text { N (\%) }\end{array}$ \\
\hline $\begin{array}{l}\text { Não vulnerável (0-10 } \\
\text { pontos) }\end{array}$ & $90(36,3)$ & $14(5,6)$ & $\begin{array}{c}104 \\
(41,9)\end{array}$ \\
\hline $\begin{array}{l}\text { Vulnerável (11 pontos } \\
\text { e +) }\end{array}$ & $80(32,3)$ & $64(25,8)$ & $\begin{array}{c}144 \\
(58,1)\end{array}$ \\
\hline Total & $170(68,5)$ & $78(31,5)$ & $\begin{array}{c}248 \\
(100)\end{array}$ \\
\hline
\end{tabular}

\subsubsection{Comparação das duas populações em relação ao IVF-ID total e a Dimensão CSA}

Os escores do IVF-ID Total e da Dimensão CSA foram comparados entre as duas regiões, eleitas para o estudo por apresentarem perfis demográficos e epidemiológicos distintos.

A região da Lapa apresenta o Índice Paulista de Vulnerabilidade Social (IPVS) inferior à média do Município, enquanto na região da Cidade Ademar o IPVS é superior à média municipal.

Analisando a presença de alguém com dependência na família, segundo o Índice de Katz, verifica-se diferença significativa entre as duas regiões, sendo que a Lapa apresenta maior porcentagem de famílias com dependência na família que a 
Cidade Ademar $(9,3 \% \times 2,0 \% ; p<0,001)$. O mesmo acontece com relação à Escala de Lawton $(22,2 \% \times 11,7 \% ; p=0,002)$.

A aplicação do IVF-ID revelou que na vulnerabilidade relacionada à Dimensão CSA houve diferença significativa entre as duas regiões, sendo que na Lapa foi encontrado um número maior de famílias vulneráveis que na Cidade Ademar (47,6\% X 31,5\%; $p<0,001)$. Porém, quando foram avaliadas as condições sociais juntamente com as condições de saúde, não houve diferença significativa entre as duas regiões $(54,8 \% \times 58,1 \% ; p=0,469)$.

É importante lembrar que na região da Lapa, a despeito de melhores índices de vulnerabilidade social, existem bolsões de pobreza e comumente as famílias com melhores condições sociais não aceitam o cadastro e, portanto, não são atendidas pelas equipes de saúde da família.

Nas combinações de vulnerabilidades (Gráfico 1), a porcentagem de famílias não vulneráveis é igual nas duas regiões. Já na Dimensão CSA, nota-se uma porcentagem significativamente superior na região da Lapa, o inverso do que se observa quando é analisada apenas a vulnerabilidade no IVF-ID Total (condições de saúde e sociais), o que indica maior vulnerabilidade na região da Cidade Ademar.

Por fim, a região da Lapa apresenta maior porcentagem de famílias com vulnerabilidades tanto no IVF-ID Total quanto na Dimensão CSA, o que pode ser explicado pelo perfil demográfico da região (maior número de idosos) e por as famílias atendidas pelas equipes de saúde da família serem, predominantemente, menos favorecidas socialmente do que as demais famílias da região que não são atendidas pela ESF por recusa de cadastro. 


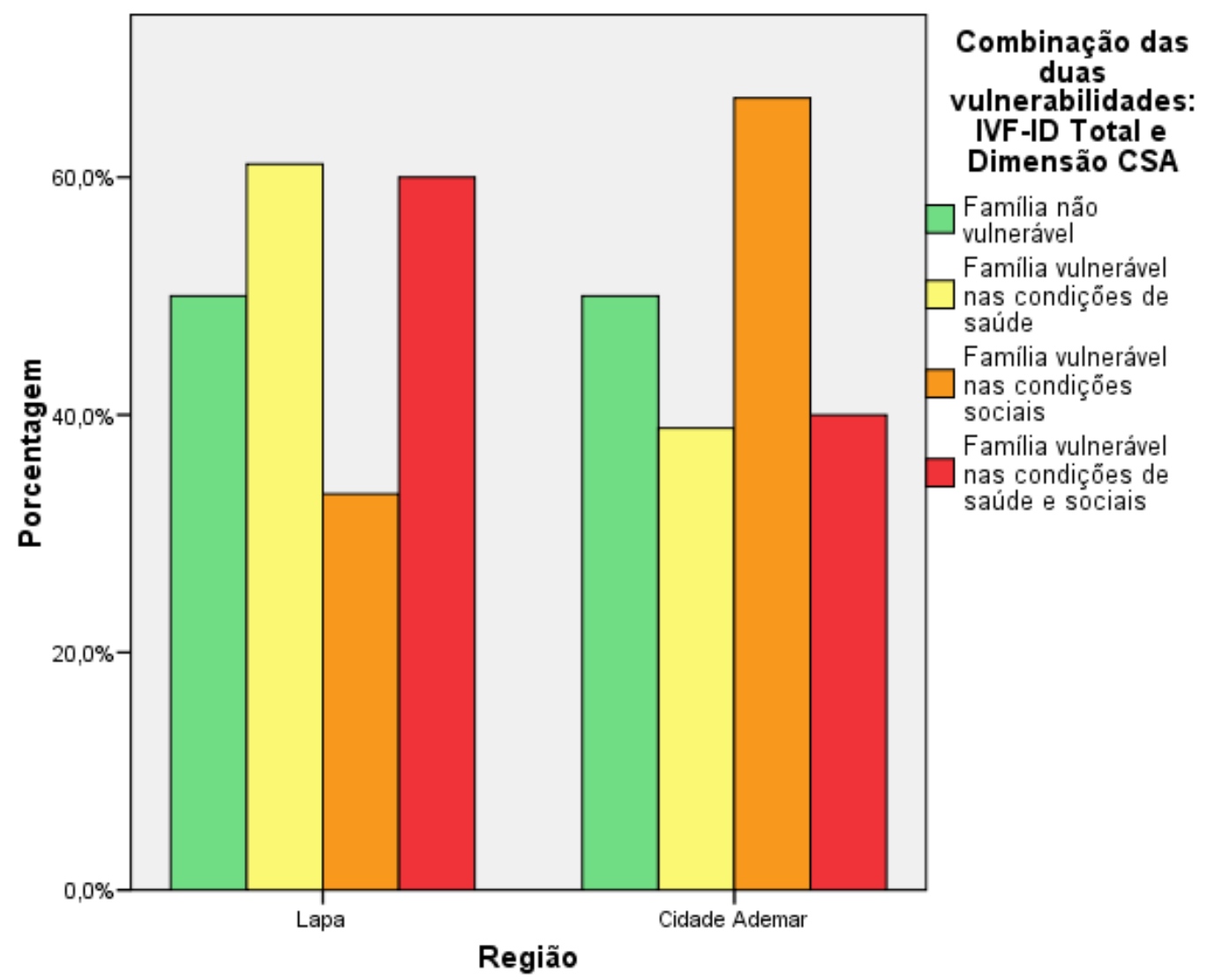

Gráfico 1 - Distribuição das combinações entre as duas vulnerabilidades entre as regiões da Lapa e Cidade Ademar. São Paulo, 2011. 


\section{DISCUSSÃO}

\subsection{Contribuição da etapa de validação aparente na construção do IVF-ID}

Após a consulta aos juízes, o instrumento original foi modificado em sua estrutura, ou seja, foram acrescidos um novo componente e 12 questões, além da exclusão de quatro questões. Essas mudanças ocorreram não somente nos itens que obtiveram menos de $80 \%$ de concordância entre os juízes, mas também em função de sugestões que, por sua relevância e coerência, foram acatadas pela autora e depois aceitas pelos demais juízes nas rodadas seguintes.

A sugestão dada pelos juízes para incluir outro componente relacionado à escolaridade do chefe da família mostrou-se relevante, já que as cinco questões referentes à escolaridade foram validadas no Índice final (IVF-ID).

A escolaridade do chefe da família representa capacidade de gerar e manter um rendimento regular ${ }^{32}$. Esse indicador tem sido bastante utilizado na construção de índices e em inquéritos sobre os aspectos sociais das famílias. O IPVS, por exemplo, elegeu a escolaridade do chefe da família como um de seus indicadores socioeconômicos, justificando que a baixa instrução de um indivíduo potencializa o risco de uma pior inserção no mercado de trabalho e acarreta maior probabilidade de situações de desemprego ${ }^{32}$.

Neste estudo, $14,9 \%$ das famílias da Lapa informaram que o chefe era analfabeto ou analfabeto funcional. Dados de 2009, da Coordenadoria Regional de Saúde Centro-oeste indicavam que $8,5 \%$ dos chefes de família tinham menos de três anos de estudo ${ }^{40,42}$. Essa diferença pode ser atribuída ao perfil socioeconômico 
das famílias atendidas pela ESF, possivelmente inferior à média das famílias da região.

$\mathrm{Na}$ Cidade Ademar a porcentagem de chefes de família analfabetos ou analfabetos funcionais foi de $14,1 \%$. Dados da Coordenadoria regional de Saúde Sul indicavam que $23,4 \%$ dos chefes de família tinham menos de três anos de estudo. Em ambos os casos, as porcentagens são elevadas.

Após a avaliação dos juízes, cinco questões foram incluídas no componente “Acesso a bens duráveis”, em consonância com o Censo 2010. De fato, os itens que representavam os bens duráveis mais contemporâneos como "telefone celular", "microcomputador", "microcomputador com acesso a internet" e "motocicleta ou automóvel de uso particular" foram os que entraram no componente Condições Sociais Favoráveis, composto por indicadores de boas condições de vida.

Nos últimos anos, o Brasil tem passado por um crescimento econômico considerável, com aumento da classe média. A Pesquisa Nacional por Amostra de Domicílios (PNAD) de $2009^{52}$ mostrou que o acesso das famílias brasileiras a bens duráveis cresceu de 2008 a 2009. Em um universo estimado em 58,5 milhões de domicílios, o número de residências que possuem carro aumentou de $36,4 \%$ para $37,4 \%$ no período. A posse de motocicletas cresceu de forma ainda mais intensa, de $14,7 \%$ para $16,2 \%$.

Dados da PNAD de $2008{ }^{53}$ indicavam que $31,2 \%$ dos domicílios brasileiros possuíam microcomputador, contra $26,5 \%$ em 2007 . Desses, $23,8 \%$ tinham acesso à internet, contra $20 \%$ em 2007. Mais da metade dos domicílios com computador estavam localizados no Sudeste em 2008 e 78,2\% tinha acesso à internet. 
Também em 2008, mais 4,4 milhões de domicílios brasileiros passaram a ter algum tipo de telefone. De 2007 para 2008, o número de domicílios com algum tipo de telefone subiu 5,3 pontos percentuais, alcançando $82,1 \%$. Já os domicílios somente com celular chegaram a $37,6 \%$, um aumento de 5,9 pontos percentuais ${ }^{53}$.

Ainda com base no suplemento do PNAD 2008, verificou-se que, em três anos, o percentual de brasileiros com dez anos ou mais de idade que acessaram ao menos uma vez a internet pelo computador aumentou $75,3 \%$, passando de $20,9 \%$ para $34,8 \%$. No mesmo período, a proporção dos que tinham telefone celular para uso pessoal passou de $36,6 \%$ para $53,8 \%$ na população com dez anos ou mais de idade, sendo que, para $44,7 \%$ dessas pessoas, o celular era o único telefone para uso pessoal ${ }^{53}$.

Após a avaliação dos juízes, também foram acrescentadas quatro questões no componente "Rede Social" e três no componente "Apoio Social". Destaca-se que esses dois componentes apresentaram menos de $80 \%$ de concordância entre os juízes na $1^{\text {a }}$ rodada. Com relação às questões acrescidas no componente "Rede Social", todas se referiam à frequência de contato com os familiares e amigos. Ou seja, na periodicidade dos contatos, além de uma vez por semana, os juízes sugeriram acrescentar uma vez ao mês e uma vez ao ano. De fato, os indicadores de frequência de contato tem sido um dos mais utilizados nos instrumentos específicos para avaliação da rede social ${ }^{54,55,56,57}$.

A justificativa dos juízes para o acréscimo de três questões no componente "Apoio Social" foi a existência de vários tipos de apoio. Com isso, foram inseridas questões relacionadas ao apoio de reforço ou emocional, instrumental ou material e afetivo ou interação positiva. Apesar das questões sobre rede e apoio social 
formarem dois componentes (4 e 6) na análise fatorial, os mesmos não foram validados para incapacidades e dependência, de tal forma que o componente “Relações Sociais” não entrou no IVF-ID.

Segundo Sluzki ${ }^{55}$ a rede e o apoio social pode atuar de diferentes formas em situações de incapacidades e dependência, a depender das circunstância geradoras da incapacidade, da doença envolvida e da natureza das relações pré existentes. Em suas palavras:

“(..) existe forte evidência de que uma rede social pessoal estável, sensível, ativa e confiável protege a pessoa contra doenças, atua como agente de ajuda e encaminhamento, afeta a pertinência e a rapidez da utilização de serviços de saúde, acelera os processos de cura, e aumenta a sobrevida, ou seja, é geradora de saúde. E também existe evidência de que a presença de doença numa pessoa - especialmente uma doença de curso prolongado como o câncer, a esquizofrenia, o mal de Alzheimer, as doenças neurológicas etc - deteriora a qualidade de sua interação social e, em longo prazo, reduz o tamanho (o número de habitantes) e a possibilidade de acesso a sua rede social.(...)".

No componente "Capacidade Funcional", quatro questões foram excluídas, a partir da sugestão de um juiz, aceita pelos demais. As questões excluídas referiamse ao grau de dificuldade para realizar sem ajuda qualquer atividade básica ou instrumental. Foi mantida apenas a questão que avalia a existência de algum membro da família incapaz de realizar sem ajuda qualquer atividade básica ou instrumental. Essa questão foi validada no IVF-ID e integrou o componente “Envelhecimento, incapacidades e dependência”, na dimensão “Condições de Saúde". 
Em relação ao conteúdo do instrumento, na $1^{\text {a }}$ rodada, houve discordância de alguns juízes sobre a questão relativa à autoavaliação de saúde, por considerarem que poderia ser influenciada por condições de saúde como, por exemplo, a presença de sintomas depressivos. Ponderaram ainda sobre a veracidade da resposta, em decorrência da subjetividade envolvida. Porém, há estudos ${ }^{8,16,58}$ mostrando que a autoavalição positiva da saúde está associada a boas condições de saúde e menor dependência. Giacomin, Peixoto, Uchoa et al $^{16}$, por exemplo, estudaram condições associadas à incapacidade funcional entre idosos, tendo verificado que a idade e a autoavaliação negativa da saúde apresentaram associações significativas e independentes com incapacidades leve e grave.

$\mathrm{Na}$ segunda rodada obteve-se consenso quanto à permanência dessa questão que integrou o IVF-ID, na dimensão "Condições de Saúde", no componente "Doenças Crônicas".

Em relação ao componente "Acesso aos serviços de saúde", a questão que pretendia abordar a existência de serviços de saúde próximos à residência ("Alguém que precisa de transporte para ir ao Serviço de Saúde?") gerou discordância entre os juízes e só foi acatada após um juiz ter sugerido um novo enfoque, visando avaliar uma possível incapacidade de mobilidade ("Alguém que não consegue ir de transporte coletivo público ao Serviço de Saúde?").

Após os testes de validação, essa questão permaneceu no IVF-ID, na dimensão "Condições de Saúde", no componente "Envelhecimento, incapacidades e dependência". 
Segundo Starfield ${ }^{59}$, a acessibilidade é um elemento importante do acesso aos serviços de saúde:

"A acessibilidade possibilita que as pessoas cheguem aos serviços. Ou seja, este é um aspecto da estrutura de um sistema ou unidade de saúde e este aspecto é necessário para se atingir a atenção ao primeiro contato. Acesso é a forma como a pessoa experimenta esta característica de seu serviço de saúde. A acessibilidade não é uma característica apenas da atenção primária, uma vez que todos os níveis de serviços devem estar acessíveis. Entretanto, os requisitos específicos para a acessibilidade diferem na atenção primária porque este é o ponto de entrada no sistema de serviços de saúde (...). O acesso à atenção é importante na redução de mortalidade e morbidade".

Fernandes ${ }^{60}$ verificou as principais dificuldades de acesso referidas por idosos atendidos em uma Unidade Básica de Saúde da ESF e as principais causas mencionadas foram: má qualidade dos serviços (13,3\%), barreiras arquitetônicas $(13,3 \%)$, falta de transporte $(10,9 \%)$, distância longa a ser percorrida até os serviços $(10,2 \%)$, falta de recursos financeiros $(9,4 \%)$, dificuldades de locomoção $(7 \%)$ e falta de companhia $(3,9 \%)$.

Em síntese, a consulta aos juízes por meio da técnica Delphi foi fundamental para a construção do Índice, visto que todas as questões incluídas ou modificadas foram validados como indicadores no IVF-ID. 


\subsection{Perfil das famílias}

Verificou-se predomínio de mulheres entre os membros das famílias entrevistadas tanto na região da Lapa $(54,6 \%)$ quanto da Cidade Ademar $(52,1 \%)$. Na Lapa, nos distritos de Jaguara e Vila Leopoldina, onde se localizam as Unidades Básicas de Saúde com ESF participantes do estudo, têm uma população total de 64.380 habitantes, sendo 31.295 do sexo masculino $(48,61 \%)$ e $33.085(51,39 \%)$, do sexo feminino. Na Cidade Ademar, nos distritos de Cidade Ademar e Pedreira, a população é de 410.998 , sendo 196.149 homens $(47,7 \%)$ e 214.849 mulheres $(52,3 \%)$.

Parahyba, Veras e Melzer ${ }^{61}$ analisaram as estimativas das taxas de incapacidade funcional na PNAD de 1998 e verificaram que a prevalência de incapacidade funcional foi maior entre as mulheres e aumentou com a idade. Ao comparar os resultados encontrados referentes às taxas de prevalência de incapacidade funcional entre as mulheres de 65 a 79 anos com outro estudo realizado na Inglaterra, encontraram prevalência semelhante de dificuldades para realizar atividades da vida diária, sendo $12 \%$ na Inglaterra e $16 \%$ no Brasil ${ }^{61}$.

Em relação à distribuição etária, na Lapa, predominaram adultos de 18 a 59 anos $(54,0 \%)$ e foram observadas porcentagens semelhantes de crianças, adolescentes e jovens até 17 anos $(23,2 \%)$ e de idosos acima de 60 anos (22,8\%).

Destaca-se que o número de idosos na amostra segue a tendência da região Centro-oeste, em que a proporção de idosos é a mais alta do Município (16,5\%). índice de envelhecimento também é alto $(110,1 \%)$, apresentando valor superior a $15 \%$ do índice geral da cidade de São Paulo ${ }^{42}$. 
Já na Cidade Ademar, houve uma diferença importante na porcentagem de crianças, adolescentes e jovens $(29,9 \%)$ e idosos $(11,2 \%)$, tendência que é observada na região Sul como um todo, que tem a proporção de idosos mais baixa do Município $(8,6 \%)$ e índice de envelhecimento de $36,3 \%, 15 \%$ inferior ao índice municipal.

A média de idade encontrada na Lapa foi de 39,1 anos, com mediana de 37,0 anos e a idade máxima encontrada foi de 93 anos. Na Cidade Ademar a média de idade foi de 31,6 anos com mediana de 28, e a idade máxima, de 89 anos.

A pirâmide populacional do Município em 2010, formada por cortes quinquenais, revela predominância da faixa etária de 30 a 35 anos entre as mulheres, faixa essa que também se destaca como a segunda mais frequente entre os homens ${ }^{42}$.

Os dados demográficos aqui apresentados evidenciam a tendência de uma população mais idosa na Lapa do que no restante do Município. Na Lapa, o número médio de residentes nos domicílios visitados foi de 3,2 pessoas, igual ao da região metropolitana de São Paulo (3,2 pessoas) e do Brasil (3,3 pessoas) em $2009{ }^{62}$. $\mathrm{Na}$ Cidade Ademar, esse número foi mais elevado, de 3,8 pessoas.

Na Lapa, 9,7\% das pessoas vivam sós, enquanto, na Cidade Ademar, essa porcentagem foi de $4,8 \%$.

Segundo dados preliminares do Censo de 2010, 6.980.378 pessoas moram sozinhas, o que equivale a $12,2 \%$ dos domicílios particulares permanentes do País $^{63}$. No censo anterior, realizado em 2000, o número de domicílios com apenas um morador era de 4.085 .568 , ou $9,1 \%$ do total. Alguns motivos que poderiam 
explicar esse aumento são o envelhecimento populacional e o aumento das separações conjugais.

Dentre as 248 famílias entrevistadas na Lapa, em 9,3\% havia pelo menos uma pessoa com dependência, parcial ou total, para as atividades básicas da vida diária e 22,2\% para as atividades instrumentais. Essas são porcentagens significativas e relevantes para a atenção à saúde oferecida pelas equipes de Atenção Básica e na gestão do cuidado. Na Cidade Ademar, apenas 2,0\% das famílias possuía entre seus membros pessoas com dependência para as atividades básicas e 11,7\% para as atividades instrumentais.

O presente estudo não avaliou a presença de deficiências (exceto a deficiência física) e sim a existência de incapacidades delas decorrentes. Sabe-se que nem todas as pessoas com deficiência apresentam incapacidades, embora quanto maior o grau de incapacidade, maior a probabilidade de dependência.

$\mathrm{Na}$ Lapa, foi encontrada prevalência de 10,9\% de incapacidade auditiva, 8,9\% de incapacidade visual e $6,0 \%$ incapacidade para se movimentar. Com relação à deficiência física, a prevalência foi de 2,4\%.

Na Cidade Ademar encontrou-se 6,5\% de incapacidade auditiva, 6,9\% de incapacidade visual, $2,8 \%$ de incapacidade para se movimentar e frequência de deficiência física foi de $1,6 \%$.

Inquérito de saúde realizado entre setembro de 2008 e fevereiro de 2009 no município de São Paulo encontrou prevalência de $12,1 \%$ de deficiências autoreferidas, sendo $7,3 \%$ visuais, $4,6 \%$ auditivas e 1,4\% físicas. Na população idosa, a 
prevalência foi maior: $21,0 \%$ de deficiência auditiva entre os homens e $18,2 \%$ de deficiência visual nas mulheres ${ }^{63}$.

Estudo realizado por Magarolas, Clot-Razquin, Fernandéz et al ${ }^{12}$ com a população espanhola estimou o perfil de dependência a partir do nível de gravidade das diferentes incapacidades. As incapacidades sensoriais predominaram nos grupos com menor dependência e as incapacidades de mobilidade e para as ABVD, no grupo com maior dependência.

No Brasil, no Censo de 2010, 6,7\% da população declarou pelo menos uma deficiência severa, que implica grande dificuldade ou impossibilidade de executar a função referente à deficiência. Houve predomínio da deficiência visual severa $(3,5 \%)$, seguida pelas deficiências motora $(2,3 \%)$ e auditiva severas $(1,1 \%)^{64}$.

O Censo de $2000{ }^{63}$ avaliou a taxa de prevalência de incapacidade funcional em mobilidade física em idosos com base em um proxy - a informação sobre a "dificuldade para caminhar e subir escadas". O município de São Paulo foi a capital brasileira que apresentou os menores índices: $20,1 \%$ entre as mulheres e $15,8 \%$ entre os homens. A taxa aumentava com a idade, passando de $12,3 \%$ entre os idosos de 60 a 69 anos para $21,5 \%$ no grupo de 70 a 79 anos, até alcançar $38,4 \%$ nos idosos com 80 anos e mais. 


\subsection{A construção do IVF-ID}

O instrumento aplicado na região da Lapa era composto por oito dimensões, 38 componentes e 103 questões. Após a análise fatorial exploratória, permaneceram 53 questões. Todas as dimensões do instrumento foram representados por essas 53 questões, exceto a dimensão "Desenvolvimento Infantil", que não foi representado por nenhuma questão. Ficaram fora da análise fatorial 16 componentes: condições econômicas, qualidade do posto de trabalho, internações, transtornos mentais, trabalho precoce, acesso à escola, progresso escolar, mortalidade infantil, ausência de mãe, extrema pobreza, incapacidade de geração de renda, abrigabilidade, acesso a abastecimento de água, saneamento, coleta de lixo e energia elétrica.

Dentre todos os componentes dos domínios "Condições de saúde" e “Relações Sociais", acrescentados ao IDF no processo de validação aparente, os únicos a não entrar na análise fatorial foram "internações" e "transtornos mentais".

Estudos têm mostrado que as internações estão relacionadas a dependência $^{18}$ e mortalidade ${ }^{65}$ em idosos. Apesar de ter sido encontrada prevalência de $26,2 \%$ de transtornos psiquiátricos e $11,7 \%$ de uso abusivo de álcool e drogas, essas variáveis não se correlacionaram em nenhum componente da análise fatorial, assim como condições menos frequentes, como as demências $(2,4 \%)$ e as deficiências intelectuais $(1,6 \%)$.

Uma explicação pode estar no fato de que o instrumento não é específico para idosos ou para determinados diagnósticos e sim para a avaliação de famílias. 
Portanto, aspectos muito importantes em estudos com idosos podem não se aplicar a esse instrumento.

O resultado da análise fatorial exploratória foi o agrupamento de 53 questões em sete fatores. Ao analisar as questões que permaneceram em cada fator foi possível identificar os indicadores de cada um. Com isso alguns componentes puderam ser agrupados.

O fator 1 mostrou-se um bom indicador de boas condições de vida, visto que agrupou as questões referentes à presença de alguém na casa com ensino fundamental, médio e superior completo, chefe da família com ensino fundamental, médio e superior completo, alguém trabalhando há mais de seis meses, alguém com rendimento superior a 1 e superior a 2 salários mínimos, acesso a telefone celular, computador, computador com internet, propriedade de moto ou carro para uso particular. Foram eliminadas duas questões sobre a existência de moradores idosos no domicílio, que já estavam contempladas em outro fator. Ao final, permaneceram 13 questões.

Alguns estudos têm indicado correlação entre baixa escolaridade e renda com maior grau de incapacidade ${ }^{61,66,67}$, porém há outros que não encontraram tal associação ${ }^{16,68}$. Escolaridade e renda não devem ser vistas apenas sob a ótica de fatores de risco para incapacidades e dependência, mas sim como uma condição familiar que, quando desfavorável, pode limitar as possibilidades de assistência adequada, expondo a família a situações de vulnerabilidade.

O fator 2 reuniu questões sobre a existência de idosos com 60 anos e mais, com 80 anos e mais, domicílios apenas com moradores idosos, uso de polifarmácia, 
idosos que haviam sofrido queda no último ano, impossibilidade de usar transporte coletivo público para ir ao serviço de saúde, incapacidade auditiva e de movimentação e necessidade de ajuda para realizar qualquer das atividades básicas ou instrumentais da vida diária. Todas essas questões são relativas a condições de saúde, com foco no envelhecimento e na dependência. Esse fator também incluiu as questões sobre alguém trabalhando por mais de seis meses no emprego atual e alguém trabalhando com rendimento superior a um salário mínimo, ambas já contempladas no fator 1 e que, por essa razão, foram excluídas. Também foram retiradas as questões sobre domicílio próprio e em terreno próprio, a que se referia à existência de mais da metade das pessoas em idade ativa exercendo trabalho remunerado, que não mantinham conexão com a demais questões desse fator. Com isso, restaram 10 questões.

É consenso na literatura que a incapacidade funcional está diretamente relacionada ao aumento da idade. Não é por acaso que há um grande número de

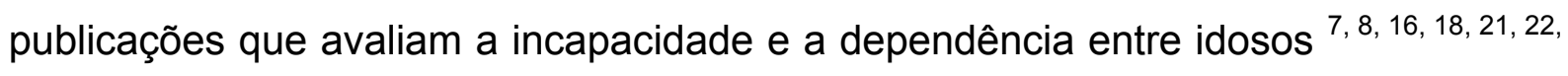
$69,70,71,72$ e poucos que as avaliam na população em geral ${ }^{12,24,73}$. Um exemplo é o estudo de Lozano e González ${ }^{10}$, que classificou a população espanhola em situação de dependência, tendo observado que, a partir dos 60 anos, há um perfil evolutivo do grau de dependência para as ABVD.

A polifarmácia e as quedas estão fortemente relacionadas ao envelhecimento, devido à alta prevalência em idosos. Há estudos sobre a correlação de incapacidades e dependência com a polifarmácia ${ }^{74}$ e as quedas em idosos ${ }^{75}$.

Ainda no fator 2, a questão sobre o acesso a serviços de saúde, está relacionada à incapacidade de se deslocar utilizando transporte coletivo público. 
A incapacidade para se deslocar usando algum meio de transporte foi a AIVD mais prevalente $(17,6 \%)$, também foi encontrada por Del Duca ${ }^{68}$ em seu estudo.

Magarolas, Clot-Razquin, Fernandéz et al ${ }^{12}$ traçaram o perfil da dependência em função do nível de gravidade de 5 tipos de incapacidade (sensorial, comunicação e cognitivas, mobilidade, ABVD e AIVD). Encontraram incapacidades mais graves em pessoas que sofriam limitações nas ABVD e verificaram que os grupos com menor dependência geralmente são compostos por homens, com idade mediana e incapacidades sensoriais. Já entre o grupo com maior dependência predominaram mulheres com mais de 80 anos e incapacidades relacionadas à mobilidade e às ABVD e AIVD. Portanto, novamente se verifica a relação entre envelhecimento, incapacidades para as ABVD e AIVD e dependência.

Dentre as incapacidades sensoriais, a deficiência auditiva mostrou-se a mais prevalente entre as mulheres idosas no inquérito de saúde realizado em São Paulo ${ }^{65}$ e também se correlacionou nesse componente.

O fator 3 diz respeito à presença de crianças, adolescentes e jovens além das condições de moradia, representadas pelo número de pessoas dividido pelo número de cômodos da residência. Também havia duas questões ("renda familiar na linha da pobreza" e "existência de idosos") que foram excluídas por já estarem presentes em outros fatores em que se correlacionavam melhor com as demais questões. Assim, o número de questões foi reduzido a cinco.

A existência de crianças ou jovens no domicílio está presente no IDF, pois os seus autores entendem que as famílias incorrem em despesas adicionais com a presença desses grupos que apresentam necessidades específicas de educação e 
cuidados de saúde frequentes ${ }^{27}$. Em função ciclo vital familiar, famílias com crianças e jovens em geral apresentam menor número de idosos. Considerando que a idade é a principal variável correlacionada a incapacidades e dependência, pode-se dizer que as famílias com crianças e jovens seriam menos vulneráveis sob esse ponto de vista. Porém, analisando sob o aspecto social dos recursos da família para oferecer suporte às pessoas com incapacidade e dependência, essas famílias seriam mais vulneráveis.

O fator 4, que reúne as questões sobre apoio social, foi o único que se manteve integralmente tal como aplicado na região da Lapa.

O fator 5 apresenta indicadores de analfabetismo e pobreza. Dentre as cinco questões que o compõem, quatro relacionam-se à presença de analfabetismo na família e do chefe da família e uma verifica se a renda familiar está situada na linha da pobreza. Da mesma forma que o fator 3 , nem sempre esses indicadores correlacionam-se a incapacidades e dependência ${ }^{16,68}$, porém indicam condições que compõem um cenário desfavorável às famílias no cuidado às pessoas nessas condições.

No fator 6 agrupa seis questões referentes à frequência de visitas de familiares e amigos, indicadores da rede social da família. Esse indicador tem se correlacionado com a incapacidade funcional e dependência em alguns estudos com idosos. Rosa, Benício, Latorre et al ${ }^{18}$ encontraram associação entre não visitar amigos e dependência modera e grave. Giacomin, Peixoto, Uchoa et al 16 encontraram associação negativa entre o número de amigos encontrados nos últimos 30 dias e incapacidade grave. 
O fator 7 reúne questões referentes a ter alguém com doença crônica na família, com dificuldades em seguir o tratamento medicamentoso e nãomedicamentoso, tomar medicamentos de uso contínuo, considerar a própria saúde ruim ou muito ruim e o acesso a consultas, exames e tratamentos. Todas elas podem ser relacionadas às doenças crônicas.

Diversos estudos encontraram associação entre incapacidades e dependência $^{16,}$ 18, 66, 67 e doenças crônicas, entre elas, hipertensão arterial, obesidade, artrite, diabetes, acidente vascular cerebral e incontinência urinária, essas duas últimas com associação mais frequente ${ }^{16,66}$.

Alves, Leimann, Vasconcelos et al ${ }^{21}$ estudaram especificamente a influência das doenças crônicas na capacidade funcional de idosos do município de São Paulo e constataram forte influência. Verificaram que a hipertensão arterial aumenta em $39 \%$ a chance do idoso ser dependente nas AIVD, a doença cardíaca, em $82 \%$; a artropatia, em 59\% e a doença pulmonar, em 50\%. Para a dependência nas ABVD e AIVD, a chance mais que dobrou para cada uma dessas doenças.

Outra variável que também entrou no fator 7 foi a autoavaliação de saúde, que aliás tem demonstrado considerável destaque nos estudos com idosos. Diversos estudos com idosos indicam associação positiva entre autoavaliação negativa de saúde e a presença de incapacidades e dependência ${ }^{16,18,66,67}$. Ramos, Simões, Albert ${ }^{65}$ encontraram influência da autoavaliação negativa de saúde no risco de morte entre idosos. Ressaltaram, entretanto, a importância de considerar o estado cognitivo e o grau de depressão do entrevistado ao avaliar essa variável. 
Analisando os indicadores dos sete fatores, a saber, boas condições de vida, envelhecimento e dependência, presença de crianças e jovens e condições de moradia, apoio social, analfabetismo e pobreza, rede social e doenças crônicas, observam-se similaridades entre alguns deles, o que permitiu que fossem agrupados.

Os fatores 2 e 7 reúnem indicadores referentes à condições de saúde relacionadas a incapacidades e dependência: existência de idosos, medicamentos, quedas, acesso aos serviços de saúde, incapacidade física, capacidade funcional, doenças crônicas, adesão ao tratamento e avaliação subjetiva da saúde. $\mathrm{Na}$ literatura, esses indicadores são os que mais se correlacionam com incapacidade e dependência ${ }^{16,18,21,66,67}$. Os fatores 3 e 5 dizem respeito a aspectos sociais, porém, diferentemente do fator 1, agrupam indicadores desfavoráveis a boas condições de vida, como o analfabetismo, a pobreza, o déficit habitacional e a existência de crianças e jovens. Os fatores 4 e 6 são indicadores de apoio e rede social e podem ser considerados indicadores das relações sociais da família.

As análises descritivas foram feitas para todos os componentes e seus respectivos agrupamentos. Em todos se verificou boa consistência interna (alfa igual ou superior a 0,68$)$.

O fator 2 manteve o valor de alfa $(0,80)$ quando agrupado ao 7 e $\circ 7$ aumentou o valor do alfa $(0,68$ para 0,80$)$ ao ser agrupado com o 2 . 0 fator 3 diminuiu o valor do alfa ao ser agrupado ao fator 5 (0,86 para 0,79$)$, assim como o 5 (de 0,80 para 0,79), mas, ainda assim, mantiveram boa consistência interna. $O$ fator 4 teve o alfa diminuído $(0,85$ para 0,77$)$ ao ser agrupado com o 6 , porém o 6 ao ser agrupado com o $4(0,69$ a 0,77), teve o alfa aumentado. 
Entretanto, ao analisar a consistência dos sete fatores conjuntamente, o alfa foi inferior a 0,40 , indicando baixa consistência interna. Por isso, foram submetidos separadamente aos testes de validade, assim como seus três agrupamentos $(27,35$ e 46).

Nos testes de validação, verificou-se que os fatores 2, 7 e 27 foram validados com boa consistência interna, em relação ao índice de Katz e à Escala de Lawton, enquanto os fatores 1, 3 e 35 validaram apenas em relação à Escala de Lawton. 0 fator 27 apresentou melhor desempenho em relação aos demais, já que se correlacionou significativamente com ambas as escalas, Katz e Lawton, enquanto que os fatores 1 e 35 correlacionam-se significativamente apenas com a Escala de Lawton.

Destaca-se que os fatores 4, 6 e 46, relacionados às relações sociais, foram os únicos que não validaram para incapacidades e dependência, possivelmente em razão da variabilidade das relações sociais que podem ser afetadas positiva ou negativamente das condições envolvidas na gênese das incapacidades e dependência e da natureza das relações pré-existentes.

Diante desse resultado, decidiu-se avaliar esses três fatores conjuntamente $(1+27+35)$ e verificou-se que o conjunto apresentava boa consistência interna e foi validado tanto para Katz quanto para Lawton.

A partir daí, o IVF-ID Total passou a ser composto pelo agrupamento desses três fatores $(1+27+35)$, em que os fatores 1 e 35 referem-se à dimensão condições sociais (CSO) e o 27, à dimensão condições de saúde (CSA). 
Entretanto, dado o desempenho mais significativo da dimensão CSA nos testes de validade, decidiu-se destacá-lo na avaliação da vulnerabilidade e foram definidos os pontos de corte tanto para o IVF-ID Total quanto para a dimensão CSA.

Assim, o índice final contém 40 questões, divididas em quatro componentes e duas dimensões: a dimensão "Condições Sociais" (CSO) que engloba os componentes "Condições sociais favoráveis" e "Condições sociais desfavoráveis", e a dimensão “Condição de Saúde" (CSA), que congrega os componentes "Envelhecimento, incapacidade e dependência" e "Doenças crônicas".

Considerando a multidimensionalidade do fenômeno da vulnerabilidade, resultado de uma interação complexa de condições, a adoção de um escore único poderia não expressar as diferentes situações que afetam as famílias. Como as dimensões que compõem o IVF-ID avaliam distintos fenômenos (sociais e de saúde) um escore único poderia encobrir situações de vulnerabilidade diversas, como por exemplo, famílias socialmente vulneráveis a incapacidades e dependência e famílias cuja vulnerabilidade decorre predominantemente de condições de saúde. Com a definição de um ponto de corte para o Índice total e outro para a Dimensão CSA foi possível discriminar as dimensões da vulnerabilidade a incapacidades e dependência entre as famílias.

Em estudo realizado por Maia ${ }^{76}$ foram encontradas associações entre as vulnerabilidade físicas e sociais, em que os idosos socialmente vulneráveis tinham mais chances de se tornar fisicamente vulnerável e os idosos fisicamente vulneráveis maior chance de se tornarem socialmente vulneráveis. Além disso, os idosos fisicamente vulneráveis apresentaram maior distribuição na categoria média, alta e muito alta vulnerabilidade social. 
Para Barata ${ }^{77}$ um dos principais desafios metodológicos para a epidemiologia social está na realização de estudos populacionais que permitam considerar de maneira apropriada os efeitos contextuais e os composicionais. Além disso, também destaca o desafio de medir adequadamente os aspectos sociais e questiona se é possível seguir usando as mesmas ferramentas dos "fatores de risco" sem infringir os pressupostos teóricos da Epidemiologia Social.

Muñoz e Bertolozzi ${ }^{78}$, ao analisar o conceito de vulnerabilidade para a construção do conhecimento em Saúde Coletiva consideram que devem ser superados os estudos que restringem as análises na perspectiva da multifatorialidade e ocultam as complexas causas da determinação das doenças.

Portanto, a proposta de avaliação da vulnerabilidade das famílias deste estudo não é apenas utilizar um conjunto diverso de indicadores relacionados à dependência para classificar as famílias e sim obter uma ferramenta que auxilie os profissionais a captar informações, sob diversas perspectivas, capazes de compor um cenário que evidencie os potenciais de fortalecimento e desgaste das famílias.

O Índice final é composto por condições sociais de fortalecimento (acesso a bens duráveis, acesso a escolaridade, acesso a emprego e renda) e de desgaste (analfabetismo, pobreza). Além disso, as condições de saúde são abordadas não apenas na esfera biológica, mas também no que diz respeito ao acesso aos serviços de saúde, autoavaliação de saúde e presença de grupos vulneráveis, como os idosos. Em que pese a ampla utilização da estatística para definição dos indicadores e da adoção de pontos de corte para classificação das famílias, não se trata de uma ferramenta de avaliação de risco, haja vista o percurso metodológico para a eleição dos indicadores e a combinação de indicadores de avaliação do desenvolvimento 
social das famílias agregada aos indicadores específicos para avaliação da vulnerabilidade à incapacidades e dependência, condição que se expressa, a priori, na esfera biológica.

\subsection{Validação em outra população}

Após a construção do IVF-ID, deu-se prosseguimento ao processo de validação aplicando-o na Cidade Ademar, outra região do município de São Paulo com vulnerabilidade social e perfil demográfico distintos da região na qual foi construído. A finalidade foi verificar se os indicadores do IVF-ID seriam válidos e confiáveis para captar vulnerabilidade a incapacidades e dependência em outras realidades. Os testes demonstraram boa consistência interna tanto na Dimensão CSA quanto no IVF-ID Total $(0,73$ e 0,78 , respectivamente).

Em relação à validade, o IVF-ID Total não apresentou capacidade discriminante entre as famílias com alguma dependência avaliada pelo Índice Katz e tampouco se correlacionou com ele. É importante lembrar que na Cidade Ademar foram encontradas apenas cinco famílias com algum membro com dependência para as atividades básicas da vida diária, o que pode ter prejudicado o poder do resultado. Contudo, o IVF-ID Total foi capaz de discriminar e se correlacionar com a Escala de Lawton.

Já a Dimensão CSA mostrou-se capaz de discriminar famílias com e sem pessoas com dependência, tanto com relação ao Índice de Katz com para a Escala de Lawton. Também foi capaz de se correlacionar com ambas as escalas.

Ao avaliar as famílias das regiões de Lapa e Cidade Ademar através do IVFID, verificou-se que ambas apresentaram porcentagens semelhantes de famílias 
consideradas vulneráveis pelo IVF-ID Total, ou seja, que obtiveram pontuação maior ou igual a 11 pontos $(54,8 \%$ e $58,1 \% ; p=0,469$, respectivamente).

Entretanto, a análise da vulnerabilidade pelo IVF-ID Total juntamente com a Dimensão CSA encontrou diferenças importantes entre essas duas regiões. $\mathrm{Na}$ região da Lapa, a porcentagem de famílias vulneráveis na Dimensão CSA foi sempre superior à da Cidade Ademar. Já o número de famílias consideradas vulneráveis somente pelo IVF-ID Total foi superior na Cidade Ademar.

Ao verificar-se a presença de alguém com dependência na família, segundo Katz e Lawton, observou-se diferença significativa entre as duas regiões, sendo que a Lapa apresenta maior porcentagem de famílias com integrantes com dependência que na Cidade Ademar $(9,3 \%$ x 2,0\%; $p<0,001$ e 22,2\% x 11,7\%; $p=0,002$, respectivamente).

Em relação à aplicação do IVF-ID nas duas regiões, verifica-se que a vulnerabilidade relacionada a Dimensão CSA houve diferença significativa entre as duas regiões, sendo que na região da Lapa foi encontrada um número maior de famílias vulneráveis que na Cidade Ademar (47,6\% X 31,5\%; $p<0,001)$. Com isso, é possível dizer que as famílias na Lapa são mais vulneráveis a incapacidades e dependência na Dimensão de Condições de Saúde.

Os achados encontrados com a aplicação do IVF-ID corroboram o perfil das famílias esperado em cada região. Na Lapa, a população é mais envelhecida e, portanto, com mais indicadores de saúde positivos para vulnerabilidade a incapacidades e dependência, enquanto a Cidade Ademar apresenta uma 
população mais jovem e, portanto, com menos indicadores de saúde positivos para incapacidades e dependência.

Em relação aos aspectos sociais, o Índice Paulista de Vulnerabilidade Social (IPVS) da Cidade Ademar é superior à média do Município, o que significa ser uma região mais vulnerável socialmente. Porém, a amostra desse estudo na região da Lapa, concentrou-se nas famílias menos favorecidas, já que foi possível observar que muitas moradias de alto padrão não estavam cadastradas na Unidades Básicas participantes do estudo. Isso pode explicar a ausência de diferenças significativas entre as duas regiões $(54,8 \%$ x 58,1\%; $p=0,469)$ em relação ao IVF-ID Total.

Além disso, também se verificou maior porcentagem de famílias vulneráveis tanto para o IVF-ID Total como para Dimensão CSA na região da Lapa $(38,7 \%$ contra $25,8 \%$ ). Porém, quando se avalia as famílias vulneráveis pelo IVF-ID Total e não vulneráveis pela Dimensão CSA, verifica-se uma porcentagem maior na Cidade Ademar $(32,3 \%$ contra $16,1 \%)$, o que indica que as famílias são mais vulneráveis socialmente do que nas condições de saúde.

Este estudo apresenta os passos para a construção de um índice abrangente, válido e com uma estrutura definida, decorrente da aplicação em 496 famílias atendidas pela ESF. Seu desempenho foi testado com outras escalas amplamente utilizadas, como é o caso do Índice de Katz e da Escala de Lawton. O resultado alcançado permite indicar a utilização do IVF-ID em outras populações, de modo a confirmar suas características psicométricas. Novos estudos empíricos são necessários para confirmar os indicadores que o compõem. 
A tentativa de traduzir em números a complexidade das determinações envolvidas no processo saúde-doença sempre será reducionista. Porém, a forma de captação e interpretação, associada à leitura do contexto social e político (dimensões sociais e programáticas) é que irá iluminar os dados obtidos, não como causa de determinado fenômeno e sim como determinantes. Barata ${ }^{77}$ esclarece que:

"o conceito de determinação é mais adequado para a compreensão de processos sociais complexos, pois não necessita do isolamento completo das variáveis nem da noção de independência entre elas. Tampouco está baseado na idéia de um vínculo necessário, genético e específico. Na perspectiva das diferentes variedades de determinação existentes no mundo material, os limites nem sempre são claros, não há vínculos unidirecionais, e a maioria das relações são contingentes, ou seja, não são nem necessárias nem suficientes em si mesmas."

O Índice construído pode ser considerado um primeiro passo que não finda com a conclusão deste estudo. Outros testes e questionamentos serão necessários para aprimorá-lo e validá-lo.

Espera-se que o IVF-ID seja uma ferramenta útil para os enfermeiros que atuam na Estratégia Saúde da Família, pois permitirá identificar determinantes relacionados a incapacidades e dependência que deverão subsidiar o planejamento de ações de prevenção, acompanhamento e intervenção, com o intuito de monitorar as famílias e acionar recursos interdisciplinares e multiprofissionais, a fim de evitar o agravamento ou a instalação do desfecho em questão. 


\section{CONCLUSÕES}

Com relação aos objetivos propostos, o presente estudo permitiu chegar às seguintes conclusões:

$>\mathrm{O}$ instrumento construído passou por duas rodadas de avaliação dos juízes, até atingir $\mathrm{O}$ consenso;

D Cinco itens foram transferidos do componente "escolaridade" para um novo componente, intitulado "escolaridade do chefe da família", foram acrescentadas cinco questões no componente "acesso a bens duráveis", quatro no componente "rede social" e três no "apoio social" e outros quatro itens foram excluídos do componente "capacidade funcional";

houve nove acréscimos ao instrumento (um componente e oito questões), de modo que 0 instrumento passou a ser composto por oito dimensões, 38 componentes e 103 questões;

na $1^{\text {a }}$ rodada foram feitas 92 sugestões, $49(53,3 \%)$ relacionadas ao conteúdo e $43(46,7 \%)$ à forma e dos 140 itens avaliados, entre dimensões, componentes e questões, apenas $17(12,1 \%)$ tiveram um nível de concordância menor do que $80 \%$, sendo quatro $(23,5 \%)$ relacionados à forma e $13(76,5 \%)$, ao conteúdo;

$\mathrm{Na} 2^{\mathrm{a}}$ rodada, os juízes fizeram 26 sugestões, sete $(26,9 \%)$ relacionadas ao conteúdo e 19 , à forma $(73,1 \%)$ e dos 149 itens avaliados, somente quatro $(2,7 \%)$ apresentaram nível de concordância menor do que $80 \%$, sendo três relacionadas ao conteúdo e um, à forma.

$>$ Inúmeras outras sugestões e observações feitas pelos juízes na $1^{\mathrm{a}}$ e $2^{\mathrm{a}}$ rodadas foram consideradas na construção do Índice, porém, como não 
apresentaram menos de $80 \%$ de concordância, não entraram na apresentação dos resultados através da técnica Delphi;

Nas três Unidades da ESF localizadas na região da Lapa, o número de pessoas pertencentes às famílias entrevistadas foi semelhante. Apenas na UBS Vila Jaguara encontrou-se um número cerca de $6 \%$ inferior ao das outras duas Unidades (234 pessoas);

As idades médias foram 33,2 anos, 40,2 anos e 43,8 anos, respectivamente, para as Unidades Parque da Lapa, Vila Jaguara e Vila Piauí;

> Nas famílias da UBS Parque da Lapa a idade média foi menor que nas demais (teste de Kruskal-Wallis $p<0,001$ ).

$>$ Observou-se um número maior de mulheres $(54,6 \%)$ nas famílias entrevistadas, representando quase $10 \%$ a mais que o número de homens $(45,4 \%)$

> Houve predomínio de adultos de 18 a 59 anos $(54,0 \%)$ e porcentagens semelhantes de crianças, adolescentes e jovens $(23,2 \%)$ e idosos acima de 60 anos $(22,8 \%)$.

> A idade média da amostra foi de 39,06 anos e a idade máxima encontrada foi de 93 anos.

A pontuação média da amostra na escala de Katz foi de apenas 0,10 , indicando independência para as atividades básicas da vida diária (AVD);

$>$ A média de pontuação na escala de Lawton também foi alta $(26,47)$, indicando independência para as AIVD;

$>$ A grande maioria das pessoas não apresentava dependência para as AVD $(97,0 \%)$, somente $13(1,6 \%)$ apresentavam dependência apenas para uma 
atividade, como é o caso de mulheres que referiam perdas urinárias ocasionais;

Apenas duas pessoas $(0,3 \%)$ foram classificadas em "G", por serem totalmente dependentes para as ABVD;

Dais de $90 \%$ da amostra apresentou-se totalmente independente, sendo 97\% segundo o Índice de Katz e 92,2\%, segundo a Escala de Lawton;

> O número de famílias entrevistadas foi uniforme nas três Unidades, sendo exatamente igual nas UBS Parque da Lapa e Vila Jaguara (78 famílias) e maior na UBS Vila Piauí (92 famílias);

A média do número de pessoas na casa por família foi 3,21;

$>$ A média da pontuação no Índice de Katz foi 0,13 , ou seja, famílias com baixo índice de pessoas com dependência;

Para dependência nas AIVD, a média foi de 26,30 pontos, indicando pouca dependência para essas atividades;

> A maioria das famílias entrevistadas (56\%) tinha entre dois e três membros, seguidas pelas famílias de até quatro pessoas $(16,1 \%)$;

$>$ Destaca-se o número de pessoas que viviam sós $(9,7 \%)$;

Pouco menos de $10 \%$ das famílias entrevistadas tinha pelo menos um membro da família com alguma dependência, parcial ou total, para uma ou mais atividades básicas da vida diária;

$>$ Aproximadamente um quarto da amostra apresentava alguma dependência (22,2\%), parcial ou total, para uma ou mais atividades instrumentais;

Itens do instrumento encontrados em menos de 10 famílias: mulheres que tiveram filhos no último ano, crianças menores de um ano, renda familiar na linha da extrema pobreza, maior parte da renda familiar advinda de 
transferências, crianças com menos de 16 anos exercendo trabalho remunerado, crianças de 0 a 17 anos fora da escola, crianças de até 14 anos com mais de dois anos de atraso escolar, crianças de 10 a 17 nos analfabeto, casas que não são feitas de material de construção permanente, casas que não tem abastecimento de água, esgoto sanitário, coleta de lixo, televisão, geladeira e fogão, alguém com deficiência física, imobilizado ou acamado, com demência ou deficiência intelectual;

não foi encontrado nenhum domicílio em que havia crianças com mãe falecida, com menores de 14 anos que exerciam trabalho remunerado e domicílios sem banheiro próprio ou sem iluminação elétrica;

a análise fatorial exploratória do instrumento definiu sete componentes com 40,0\% de explicação da variância total acumulada;

das 103 questões do instrumento original, 56 questões permaneceram na análise fatorial exploratória;

a dimensão intitulada 'desenvolvimento infantil', composto por quatro componentes (trabalho precoce, acesso à escola, progresso escolar e mortalidade infantil), não apareceu em nenhum componente, na análise fatorial;

outros 12 componentes não apareceram na análise fatorial: condições econômicas, ausência de mãe, qualidade do posto de trabalho, extrema pobreza, incapacidade de geração de renda, abrigabilidade, acesso a abastecimento de água, saneamento, coleta de lixo e energia elétrica, internações e transtornos mentais.

as questões 7, 10, 26, 29, 32 e 79 aparecem em mais de um fator; 
no fator 1 , em geral, as questões relacionadas referem-se à melhores condições de vida, como acesso à educação, maior tempo no emprego atual, rendimento superior a um e dois salários mínimos, ter telefone celular, ter computador e com acesso a internet e ter moto ou carro;

no fator 2, a questão sobre a existência de idosos na casa correlacionou-se com outros itens relativos ao processo de envelhecimento e às incapacidades e dependência, como é o caso da presença de pelo menos duas doenças crônicas, uso de polifarmácia, ocorrência de quedas em idosos, não conseguir utilizar o transporte público para ir ao serviço de saúde, presença de incapacidade auditiva, incapacidade para se movimentar e dependência para alguma atividade básica ou instrumental da vida diária;

$>$ no fator 3 correlacionaram-se as questões que verificavam a presença de crianças, idosos, famílias com renda na linha da pobreza e condição de moradia $\left(\mathrm{n}^{\circ}\right.$ de dormitórios divido pelo número total de moradores do domicílio);

$>$ no fator 4 foi mantido na íntegra, correlacionando todas as questões referentes ao apoio social da família;

a presença de algum adulto analfabeto no domicílio, o analfabetismo entre os chefes de família e a renda familiar na linha da pobreza correlacionaram-se no fator 5;

$>$ as questões relacionadas à frequência de contatos com familiares e amigos, foram correlacionadas no fator 6

o fator 7 agrupou as questões associadas a presença de doenças crônicas, adesão ao tratamento medicamentoso e não medicamentoso, uso de 
medicamentos contínuos, autoavaliação negativa de saúde e dificuldade de acesso no agendamento de consultas, exames ou tratamentos;

o Índice resultante totalizou 53 questões distribuídas em sete fatores;

entre os fatores é possível identificar os seguintes agrupamentos: Fator 1: Condições sociais favoráveis (Fator 1); Fator 35: Condições sociais desfavoráveis (Fatores 3 e 5); Fator 27: Condições de saúde e existência de idosos (Fatores 2 e 7); Fator 46: Relações sociais (Fatores 4 e 6)

a consistência interna dos componentes, isolados ou agrupados, foi considerada boa, pois o alfa é igual ou superior a 0,68 ;

os fatores 2 e 7, bem como sua combinação (27), foram capazes de discriminar famílias com e sem pessoas com dependência para as AVD ( $p<0,001)$, com médias superiores nas famílias com pessoas com dependência;

os fatores 1, 2, 7 e 27 foram capazes de discriminar famílias com e sem pessoas com dependência para as AIVDs $(p<0,001)$, médias superiores nas famílias com pessoas com dependência nos fatores 1, 2, 7 e 27 e com médias superiores nas famílias sem pessoas com dependência nos fatores 3 e 35;

o fator 1 apresenta correlação negativa estatisticamente significativa com a Escala de Lawton $(r=-0,178 ; p=0,005)$;

o fator 2 apresentou correlação estatisticamente significativa com o Índice de Katz $(r=0,395 ; p=0,000)$ e correlação negativa com a Escala de Lawton $(r=-$ $0,618 ; p=0,000)$

o fator 3 obteve correlação estatisticamente significativa com a Escala de Lawton $(r=0,277 ; p=0,000)$; 
$>$ o fator 7 obteve correlação estatisticamente significativa com o Índice de Katz $(r=0,214 ; p=0,001)$ e a Escala de Lawton $(r=-0,322 ; p=0,000) ;$

o fator 27 também obteve correlação positiva estatisticamente significativa com Katz $(r=0,370 ; p=0,000)$ e negativa com Lawton $(r=-0,593 ; p=0,000)$.

$>$ o fator 35 apresentou correlação estatisticamente significativa com a Escala de Lawton $(r=0,157 ; p=0,013)$;

$>$ os fatores 2, 7 e 27 foram validados com boa consistência interna, em relação ao índice de Katz e à Escala de Lawton, já os fatores 1, 3 e 35 validaram apenas em relação à Escala de Lawton;

o fator 27 apresentou melhor desempenho em relação aos demais porque correlacionou-se significativamente com ambas as escalas, Katz e Lawton, enquanto os fatores 1 e 35 correlacionam-se significativamente apenas com a Escala de Lawton;

ao se analisar os três fatores conjuntamente $(1+27+35)$, encontrou-se alpha de Cronbach de 0,82, pontuação média de 11,83 com desvio padrão de 5,73, mediana de 11,0 e mínima de 0 e máxima de 25 pontos;

$>$ na análise da validade discriminante, o fator $1+27+35$ foi capaz de discriminar famílias com e sem pessoas com dependência para as ABVD (Katz) e AIVD (Lawton) (respectivamente 16,87x11,31; $p<0,001$ e 16,07 x $10,62 ; p<0,001)$

na validade concorrente, o fator $1+27+35$ apresentou correlação positiva com o Katz $(r=0,27 ; p<0,001)$ e apresentou correlação negativa com a Escala de Lawton ( $r=-0,39 ; p<0,001)$; 
> assim, o IVF-ID Total compõe-se pelo agrupamento dos três fatores $(1+27+35)$, onde os fatores 1 e 35 referem-se às condições sociais (CSO) e o fator 27 às condições de saúde (CSA);

o Índice, composto pelo agrupamento desses três fatores $(1+27+35)$, passou a ser designado IVF-ID Total, composto pela Dimensão Condições de Saúde (CSA) e pela Dimensão Condições Sociais (CSO);

$>$ o IVF-ID final é composto por duas dimensões, quatro componentes e 40 indicadores;

$>$ foram definidos um ponto de corte para o IVF-ID Total e para a Dimensão CSA;

> para a definição do ponto de corte do IVF-ID Total foi utilizada a curva ROC, construída com base na Escala de Lawton. A curva ROC obteve área de $0,764(p<0,001)$ e o ponto de corte 10 revelou sensibilidade de 0,84 e especificidade de 0,53. Assim, definiu-se como família vulnerável para incapacidades e dependência aquela com 11 ou mais pontos no IVF-ID Total; em relação à Dimensão CSA, a curva ROC obteve área de 0,904 $(p<0,001)$ e o ponto de corte 5 revelou sensibilidade $=0,95$ e especificidade de 0,76. Assim, definiu-se como família vulnerável para incapacidades e dependência aquela com 5 ou mais pontos na Dimensão CSA;

na região da Lapa, 136 famílias (54,8\%) apresentaram-se vulneráveis para incapacidade e dependência, segundo o IVF-ID Total e dessas, $96(38,7 \%)$ apresentaram-se vulneráveis também na Dimensão CSA e as 40 famílias restantes $(16,1 \%)$ não são vulneráveis quando avaliadas somente na Dimensão CSA. 
> 112 famílias $(45,2 \%)$ não foram consideradas vulneráveis no IVF-ID Total (CSO+CSA), mas apresentaram vulnerabilidade na Dimensão CSA e 90 famílias $(36,3 \%)$ não foram classificadas como vulneráveis nem pelo IVF-ID Total e nem pela Dimensão CSA;

na Cidade Ademar, observou-se predomínio de mulheres nas famílias entrevistadas $(52,1 \%)$;

$>$ em relação à faixa etária, verificou-se que a maior parte das pessoas estava na faixa de 18 a 59 anos $(58,9 \%)$, seguidas pelas crianças, adolescentes e jovens $(29,9 \%)$ e idosos $(11,2 \%)$;

a idade média encontrada foi de 31,63 anos e mediana de 28 anos;

$>$ foram encontradas apenas cinco pessoas com alguma dependência para as ABVD, sendo apenas uma totalmente dependente;

mais de $90 \%$ da amostra era totalmente independente para as ABVD e AIVD, sendo que foram encontradas 34 pessoas com alguma dependência $(3,6 \%)$ para as atividades instrumentais da vida diária;

a média do número de pessoas na casa foi de 3,79 pessoas, sendo encontradas famílias com até 11 pessoas;

98\% das famílias não apresentava ninguém com dependência para as atividades básicas da vida diária, segundo Katz;

$>$ já para as atividades instrumentais da vida diária verificou-se um número maior de famílias que tem alguém com alguma dependência $(11,7 \%)$;

$>$ ao aplicar o IVF-ID, na Cidade Ademar, observou-se o baixo número de famílias com idosos com mais de 80 anos e com pessoas com incapacidades para se movimentar e que não realizam as ABVD sem ajuda. Destacou-se 
também o elevado número de famílias com crianças, adolescentes ou jovens $(58,5 \%)$

verificou-se que o IVF-ID apresentou boa consistência interna, tanto na Dimensão CSA quanto no IVF-ID Total (0,73 e 0,78, respectivamente);

a Dimensão CSA foi capaz de discriminar famílias com e sem pessoas com dependência, segundo Katz, $(p<0,05)$, já o IVF-ID Total não apresentou capacidade discriminante;

para a Escala de Lawton, a Dimensão CSA e o IVF-ID Total mostram-se capazes de discriminar as famílias com e sem pessoas com dependência $(p<0,001)$

na validação concorrente, a Dimensão CSA apresentou correlação estatisticamente significativa $(r=0,18 ; p=0,005)$ com o índice de Katz;

para a escala de Lawton, observou-se correlação negativa estatisticamente significativa com a Dimensão CSA e o IVF-ID Total;

o Índice proposto para avaliar a vulnerabilidade de famílias à incapacidades e dependência mostrou-se confiável e válido ao ser aplicado em duas populações com vulnerabilidades sociais e perfis demográficos distintos;

na Cidade Ademar, 144 famílias $(58,1 \%)$ apresentaram-se vulneráveis para incapacidade e dependência, segundo o IVF-ID total, dessas 64 (25,8\%) apresentaram-se vulneráveis na Dimensão CSA e 80 (32,3\%) não são vulneráveis quando avaliadas somente na Dimensão CSA;

> 14 famílias $(5,6 \%)$ não foram consideradas vulneráveis no IVF-ID Total, mas apresentaram-se vulnerabilidade na Dimensão CSA e 90 famílias (36,3\%) não foram classificadas como vulneráveis nem pelo IVF-ID Total e nem pela Dimensão CSA; 
$>$ a Lapa apresentou maior porcentagem de famílias dependentes, segundo o Índice de Katz, que na Cidade Ademar (9,3\% x 2,0\%; $p<0,001)$, assim como, segundo a Escala de Lawton $(22,2 \% \times 11,7 \% ; p=0,002)$;

em relação à vulnerabilidade relacionada a Dimensão CSA, houve diferença significativa entre as duas regiões, sendo que na região da Lapa foi encontrada um número maior de famílias vulneráveis do que na Cidade Ademar (47,6\% X 31,5\%; $p<0,001)$;

em relação ao IVF-ID total, verificou-se que não houve diferença significativa entre as duas regiões $(54,8 \% \times 58,1 \% ; p=0,469)$;

ao comparar-se as combinações das vulnerabilidades, verificou-se que a porcentagem de famílias não vulneráveis foram iguais nas duas regiões;

$>$ em relação a vulnerabilidade ao IVF-ID Dimensão CSA, nota-se uma porcentagem significativamente superior na região da Lapa e verificar-se o inverso quando se analisa apenas a vulnerabilidade no IVF-ID Total indicando maior porcentagem de vulnerabilidade na região da Cidade Ademar;

$>$ a região da Lapa apresentou maior porcentagem de famílias com duas vulnerabilidades (IVF-ID Total e Dimensão CSA). 


\section{REFERÊNCIAS ${ }^{1}$}

1. Brasil. Ministério da Saúde. Diretrizes e recomendações para o cuidado integral de doenças crônicas não-transmissíveis. Promoção da saúde, vigilância, prevenção e assistência. Brasília; 2008.

2. Rasanathan $\mathrm{K}$, Montesinos $\mathrm{EV}$, Matheson $\mathrm{D}$, et al. Primary health care and the social determinants of health: essential and complementary approaches for reducing inequities in healthJ Epidemiol Community Health (2010).

3. Brasil. Lei $n^{\circ} 8.080$, de 19 de setembro de 1990. Dispõe sobre as condições para promoção, proteção e recuperação da saúde, a organização e o funcionamento dos serviços correspondentes e dá outras providências. Diário Oficial da União, Brasília, 20 set. 1990. Seção 1:18055.

4. Brasil. Ministério da Saúde. Saúde da Família: uma estratégia para reorientação do modelo assistencial. Brasília; 1997.

5. Freitas EV et al. Tratado de Geriatria e Gerontologia. 2a. Ed. Rio de Janeiro: Guanabara-Koogan; 2006.

6. Netto MP. Tratado de gerontologia. 2a ed. Rio de Janeiro: Editora Atheneu; 2006.

7. Ribeiro RCL, Oliveira e Silva Al, Modena CM, Fonseca MC. Capacidade funcional e qualidade de vida de idosos. Estud interdiscip envelhec 2002; 4: 85-96.

8. Ramos LR. Fatores determinantes do envelhecimento saudável em idosos residentes em centro urbano: Projeto Epidoso, São Paulo. Cad Saúde Pública maijun 2003; 19(3): 793-98.

9. Farias N, Buchalla CM. A Classificação Internacional de Funcionalidade, Incapacidade e Saúde: conceitos, usos e perspectivas. Rev Bras Epidemiol 2005; 8 (2): 187-93.

\footnotetext{
${ }^{1}$ De acordo com o estilo Vancouver
} 
10. González MQ. Discapacidad/dependencia: unificación de critérios de valoración y clasificación. IMSERSO; s/a.

11. Farinati PTV. Avaliação da autonomia do idoso: definição de critérios para uma abordagem positiva a partir de um modelo de interação saúde-autonomia. Arq Geriatr Gerontol 1997; 1: 1-9.

12. Magarolas RG, Clot-Razquin G, Fernandéz AR, Ramírez AF, Ruíz-Ramos M, Luque CR, Bou ES, Pallás JMA. El perfil de la dependencia en España: un análisis de la encuesta de discapacidades de 1999. Rev esp salud pública 2008; 82 (6): 653665.

13. Organização Mundial da Saúde (OMS). CIF: Classificação Internacional de Funcionalidade, Incapacidade e Saúde. Centro Colaborador da Organização Mundial da Saúde para a Família de Classificações Internacionais, org.; coordenação da tradução Cassia Maria Buchalla. São Paulo: Editora da Universidade de São Paulo EDUSP; 2003.

14. Brasil. Portaria $\mathrm{n}^{\circ}$ 2.029, de 24 de agosto de 2011. Institui a Atenção Domiciliar no âmbito do Sistema Único de Saúde. Diário Oficial da União, Brasília, 25 ago. 2011. Seção 1:91.

15. Verbrugge LM, Jette AM. The disablement process Soc Sci Med 1994; 38(1): 1-14.

16. Giacomin KC, Peixoto SV, Uchoa E, Lima-costa MF. Estudo de base populacional dos fatores associados à incapacidade funcional entre idosos na Região Metropolitana de Belo Horizonte, Minas Gerais, Brasil. Cad. Saúde Pública [online] 2008; 24(6): 1260-70.

17. Ramos LR, Goihman S. Geographic stratification by socio-economic status: Methodology from a household survey with elderly people in Sao Paulo, Brazil. Revista de Saúde Pública 1989, 23: 478-492. 
18. Rosa TEC, Benicio MHD'Aquino, Latorre MRDO, Ramos LR. Fatores determinantes da capacidade funcional entre idosos. Rev. Saúde Pública [online] 2003; 37(1): 40-8.

19. Costa AJL. Metodologias e indicadores para avaliação da capacidade funcional: análise preliminar do Suplemento Saúde da Pesquisa Nacional por Amostra de - Domicílios PNAD, Brasil, 2003. Ciênc. saúde coletiva [online] 2006; 11(4): 927-40.

20. Lebrão ML, Duarte YAO. SABE - Saúde, Bem-estar e Envelhecimento. O Projeto SABE no município de São Paulo: uma abordagem inicial. Brasília: Organização Pan-Americana da Saúde; 2003.

21. Alves LC, Leimann BCQ, Vasconcelos MEL, Carvalho MS, Vasconcelos AGG, Fonseca TCO et al. A influência das doenças crônicas na capacidade funcional dos idosos do Município de São Paulo, Brasil. Cad. Saúde Pública [online] 2007; 23 (8): 1924-30.

22. Fiedler MM, Peres KG. Capacidade funcional e fatores associados em idosos do Sul do Brasil: um estudo de base populacional. Cad. Saúde Pública [online] 2008; 24 (2): 409-15.

23. Lima-costa M, Matos DL, Camarano AA. Evolução das desigualdades sociais em saúde entre idosos e adultos brasileiros: um estudo baseado na Pesquisa Nacional por Amostra de Domicílios (PNAD 1998, 2003). Ciênc. saúde coletiva [online] 2006; 11 (4): 941-50.

24. Gaspar JC, Oliveira MAC, Duayer MFF. Perfil dos pacientes com perdas funcionais e dependência atendidos pelo PSF no município de São Paulo. Rev Esc Enferm USP 2007; 41(4):619-28.

25. Ayres JR, Calazans GJ, Saletti Filho HC, França Junior I. Risco, vulnerabilidade e práticas de prevenção e promoção da saúde. In: Campos GWSC, Minayo MCS, Akerman M, Drumond Júnior M, Carvalho YM, organizadores. Tratado de Saúde Coletiva. São Paulo/Rio de Janeiro: Editora Hucitec/Editora Fiocruz; 2006. p. 375-417. 
26. Ayres JRCM, França Júnior I, Calazans GJ, Saletti Filho HC. O conceito de vulnerabilidade e as práticas de saúde: novas perspectivas e desafios. In: Czeresnia $D$, Freitas CM organizadores. Promoção da saúde: conceitos, reflexões, tendências. Rio de Janeiro: Fiocruz; 2003. p. 117-139.

27. Carvalho M, Barros RP, Franco S. Índice de desenvolvimento da família. In: Acosta AR, Vitale MAF, organizadores. Família: redes, laços e políticas. São Paulo: Instituto de Estudos Especiais/Pontifícia Universidade Católica de São Paulo; 2003. p. 241-65.

28. Carvalho M, Barros RP, Franco S. O índice de desenvolvimento da família (IDF). Texto para discussão $n^{\circ}$ 986. Rio de Janeiro: IPEA; 2003. 19p. Disponível em: http://www.ipea.gov.br/pub/td/2003/td_0986.pdf

29. Cobo B, Sabóia AL. Uma Contribuição para a Discussão sobre a Construção de Indicadores para Implementação e Acompanhamento de Políticas Públicas. Trabalho apresentado no XV Encontro Nacional de Estudos Populacionais, ABEP, realizado em Caxambu - MG - Brasil, de 18 a 22 de Setembro de 2006 [trabalho na internet]. Caxambu; 2006. [citado 2010 mar 07]. Disponível em: http://www.abep.nepo.unicamp.br/encontro2006/docspdf/ABEP2006_411.pdf

30. Guimarães JRS, Jannuzzi PM. IDH , indicadores sintéticos e suas aplicações em políticas públicas. Uma análise crítica. Revista Brasileira de Estudos Urbanos e Regionais 2005; 7 (1): 73-90.

31. Instituto de Pesquisas Aplicadas (IPEA), Fundação João Pinheiro, Instituto Brasileiro de Geografia e Estatística (IBGE). Atlas do Desenvolvimento Humano no Brasil. Rio de Janeiro: PNUD; 1998.

32. São Paulo (Estado). Secretaria de Economia e Planejamento. Fundação Sistema Estadual de Análise de Dados (SEADE). Índice Paulista de Vulnerabilidade Social - IPVS. Espaços e dimensões da pobreza nos municípios do Estado de São Paulo [documento na internet]. São Paulo; 2007. [citado 2010 jan 13]. Disponível em: http://www.seade.gov.br/produtos/ipvs/pdf/oipvs.pdf 
33. São Paulo (Município). Secretaria Municipal de Saúde. Coordenação de Epidemiologia e Informação - CEInfo. Índice de Necessidades em Saúde por distrito administrativo do Município de São Paulo - $3^{a}$ edição (junho/2008) [documento na internet]. São Paulo; 2008. [citado 2010 jan 13]. Disponível em: http://www.prefeitura.sp.gov.br/cidade/secretarias/upload/saude/arquivos/infsaude/IN S_3edicao_Junho2008.pdf

34. Paixão M. IDH: uma forma razoável de avaliação do desenvolvimento social? In: Olhar Virtual UFRJ [opinião na internet]. Rio de Janeiro; 2004 [citado 2010 set 02]. Disponível em: http://olharvirtual.ufrj.br/ant/2004-07-27/olhonoolho.htm>

35. Najar AL, Baptista TWF, Andrade CLT. Índice de desenvolvimento da Família: uma análise comparativa em 21 municípios do Estado do Rio de Janeiro. Cad. Saúde Pública 2008; 24, Supl 1: S134-S147.

36. Silva TMR. Avaliação da vulnerabilidade de famílias na Atenção Básica. [dissertação]. São Paulo: Escola de Enfermagem da Universidade de São Paulo; 2011.

37. Wright JTC, Giovinazzo RA. DELPHI - Uma ferramenta de apoio ao planejamento prospectivo. Caderno de pesquisas em administração 2000; 1(12): 5465.

38. São Paulo (Estado). Secretaria de Economia e Planejamento. Fundação Sistema Estadual de Análise de Dados (SEADE). Índice Paulista de Vulnerabilidade Social - IPVS. [homepage na internet]. São Paulo; 2007. [citado 2010 jan 13]. Disponível em: http://www.seade.gov.br/projetos/ipvs/

39. São Paulo (Estado). Secretaria de Economia e Planejamento. Fundação Sistema Estadual de Análise de Dados (SEADE). Índice Paulista de Vulnerabilidade Social - IPVS. Análise. Subprefeituras do município de São Paulo [homepage na internet]. São Paulo; 2007. [citado 2010 jan 13]. Disponível em: http://www.seade.gov.br/projetos/ipvs/subprefeituras.php

40. São Paulo (Município). Secretaria Municipal de Saúde. Coordenação de Epidemiologia e Informação (CEInfo). Indicadores para diagnóstico de saúde da 
cidade de são Paulo. São Paulo; 2011. [citado 2011 ago 20]. Disponível em: http://www.prefeitura.sp.gov.br/cidade/secretarias/upload/saude/arquivos/publicacoe s/DiagnosticoSinteticoSaudeCidSaoPaulo_CEInfo_18jan11.pdf

41. São Paulo (Município). Secretaria Municipal de Saúde. Dados. Dados demográficos dos distritos pertencentes as subprefeituras [homepage na internet]. São Paulo; 2011. [citado 2012 jan. 03]. Disponível em: http://www.prefeitura.sp.gov.br/cidade/secretarias/subprefeituras/subprefeituras/dado s_demograficos/index.php? $\mathrm{p}=12758$

42. São Paulo (Município). Secretaria Municipal de Saúde. Coordenação de Epidemiologia e Informação (CEInfo). Diagnóstico sintético da saúde na cidade de São Paulo: análise de tendência 2004 a 2009. São Paulo; 2011d. [citado 2011 set 21]. Disponível em:

http://www.prefeitura.sp.gov.br/cidade/secretarias/upload/saude/arquivos/publicacoe s/DiagnosticoSinteticoSaudeCidSaoPaulo_CEInfo_18jan11.pdf

43. São Paulo (Município). Secretaria Municipal de Saúde. Organização Social Associação Congregação Santa Catarina. Unidades de Atendimento [homepage na internet]. São Paulo; 2011. [citado 2010 jul. 05]. Disponível em: http://www.osacsc.org.br/conteudo.asp?cod_site=0\&id_menu=28\&keyword=Unidade s_de_Atendimento

44. Gil AC. Pesquisa Social. $5^{a}$ ed. São Paulo: Editora Atlas; 1999.

45. Katz S, Ford AB, Moskowitz RW, Jackson BA, Jaffe MW. Studies of illness in the aged. The index of ADL: a standardized measure of biological and psychosocial function. JAMA 1963; 185 (12): 914-9.

46. Duarte YAO, Andrade CL, Lebrão ML. O Índex de Katz na avaliação da funcionalidade dos idosos. Rev Escola de Enfermagem da USP 2007; 41 (2): 317 25.

47. Brasil. Ministério da Saúde. Secretaria de Atenção à Saúde. Departamento de Atenção Básica. Envelhecimento e saúde da pessoa idosa. Brasília, 2006. (Cadernos de Atenção Básica, 19). 
48. Freitas EV, Miranda RD. Parâmetros clínicos do envelhecimento e Avaliação Geriátrica Ampla. In: Freitas EV et al. Tratado de Geriatria e Gerontologia. 2a. Ed. Rio de Janeiro: Guanabara-Koogan; 2006. p.900-9.

49. Pedro ICS, Rocha SMM, Nascimento LC. Apoio e rede social em enfermagem familiar: revendo conceitos. Rev Latino-am Enfermagem 2008; 16 (2): 324-7.

50. Chor D, Griep RH, Lopes CS, Faerstein E. Medidas de rede e apoio social no Estudo Pró-Saúde: pré-testes e estudo piloto. Cad. Saúde Pública 2001; 17 (4): 88796.

51. Instituto Brasileiro de Geografia e Estatística (IBGE). Coleta. Questionários [documento na internet]. Brasília; 2010. [citado 2011 mai. 05]. Disponível em: http://www.censo2010.ibge.gov.br/download/questionarios/censo2010_amostra.pdf

52. Instituto Brasileiro de Geografia e Estatística (IBGE). PNAD 2009: rendimento e número de trabalhadores com carteira assinada sobem e desocupação aumenta [notícia na internet]. Brasília; 2010. [citado 2011 jun. 15]. Disponível em: http://www.ibge.gov.br/home/presidencia/noticias/noticia_visualiza.php?id_noticia=17 08

53. Instituto Brasileiro de Geografia e Estatística (IBGE). Síntese de indicadores 2009 [periódico na internet]. Rio de Janeiro; 2010. [citado 2011 mar. 07] Disponível em:

http://www.ibge.gov.br/home/estatistica/populacao/trabalhoerendimento/pnad2009/p nad_sintese_2009.pdf

54. Griep RH, Chor D, Faerstein E, Lopes CS. Confiabilidade teste-reteste de aspectos da rede social no Estudo Pró-Saúde. Rev. Saúde Pública 2003; 37 (3): 379-85.

55. Sluzki CE. A rede social na prática sistêmica: alternativas terapêuticas. São Paulo: Casa do Psicólogo; 1997. 
56. Domingues MARC. Mapa Mínimo de Relações: instrumento gráfico para identificar a rede de suporte social do idoso. [tese]. São Paulo: Faculdade de Saúde Pública da Universidade de São Paulo; 2004.

57. Alvarenga MRM, Oliveira MAC, Domingues MAR, Amendola F, Faccenda O. Rede de suporte social do idoso atendido por equipes de saúde da família. Ciência e Saúde Coletiva 2011; 16 (5): 2603-11.

58. Santos KA, Koszuoski R, Dias-da-Costa JS, Pattussi MP. Fatores associados com a incapacidade funcional em idosos do Município de Guatambu, Santa Catarina, Brasil. Cad Saúde Pública nov 2007; 23(11):2781-2788.

59. Starfield B. Atenção primária, equilíbrio entre necessidades de saúde, serviços e tecnologia. Brasília: Organização das Nações Unidas para a Educação, a Ciência e a Cultura/Ministério da Saúde; 2002.

60. Fernandes HCL. O acesso aos serviços de saúde e sua relação com a capacidade funcional e a fragilidade em idosos atendidos pela Estratégia Saúde da Família. [dissertação]. São Paulo: Escola de Enfermagem da Universidade de São Paulo; 2010.

61. Parahyba MI, Veras R, Melzer D. Incapacidade funcional entre as mulheres idosas no Brasil. Rev Saúde Pública 2005; 39(3): 383-91.

62. IBGE. Indicadores sociais municipais. Estudos e pesquisas. Informação demográfica e socioeconômica número 28. Uma análise dos resultados do universo de Censo Demográfico 2010. http://www.ibge.gov.br/home/estatistica/populacao/censo2010/indicadores_sociais_ municipais/indicadores_sociais_municipais.pdf

63. São Paulo (Município). Secretaria Municipal de Saúde. Coordenação de Epidemiologia e Informação (CEInfo). Boletim Inquérito de Saúde: Primeiros Resultados [periódico na internet]. São Paulo; 2010. [citação 2011 ago 20]. Disponível em: http://www.prefeitura.sp.gov.br/cidade/secretarias/upload/saude/arquivos/publicacoe s/PrimeirosResultados.pdf 
64. Instituto Brasileiro de Geografia e Estatística (IBGE). Indicadores Sociodemograficos e de Saúde no Brasil 2009. Sobre a condição de Saúde dos idosos: indicadores selecionados [periódico na internet]. Brasília; 2010. Disponível em:

http://www1.ibge.gov.br/home/estatistica/populacao/indic_sociosaude/2009/com_sob re.pdf

65. Ramos LR, Simões E, Albert MS. Dependency on daily living and cognitive impairment strongly predicted mortality among urban elderly residentes in Brazil: a two-year follow-up. Journal of the American Geriatric Society 2011; 49: 1168-75.

66. Giacomin KC, Uchôa E, Firmo JOA, Lima-Costa MF. Projeto Bambuí: um estudo de base populacional da prevalência e dos fatores associados à necessidade de cuidador entre idosos. Cad Saúde Pública jan-fev 2005; 21(1): 80-91.

67. Santos KA, Koszuoski R, Dias-da-Costa JS, Pattussi MP. Fatores associados com a incapacidade funcional em idosos do Município de Guatambu, Santa Catarina, Brasil. Cad Saúde Pública nov 2007; 23(11):2781-2788.

68. Del Duca GF, Silva MC, Hallal PC. Incapacidade funcional para atividades básicas e instrumentais da vida diária em idosos. Rev Saúde Pública 2009; 43(5): 796-805.

69. Lima-costa MF, Barreto SM, Giatti L. Condições de saúde, capacidade funcional, uso de serviços de saúde e gastos com medicamentos da população idosa brasileira: um estudo descritivo baseado na Pesquisa Nacional por Amostra de Domicílios. Cad. Saúde Pública 2003; 19(3):735-43.

70. Parahyba MI, Simões CCS. A prevalência de incapacidade funcional em idosos no Brasil. Ciência e Saúde Coletiva 2006; 11 (4): 967-74.

71. Nogueira SL, Ribeiro RCL, Rosado LEFPL, Franceschini SCC, Ribeiro AQ, Pereira ET. Fatores determinantes da capacidade funcional em idosos longevos. Revista Brasileira Fisioterapia São Carlos 2010; 14 (4): 322-9. 
72. Pedrazzi EC, Rodrigues RAP, Schiaveto FV. Morbidade referida e capacidade funcional de idosos. Ciencia Cuid Saude out-dez 2007; 6(4): 407-413.

73. Lozano IA, Gonzáles PA. Clasificación de las personas dependientes a partir de la encuesta de discapacidades, deficiências y estado de salud de 1999. Rev Esp Salud Publica 2006; 80: 349-360.

74. Cunha FCM, Cintra MTG, Cunha LCM, Couto EAB, Giacomin KC. Fatores que predispõem ao declínio funcional em idosos hospitalizados. Rev Bras Geriatr Gerontol 2009; 12(3): 475-87.

75. Perracini MR, Ramos LR. Fatores associados a quedas em uma coorte de idosos residentes na comunidade. Rev Saúde Pública 2002; 36 (6): 709-16.

76. Maia FOM. Vulnerabilidade e envelhecimento: panorama dos idosos residentes no Município de São Paulo - Estudo SABE [tese]. São Paulo: Escola de Enfermagem, Universidade de São Paulo, 2011.

77. Barata RB. Epidemiologia Social. Rev Bras Epidemiol 2005; 8(1): 7-17.

78. Sánchez AIM, Bertolozzi MR. Pode o conceito de vulnerabilidade apoiar a construção do conhecimento em Saúde Coletiva? Ciência e Saúde Coletiva 2007; 12(2): 319-24. 


\section{APÊNDICE I}

DATA DA COLETA:

I

l

\begin{tabular}{|c|c|c|c|c|c|}
\hline $\begin{array}{c}\text { Número } \\
\text { Região }\end{array}$ & $\begin{array}{c}\text { Número } \\
\text { UBS }\end{array}$ & Equipe & Microárea & $\begin{array}{c}\text { Número } \\
\text { Cadastro Família }\end{array}$ & $\begin{array}{c}\text { Número } \\
\text { Questionário }\end{array}$ \\
\hline & & & & & \\
\hline
\end{tabular}

\section{CADASTRO DA FAMÍLIA}

\begin{tabular}{|c|c|c|c|c|}
\hline Número & Nome (iniciais) & Sexo & Data de Nascimento & Idade \\
\hline & & & & \\
\hline & & & & \\
\hline & & & & \\
\hline & & & & \\
\hline & & & & \\
\hline & & & & \\
\hline & & & & \\
\hline & & & & \\
\hline & & & & \\
\hline & & & & \\
\hline & & & & \\
\hline & & & & \\
\hline
\end{tabular}


APÊNDICE II

\begin{tabular}{|c|c|c|c|c|c|}
\hline $\begin{array}{c}\text { Número } \\
\text { Região }\end{array}$ & $\begin{array}{c}\text { Número } \\
\text { UBS }\end{array}$ & Equipe & Microárea & $\begin{array}{c}\text { Número } \\
\text { Cadastro Família }\end{array}$ & $\begin{array}{c}\text { Número } \\
\text { Questionário }\end{array}$ \\
\hline & & & & & \\
\hline
\end{tabular}

\section{INSTRUMENTO DE VULNERABILIDADE DA FAMÍLIA A INCAPACIDADES E DEPENDÊNCIA}

\begin{tabular}{|c|c|c|}
\hline \multicolumn{3}{|l|}{ DIMENSÃO 1: VULNERABILIDADE DAS FAMÍLIAS } \\
\hline \multicolumn{3}{|l|}{ COMPONENTE: Fecundidade } \\
\hline Neste domicílio há: & SIM & NÃ̃o \\
\hline 1. Alguma mulher que teve filho nascido vivo nos últimos 12 meses? & 1 & 0 \\
\hline 2. Alguma mulher que teve filho nascido vivo nos últimos 24 meses? & 1 & 0 \\
\hline \multicolumn{3}{|l|}{ COMPONENTE: Existência de crianças, adolescentes e jovens } \\
\hline Neste domicílio há: & SIM & NÃO \\
\hline 3. Alguma criança menor de um ano? & 1 & 0 \\
\hline 4. Alguma criança até 10 anos? & 1 & 0 \\
\hline 5. Alguma criança ou adolescente até 14 anos? & 1 & 0 \\
\hline 6. Alguma criança, adolescente ou jovem até 17 anos? & 1 & 0 \\
\hline \multicolumn{3}{|l|}{ COMPONENTE: Existência de idosos } \\
\hline Neste domicílio há: & SIM & NÃO \\
\hline 7. Algum idoso (60 anos ou mais)? & 1 & 0 \\
\hline 8, Algum idoso com 80 anos ou mais? & 1 & 0 \\
\hline 9. Apenas um morador no domicílio e é idoso ( 60 anos ou mais)? & 1 & 0 \\
\hline 10. Apenas moradores idosos ( 60 anos ou mais)? & 1 & 0 \\
\hline \multicolumn{3}{|l|}{ COMPONENTE: Condição econômica } \\
\hline Neste domicílio há: & SIM & NÃO \\
\hline 11. Pessoas vivendo maritalmente (casais)? & 0 & 1 \\
\hline 12. Mais da metade dos moradores com mais de 10 anos de idade (idade ativa)? & 0 & 1 \\
\hline \multicolumn{3}{|l|}{ COMPONENTE: Ausência da mãe } \\
\hline Neste domicílio há: & SIM & NÃO \\
\hline 13. Crianças cuja mãe tenha falecido? & 1 & 0 \\
\hline 14. Crianças que não morem com a mãe? & 1 & 0 \\
\hline \multicolumn{3}{|l|}{ DIMENSÃO 2: ACESSO AO CONHECIMENTO } \\
\hline \multicolumn{3}{|l|}{ COMPONENTE: Analfabetismo } \\
\hline Neste domicílio há: & SIM & NÃO \\
\hline 15. Algum adulto analfabeto ou que só lê e escreve o próprio nome? & 1 & 0 \\
\hline 16. Algum adulto com dificuldade para ler e escrever (analfabeto funcional)? & 1 & 0 \\
\hline 17. Pelo menos um adulto com ensino fundamental completo? & 0 & 1 \\
\hline \multicolumn{3}{|l|}{ COMPONENTE: Escolaridade } \\
\hline Neste domicílio há: & SIM & NÃO \\
\hline 18. Alguma pessoa com ensino médio completo? & 0 & 1 \\
\hline 19. Alguma pessoa com educação superior? & 0 & 1 \\
\hline \multicolumn{3}{|l|}{ COMPONENTE: Escolaridade do chefe da família* } \\
\hline Neste domicílio o chefe da família: & SIM & NÃO \\
\hline 20. É analfabeto ou só lê e escreve o próprio nome? & 1 & 0 \\
\hline 21. Tem dificuldade para ler e escrever (analfabeto funcional)? & 1 & 0 \\
\hline 22. Tem o ensino fundamental completo? & 0 & 1 \\
\hline 23. Tem o ensino médio completo? & 0 & 1 \\
\hline 24. Tem ensino superior? & 0 & 1 \\
\hline \multicolumn{3}{|l|}{ *Pessoa reconhecida, pelos demais moradores, como responsável pelo domicílio. } \\
\hline \multicolumn{3}{|l|}{ DIMENSÃO 3: ACESSO AO TRABALHO } \\
\hline \multicolumn{3}{|l|}{ COMPONENTE: Disponibilidade de trabalho } \\
\hline Neste domicílio: & SIM & NÃO \\
\hline $\begin{array}{l}\text { 25. Mais da metade das pessoas em idade ativa* exerce trabalho remunerado? } \\
\text { *neste caso, considerar } 16 \text { anos ou mais (excluir trabalho infantil) }\end{array}$ & 0 & 1 \\
\hline
\end{tabular}




\begin{tabular}{|c|c|c|}
\hline 26. Alguma pessoa trabalha há mais de seis meses no emprego atual? & 0 & 1 \\
\hline \multicolumn{3}{|l|}{ COMPONENTE: Qualidade do posto de trabalho } \\
\hline Neste domicílio há: & SIM & NÃO \\
\hline 27. Alguma pessoa trabalhando no setor formal (com carteira assinada)? & 0 & 1 \\
\hline 28. Alguma pessoa trabalhando mais do que 50 horas/semana? & 1 & 0 \\
\hline \multicolumn{3}{|l|}{ COMPONENTE: Remuneração } \\
\hline Neste domicílio há: & SIM & NÃO \\
\hline 29. Alguma pessoa trabalhando com rendimento superior a 1 salário mínimo? ( $\mathrm{R} \$ 545,00)$ & 0 & 1 \\
\hline $\begin{array}{l}\text { 30. Alguma pessoa trabalhando com rendimento superior a } 2 \text { salários mínimos? (R\$ } \\
1.090,00 \text { ) }\end{array}$ & 0 & 1 \\
\hline \multicolumn{3}{|l|}{ DIMENSÃO 4: DISPONIBILIDADE DE RECURSOS } \\
\hline \multicolumn{3}{|l|}{ COMPONENTE: Extrema pobreza } \\
\hline Neste domicílio: & SIM & NÃo \\
\hline $\begin{array}{l}\text { 31. A renda familiar é inferior a } 1 / 4 \text { do salário mínimo vigente por pessoa*? } \\
\text { *Salário Mínimo em } 2011=\mathbf{R} \$ 545,00 ; 1 / 4=R \$ 136,25 \text { - Instituto de Pesquisa Econômicas Aplicadas - IPEA }\end{array}$ & 1 & 0 \\
\hline \multicolumn{3}{|l|}{ COMPONENTE: Pobreza } \\
\hline Neste domicílio: & SIM & NÃO \\
\hline $\begin{array}{l}\text { 32. A renda familiar é de } 1 / 4 \text { até } 1 / 2 \text { salário mínimo por pessoa*? } \\
\text { *Salário Mínimo em } 2011=\mathbf{R} \$ \mathbf{5 4 5 , 0 0 ;} 1 / 2=\mathbf{R} \$ 272,50,1 / 4=\mathbf{R} \$ 136,25-\text { Instituto de Pesquisa } \\
\text { Econômicas Aplicadas - IPEA }\end{array}$ & 1 & 0 \\
\hline \multicolumn{3}{|l|}{ COMPONENTE: Incapacidade de geração de renda } \\
\hline Neste domicílio: & SIM & NÃO \\
\hline $\begin{array}{l}\text { 33. A maior parte (mais de } 50 \% \text { ) da renda familiar advém de transferências*? } \\
\text { *benefícios como moradia, alimentação, roupas, vales-refeição, alimentação ou transporte, } \\
\text { bolsa-família, benefício de prestação continuada }\end{array}$ & 1 & 0 \\
\hline \multicolumn{3}{|l|}{ DIMENSÃO 5: DESENVOLVIMENTO INFANTIL } \\
\hline \multicolumn{3}{|l|}{ COMPONENTE: Trabalho precoce } \\
\hline Neste domicílio há: & SIM & NÃO \\
\hline 34. Alguma criança com menos de 14 anos exercendo trabalho remunerado? & 1 & 0 \\
\hline 35. Alguma criança com menos de 16 anos exercendo trabalho remunerado? & 1 & 0 \\
\hline \multicolumn{3}{|l|}{ COMPONENTE: Acesso à escola } \\
\hline Neste domicílio há: & SIM & NÃO \\
\hline 36 Alguma criança de 0 a 6 anos fora da escola? & 1 & 0 \\
\hline 37. Alguma criança de 7 a 14 anos fora da escola? & 1 & 0 \\
\hline 38. Alguma criança de 7 a 17 anos fora da escola? & 1 & 0 \\
\hline \multicolumn{3}{|l|}{ COMPONENTE: Progresso escolar } \\
\hline Neste domicílio há: & SIM & NÃO \\
\hline 39. Alguma criança de até 14 anos com mais de dois anos de atraso escolar? & 1 & 0 \\
\hline 40. Algum adolescente de 10 a 14 anos analfabeto? & 1 & 0 \\
\hline 41. Algum jovem de 15 a 17 anos analfabeto? & 1 & 0 \\
\hline \multicolumn{3}{|l|}{ COMPONENTE: Mortalidade infantil } \\
\hline Neste domicílio há: & SIM & NÃO \\
\hline 42. Alguma mãe cujo filho tenha nascido morto? & 1 & 0 \\
\hline 43. Alguma mãe cujo filho tenha morrido com menos de um ano? & 1 & 0 \\
\hline \multicolumn{3}{|l|}{ DIMENSÃO 6: CONDIÇÕES HABITACIONAIS } \\
\hline \multicolumn{3}{|l|}{ COMPONENTE: Propriedade } \\
\hline Este domicílio é: & SIM & NÃo \\
\hline 44. Próprio? & 0 & 1 \\
\hline 45. Próprio em terreno próprio? & 0 & 1 \\
\hline \multicolumn{3}{|l|}{ COMPONENTE: Condições de moradia } \\
\hline Neste domicílio: & SIM & NÃO \\
\hline 46. 0 número total de moradores dividido pelo número de dormitórios é maior que dois? & 1 & 0 \\
\hline \multicolumn{3}{|l|}{ COMPONENTE: Abrigabilidade } \\
\hline Este domicílio: & SIM & NÃO \\
\hline 47.É feito de material de construção permanente? & 0 & 1 \\
\hline 48. Tem banheiro próprio? & 0 & 1 \\
\hline
\end{tabular}




\begin{tabular}{|c|c|c|}
\hline Neste domicílio há: & SIM & NÃo \\
\hline \multirow{2}{*}{\multicolumn{3}{|c|}{$\begin{array}{l}\text { 49. Abastecimento de água da rede pública? } \\
\text { COMPONENTE: Acesso a saneamento }\end{array}$}} \\
\hline & & \\
\hline Neste domicílio há: & SIM & NÃO \\
\hline 50. Esgoto sanitário (rede geral ou fossa séptica)? & 0 & 1 \\
\hline \multicolumn{3}{|l|}{ COMPONENTE: Acesso a coleta de lixo } \\
\hline Neste domicílio há: & SIM & NÃo \\
\hline 51. Acesso regular a serviço de coleta de lixo? & 0 & 1 \\
\hline \multicolumn{3}{|l|}{ COMPONENTE: Acesso a energia elétrica } \\
\hline $\begin{array}{l}\text { Neste domicílio há: } \\
52 \text { Jluminacão elétrica? }\end{array}$ & SIM & NÃO \\
\hline 52. Iluminação elétrica? & 0 & 1 \\
\hline \multicolumn{3}{|l|}{ COMPONENTE: Acesso a bens duráveis } \\
\hline Neste domicílio há: & SIM & NÃO \\
\hline 53. Rádio (inclusive integrado a outro tipo de aparelho)? & 0 & 1 \\
\hline 54. Televisão? & 0 & 1 \\
\hline 55. Máquina de lavar roupa (não considerar tanquinho)? & 0 & 1 \\
\hline 56. Geladeira? & 0 & 1 \\
\hline 57. Fogão? & 0 & 1 \\
\hline 58. Telefone celular? & 0 & 1 \\
\hline 59. Telefone fixo? & 0 & 1 \\
\hline 60. Microcomputador? & 0 & 1 \\
\hline \multirow{2}{*}{$\begin{array}{l}\text { 61. Microcomputador com acesso a internet? } \\
\text { 62. Motocicleta ou automóvel para uso particular? }\end{array}$} & 0 & 1 \\
\hline & 0 & 1 \\
\hline \multicolumn{3}{|l|}{ DIMENSÃO 7: RELAÇÕES SOCIAIS } \\
\hline \multicolumn{3}{|l|}{ COMPONENTE: Rede Social } \\
\hline Neste domicílio há: & SIM & NÃO \\
\hline $\begin{array}{l}\text { 63. Familiares }{ }^{1} \text { que moram próximos (a ponto de ser possível ir a pé) e que mantém } \\
\text { contato? }\end{array}$ & 0 & 1 \\
\hline 64. Amigos ${ }^{2}$ que moram próximos (a ponto de ir a pé) e que mantém contato? & 0 & 1 \\
\hline $\begin{array}{l}\text { 65. Alguma pessoa que participa de associações, clubes, igrejas, grupos ou trabalho } \\
\text { voluntário não remunerado? }\end{array}$ & 0 & 1 \\
\hline 66. Visitas de familiares pelo menos uma vez por semana? & 0 & 1 \\
\hline 67. Visitas de familiares pelo menos uma vez ao mês? & 0 & 1 \\
\hline 68. Visitas de familiares pelo menos uma vez ao ano? & 0 & 1 \\
\hline 69. Visitas de amigos pelo menos uma vez por semana? & 0 & 1 \\
\hline 70. Visitas de amigos pelo menos uma vez por mês? & 0 & 1 \\
\hline 71. Visitas de amigos pelo menos uma vez ao ano? & 0 & 1 \\
\hline 1 Pessoas que considera da família, com ou sem laços de consangüinidade & & \\
\hline Pessoas com quem mantém relações de amizade & & \\
\hline COMPONENTE: Apoio Social & & \\
\hline Neste domicílio há: & SIM & NÃO \\
\hline $\begin{array}{l}\text { 72. Alguma pessoa que não tem com quem contar, caso necessite de ajuda para realizar } \\
\text { tarefas domésticas como fazer a comida e limpar a casa? }\end{array}$ & 1 & 0 \\
\hline $\begin{array}{l}\text { 73. Alguma pessoa que não tem com quem contar, caso necessite de ajuda com bens } \\
\text { materiais? }\end{array}$ & 1 & 0 \\
\hline $\begin{array}{l}\text { 74. Alguma pessoa que não tem com quem contar, caso necessite de dinheiro ou ajuda } \\
\text { financeira? }\end{array}$ & 1 & 0 \\
\hline 75. Alguma pessoa que não tem com quem contar, caso necessite de companhia? & 1 & 0 \\
\hline $\begin{array}{l}\text { 76. Alguma pessoa que não tem com quem contar, caso necessite receber cuidados de } \\
\text { saúde? }\end{array}$ & 1 & 0 \\
\hline $\begin{array}{l}\text { 77. Alguma pessoa que não tem com quem contar para acompanhá-lo, caso necessite sair de } \\
\text { casa (para consultas, fazer compras, passear...)? }\end{array}$ & 1 & 0 \\
\hline DIMENSÃO 8: CONDIÇõES DE SAÚDE & & \\
\hline COMPONENTE: Doenças Crônicas & & \\
\hline Neste domicílio há: & SIM & NÃO \\
\hline 78. Alguma pessoa com pelo menos uma doença crônica ${ }^{3}$ ? & 1 & 0 \\
\hline 79. Alguma pessoa com pelo menos duas doenças crônicas ${ }^{3}$ ? & 1 & 0 \\
\hline
\end{tabular}




\begin{tabular}{|c|c|c|}
\hline 80. Alguma pessoa da família com três ou mais doenças crônicas? & 1 & 0 \\
\hline \multicolumn{3}{|l|}{$\begin{array}{l}3 \text { Doenças cardiovasculares (cerebrovasculares, isquêmicas), neoplasias, doenças respiratórias } \\
\text { crônicas, diabetes mellitus e etc. }\end{array}$} \\
\hline \multicolumn{3}{|l|}{ COMPONENTE: Adesão ao tratamento } \\
\hline Neste domicílio há: & SIM & NÃO \\
\hline $\begin{array}{l}\text { 81. Alguma pessoa com doença crônica que tem dificuldades em seguir o tratamento } \\
\text { medicamentoso, por motivos pessoais ou por dificuldade de acesso aos medicamentos? }\end{array}$ & 1 & 0 \\
\hline $\begin{array}{l}\text { 82. Alguma pessoa com doença crônica que tem dificuldades em seguir o tratamento não- } \\
\text { medicamentoso, como fazer atividade física, seguir uma dieta recomendada, parar de fumar? }\end{array}$ & 1 & 0 \\
\hline \multicolumn{3}{|l|}{ COMPONENTE: Medicamentos } \\
\hline Neste domicílio há: & SIM & NÃO \\
\hline 83. Alguma pessoa que faz uso de medicamento contínuo? & 1 & 0 \\
\hline $\begin{array}{l}\text { 84. Alguma pessoa que faz uso contínuo de } 5 \text { ou mais medicamentos diferentes ao mesmo } \\
\text { tempo? (polifarmácia) }\end{array}$ & 1 & 0 \\
\hline \multicolumn{3}{|l|}{ COMPONENTE: Internações } \\
\hline Neste domicílio: & SIM & NÃO \\
\hline 85. Alguma pessoa foi internada nos últimos 12 meses (exceto parto)? & 1 & 0 \\
\hline $\begin{array}{l}\text { 86. Alguma pessoa foi internada por doença crônica }{ }^{3} \text { descompensada, nos ú }_{\text {meses? }} \\
\text { me }\end{array}$ & 1 & 0 \\
\hline
\end{tabular}

3 Doenças cardiovasculares (cerebrovasculares, isquêmicas), neoplasias, doenças respiratórias crônicas, diabetes mellitus e etc.

\begin{tabular}{|c|c|c|}
\hline \multicolumn{3}{|l|}{ COMPONENTE: Quedas } \\
\hline Neste domicílio: & SIM & NÃO \\
\hline 87. Algum idoso sofreu queda nos últimos 12 meses? & 1 & 0 \\
\hline \multicolumn{3}{|l|}{ COMPONENTE: Avaliação subjetiva da saúde } \\
\hline Neste domicílio há: & SIM & NÃO \\
\hline 88. Alguma pessoa que considera sua saúde ruim ou muito ruim? & 1 & 0 \\
\hline \multicolumn{3}{|l|}{ COMPONENTE: Acesso aos Serviços de Saúde } \\
\hline Neste domicílio há: & SIM & NÃO \\
\hline 89. Alguma pessoa com dificuldade para utilizar os serviços de saúde? & 1 & 0 \\
\hline $\begin{array}{l}\text { 90. Alguma pessoa que não conseguiu agendar consultas, exames ou tratamentos nos } \\
\text { últimos } 12 \text { meses? }\end{array}$ & 1 & 0 \\
\hline 91. Alguma pessoa que não consegue ir de transporte coletivo público ao serviço de saúde? & 1 & 0 \\
\hline $\begin{array}{l}\text { 92. Serviços de saúde, muito utilizados, que são distantes da residência, a ponto de não se } \\
\text { conseguir ir a pé? }\end{array}$ & 1 & 0 \\
\hline \multicolumn{3}{|l|}{ COMPONENTE: Incapacidade física } \\
\hline Neste domicílio há: & SIM & NÃO \\
\hline $\begin{array}{l}\text { 93. Alguma pessoa com incapacidade visual? (considerar pessoa incapaz, com grande } \\
\text { dificuldade permanente ou alguma dificuldade permanente de enxergar mesmo com uso de } \\
\text { óculos ou lentes de contato) }\end{array}$ & 1 & 0 \\
\hline $\begin{array}{l}\text { 94. Alguma pessoa com incapacidade auditiva? (considerar pessoa incapaz, com grande } \\
\text { dificuldade permanente ou alguma dificuldade permanente de ouvir mesmo com uso de } \\
\text { aparelho auditivo) }\end{array}$ & 1 & 0 \\
\hline $\begin{array}{l}\text { 95. Alguma pessoa com incapacidade para se movimentar? (considerar pessoa incapaz, com } \\
\text { grande dificuldade permanente ou alguma dificuldade permanente de caminhar mesmo com } \\
\text { uso de prótese, bengala ou aparelho auxiliar) }\end{array}$ & 1 & 0 \\
\hline $\begin{array}{l}\text { 96. Alguma pessoa com deficiência física? (considerar tetraplegia, paraplegia, hemiplegia, } \\
\text { falta de membro ou parte dele) }\end{array}$ & 1 & 0 \\
\hline \multicolumn{3}{|l|}{ COMPONENTE: Capacidade Funcional } \\
\hline Neste domicílio há: & SIM & NÃO \\
\hline $\begin{array}{l}\text { 97. Alguma pessoa que, sem ajuda, não realiza qualquer das seguintes atividades: } \\
\text { alimentação, higiene pessoal, vestir-se, controle de eliminação intestinal e vesical, } \\
\text { deambulação e transferências? (Atividades Básicas da Vida Diária - ABVD)? }\end{array}$ & 1 & 0 \\
\hline 98. Alguma pessoa imobilizada/acamada permanentemente? & 1 & 0 \\
\hline $\begin{array}{l}\text { 99. Alguma pessoa que, sem ajuda, não consegue realizar nenhuma das seguintes atividades: } \\
\text { limpar a casa, cuidar da roupa, da comida, usar equipamentos domésticos, fazer compras, } \\
\text { usar transporte pessoal ou público, controlar a própria medicação e finanças? (Atividades } \\
\text { Instrumentais da Vida Diária - AIVD) }\end{array}$ & 1 & 0 \\
\hline
\end{tabular}


COMPONENTE: Transtornos mentais

\begin{tabular}{|l|c|c|}
\hline Neste domicílio há: & SIM & NÃo \\
\hline $\begin{array}{l}\text { 100. Alguma pessoa com transtornos psiquiátricos como depressão ou tentativa de suicídio } \\
\text { ou transtorno de ansiedade ou transtorno obsessivo- compulsivo ou esquizofrenia ou } \\
\text { psicose ou transtorno bipolar? }\end{array}$ & 1 & 0 \\
\hline 101. Alguma pessoa com demência ${ }^{4}$, como por exemplo, Alzheimer, demência vascular? & 1 & 0 \\
\hline 102. Alguma pessoa que faça uso abusivo de álcool e drogas? & 1 & 0 \\
\hline 103. Alguma pessoa com deficiência intelectual ${ }^{5}$ ? & 1 & 0 \\
\hline
\end{tabular}

4 Demência é uma síndrome clínica que ocasiona perturbações na memória, atenção, aprendizado, pensamento, orientação, compreensão, julgamento acompanhado por deterioração do controle emocional e comportamento social.

5 Caracterizada por dificuldades ou limitações intelectuais associadas a pelo menos duas áreas de habilidades adaptativas como comunicação, cuidado pessoal, autodeterminação, lazer, aprendizagem

TOTAL 


\section{APÊNDICE III}

\section{ÍNDICE DE VULNERABILIDADE DAS FAMÍLIAS A INCAPACIDADES E DEPENDÊNCIA IVF-ID}

\begin{tabular}{|c|c|c|}
\hline \multicolumn{3}{|l|}{ Dimensão 1: CONDIÇÕES DE SAÚDE } \\
\hline \multicolumn{3}{|l|}{ Componente: Envelhecimento, incapacidade e dependência } \\
\hline Neste domicílio há: & SIM & NÃO \\
\hline 1. Algum idoso (60 anos ou mais)? & 1 & 0 \\
\hline 2. Algum idoso com 80 anos ou mais? & 1 & 0 \\
\hline 3. Apenas moradores idosos (60 anos ou mais)? & 1 & 0 \\
\hline $\begin{array}{l}\text { 4. Alguma pessoa que faz uso contínuo de } 5 \text { ou mais medicamentos diferentes ao mesmo } \\
\text { tempo? (polifarmácia) }\end{array}$ & 1 & 0 \\
\hline 5. Algum idoso sofreu queda nos últimos 12 meses? & 1 & 0 \\
\hline 6. Alguma pessoa que não consegue ir de transporte público coletivo ao serviço de saúde? & 1 & 0 \\
\hline $\begin{array}{l}\text { 7. Alguma pessoa com incapacidade auditiva? (considerar pessoa incapaz, com grande } \\
\text { dificuldade permanente ou alguma dificuldade permanente de ouvir mesmo com uso de } \\
\text { aparelho auditivo) }\end{array}$ & 1 & 0 \\
\hline $\begin{array}{l}\text { 8. Alguma pessoa com incapacidade para se movimentar? (considerar pessoa incapaz, com } \\
\text { grande dificuldade permanente ou alguma dificuldade permanente de caminhar mesmo com } \\
\text { uso de prótese, bengala ou aparelho auxiliar) }\end{array}$ & 1 & 0 \\
\hline $\begin{array}{l}\text { 9. Alguma pessoa que, sem ajuda, não realiza qualquer das seguintes atividades: alimentação, } \\
\text { higiene pessoal, vestir-se, controle de eliminação intestinal e vesical, deambulação e } \\
\text { transferências? (Atividades Básicas da Vida Diária - ABVD)? }\end{array}$ & 1 & 0 \\
\hline $\begin{array}{l}\text { 10. Alguma pessoa que, sem ajuda, não consegue realizar nenhuma das seguintes atividades: } \\
\text { limpar a casa, cuidar da roupa, da comida, usar equipamentos domésticos, fazer compras, usar } \\
\text { transporte pessoal ou público, controlar a própria medicação e finanças? (Atividades } \\
\text { Instrumentais da Vida Diária - AIVD) }\end{array}$ & 1 & 0 \\
\hline \multicolumn{3}{|l|}{ Componente: Doenças crônicas } \\
\hline Neste domicílio há: & SIM & NÃO \\
\hline $\begin{array}{l}\text { 11. Alguma pessoa com pelo menos uma doença crônica? } \\
\text { * Doenças cardiovasculares (cerebrovasculares, isquêmicas), neoplasias, doenças respiratórias } \\
\text { crônicas, diabetes mellitus e etc. }\end{array}$ & 1 & 0 \\
\hline $\begin{array}{l}\text { 12. Alguma pessoa com pelo menos duas doenças crônicas’? } \\
\text { * Doenças cardiovasculares (cerebrovasculares, isquêmicas), neoplasias, doenças respiratórias } \\
\text { crônicas, diabetes mellitus e etc. }\end{array}$ & 1 & 0 \\
\hline $\begin{array}{l}\text { 13. Alguma pessoa com doença crônica que tem dificuldades em seguir o tratamento } \\
\text { medicamentoso, por motivos pessoais ou por dificuldade de acesso aos medicamentos? }\end{array}$ & 1 & 0 \\
\hline $\begin{array}{l}\text { 14. Alguma pessoa com doença crônica que tem dificuldades em seguir o tratamento não- } \\
\text { medicamentoso, como fazer atividade física, seguir uma dieta recomendada, parar de fumar? }\end{array}$ & 1 & 0 \\
\hline 15. Alguma pessoa que faz uso de medicamento contínuo? & 1 & 0 \\
\hline 16. Alguma pessoa que considera sua saúde ruim ou muito ruim? & 1 & 0 \\
\hline $\begin{array}{l}\text { 17. Alguma pessoa que não conseguiu agendar consultas, exames ou tratamentos nos últimos } \\
12 \text { meses? }\end{array}$ & 1 & 0 \\
\hline \multicolumn{3}{|l|}{ TOTAL DIMENSÃO CSA } \\
\hline \multicolumn{3}{|l|}{ DIMENSÃO 2: CONDIÇÕES SOCIAIS } \\
\hline \multicolumn{3}{|l|}{ Componente: Condições sociais favoráveis } \\
\hline Neste domicílio há: & SIM & NÃO \\
\hline 18. Pelo menos um adulto com ensino fundamental completo? & 0 & 1 \\
\hline 19. Alguma pessoa com ensino médio completo? & 0 & 1 \\
\hline 20. Alguma pessoa com educação superior? & 0 & 1 \\
\hline 21. O chefe da família com o ensino fundamental completo? & 0 & 1 \\
\hline 22. O chefe da família com ensino médio completo? & 0 & 1 \\
\hline 23. O chefe da família com ensino superior? & 0 & 1 \\
\hline
\end{tabular}




\begin{tabular}{|c|c|c|}
\hline 24. Alguma pessoa trabalha há mais de seis meses no emprego atual? & 0 & 1 \\
\hline 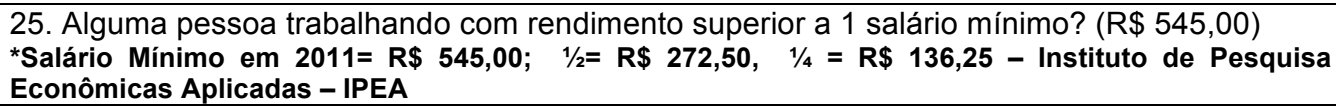 & 0 & 1 \\
\hline $\begin{array}{l}\text { 26. Alguma pessoa trabalhando com rendimento superior a } 2 \text { salários mínimos? }(\mathrm{R} \$ 1.090,00) \\
\text { *Salário Mínimo em } 2011=R \$ \mathbf{5 4 5 , 0 0} ; \quad 1 / 2=R \$ 272,50, \quad 1 / 4=R \$ 136,25-\text { Instituto de Pesquisa } \\
\text { Econômicas Aplicadas - IPEA }\end{array}$ & 0 & 1 \\
\hline 27. Telefone celular? & 0 & 1 \\
\hline 28. Microcomputador? & 0 & 1 \\
\hline 29. Microcomputador com acesso a internet? & 0 & 1 \\
\hline 30. Motocicleta ou automóvel para uso particular? & 0 & 1 \\
\hline \multicolumn{3}{|l|}{ Componente: Condições sociais desfavoráveis } \\
\hline Neste domicílio: & SIM & NÃO \\
\hline 31. Há alguma mulher que teve filho nascido vivo nos últimos 24 meses? & 1 & 0 \\
\hline 32. Há alguma criança até 10 anos? & 1 & 0 \\
\hline 33. Há alguma criança ou adolescente até 14 anos? & 1 & 0 \\
\hline 34. Há alguma criança, adolescente ou jovem até 17 anos? & 1 & 0 \\
\hline 35. O número total de moradores dividido pelo número de dormitórios é maior que dois? & 1 & 0 \\
\hline 36. Há algum adulto analfabeto ou que só lê e escreve o próprio nome? & 1 & 0 \\
\hline 37. Há algum adulto com dificuldade para ler e escrever (analfabeto funcional)? & 1 & 0 \\
\hline 38. O chefe da família é analfabeto ou só lê e escreve o próprio nome? & 1 & 0 \\
\hline 39. O chefe da família tem dificuldade para ler e escrever (analfabeto funcional)? & 1 & 0 \\
\hline $\begin{array}{l}\text { 40. A renda familiar é de } 1 / 4 \text { até } 1 / 2 \text { salário mínimo por pessoa*? } \\
\text { *Salário Mínimo em } 2011=R \$ 545,00 ; 1 / 2=R \$ 272,50,1 / 4=R \$ 136,25-\text { Instituto de Pesquisa } \\
\text { Econômicas Aplicadas - IPEA }\end{array}$ & 1 & 0 \\
\hline IVF-ID TOTAL & & \\
\hline
\end{tabular}

\begin{tabular}{|l|c|c|}
\hline \multirow{2}{*}{$\begin{array}{c}\text { IVF-ID TOTAL (Dimensão } \\
\text { CSA+ Dimensão CSO) }\end{array}$} & \multicolumn{2}{|c|}{ DIMENSÃO CSA } \\
& \multicolumn{2}{|c|}{$\geq$ PONTOS? } \\
\cline { 2 - 3 } & NANO & SIM \\
\hline NÃO & $\begin{array}{c}\text { Família não } \\
\text { vulnerável }\end{array}$ & $\begin{array}{c}\text { Família vulnerável nas } \\
\text { condições de saúde (CSA) }\end{array}$ \\
\hline SIM & $\begin{array}{c}\text { Família vulnerável } \\
\text { nas condições } \\
\text { sociais (CSO) }\end{array}$ & $\begin{array}{c}\text { Família mais vulnerável } \\
\text { (CSA+CSO) }\end{array}$ \\
\hline
\end{tabular}


ANEXO I

\begin{tabular}{|c|c|c|c|c|c|}
\hline $\begin{array}{c}\text { Número } \\
\text { Região }\end{array}$ & $\begin{array}{c}\text { Número } \\
\text { UBS }\end{array}$ & Equipe & Microárea & $\begin{array}{c}\text { Número } \\
\text { Cadastro Família }\end{array}$ & $\begin{array}{c}\text { Número } \\
\text { Questionário }\end{array}$ \\
\hline & & & & & \\
\hline
\end{tabular}

Para cada área de funcionamento listada abaixo assinale a descrição que melhor se aplica. A palavra "assistência" significa supervisão, orientação ou auxilio pessoal.

Banho - a avaliação da atividade "banhar-se" é realizada em relação ao uso do chuveiro, da banheira e ao ato de esfregar-se em qualquer uma dessas situaçōes. Nessa função, além do padronizado para todas as outras, também são considerados independentes os idosos que receberem algum auxílio para banhar uma parte específica do corpo como, por exemplo, a regiāo dorsal ou uma das extremidades.

\begin{tabular}{l|l|l}
$\begin{array}{l}\text { Não recebe assistência (entra e sai do } \\
\text { banheiro sozinho se essa é usualmente }\end{array}$ & $\begin{array}{l}\text { Recebe assistência no banho } \\
\text { somente para uma parte do corpo }\end{array}$ & $\begin{array}{l}\text { Recebe assistência no banho em mais } \\
\text { de uma parte do corpo. }\end{array}$
\end{tabular}
utilizada para banho) $\square$ (como costas ou uma perna) de uma parte do corpo.

Vestir - para avaliar a função "vestir-se" considera-se o ato de pegar as roupas no armário, bem como o ato de se vestir propriamente dito. Como roupas são compreendidas roupas íntimas, roupas externas, fechos e cintos. Calçar sapatos está excluído da avaliação. A designaçāo de dependência é dada às pessoas que recebem alguma assistência pessoal ou que permanecem parcial ou totalmente despidos

Pega as roupas e se veste completamente sem assistência.
Pega as roupas e se veste sem assistência, exceto para amarrar os sapatos.
Recebe assistência para pegar as roupas ou para vestir-se ou permanece parcial ou totalmente despido.

Banheiro - a função "ir ao banheiro" compreende o ato de ir ao banheiro para excreções, higienizar-se e arrumar as próprias roupas. Os idosos considerados independentes podem ou não utilizar algum equipamento ou ajuda mecânica para desempenhar a função sem que isso altere sua classificação. Dependentes são aqueles que recebem qualquer auxílio direto ou que não desempenham a função. Aqueles que utilizam "papagaios" ou "comadres" também são considerados dependentes;

Vai ao banheiro, higieniza-se e se veste após as eliminações sem assistência (pode utilizar objetos de apoio como bengala, andador, barras de apoio ou cadeira de rodas e pode utilizar comadre ou urinol à noite esvaziando por si mesmo pela manhã)
Recebe assistência para ir ao banheiro ou para higienizar-se ou para vestir-se após as eliminações ou para usar o urinol ou comadre à noite.
Não vai ao banheiro para urinar ou evacuar.

Transferência - a função "transferência" é avaliada pelo movimento desempenhado pelo idoso para sair da cama e sentarse em uma cadeira e vice-versa. Como na funçāo anterior, o uso de equipamentos ou suporte mecânico nāo altera a classificaçāo de independência para a funçāo. Dependentes sāo as pessoas que recebem qualquer auxílio em qualquer das transferências ou que nāo executam uma ou mais transferências;

Deita-se e levanta-se da cama ou da cadeira sem assistência (pode utilizar um objeto de apoio como bengala ou andador

Deita-se e levanta-se da cama ou da cadeira com auxílio.
Não sai da cama.

Continência - "continência" refere-se ao ato inteiramente autocontrolado de urinar ou defecar. A dependência está relacionada à presença de incontinência total ou parcial em qualquer das funçōes. Qualquer tipo de controle externo como enemas, cateterizaçāo ou uso regular de fraldas classifica a pessoa como dependente;

\begin{tabular}{l|l|l} 
Tem controle sobre as funções de urinar & $\begin{array}{l}\text { Tem "acidentes" *ocasionais. } \\
\text { e evacuar. }\end{array}$ & $\begin{array}{l}\text { Supervisão para controlar urina e } \\
\text { fezes, utiliza cateterismo ou é } \\
\text { fecais }\end{array}$
\end{tabular}

Alimentação - a função "alimentação" relaciona-se ao ato de dirigir a comida do prato (ou similar) à boca. $\mathbf{O}$ ato de cortar os alimentos ou prepará-los está excluído da avaliação. Dependentes são as pessoas que recebem qualquer assistência pessoal. Aqueles que não se alimentam sem ajuda ou que utilizam sondas para se alimentarem são considerados dependentes.

Alimenta-se sem assistência.

Alimenta-se sem assistência, exceto para cortar carne ou passar manteiga no pão.
Recebe assistência para se alimentar ou é alimentado parcial ou totalmente por sonda enteral ou parenteral.

\section{INDEX DE INDEPENDÊNCIA NAS ATIVIDADES DE BÁSICAS VIDA DIÁRIA, KATZ}

\begin{tabular}{|c|l|}
\hline $\begin{array}{c}\text { Index de AVDs } \\
\text { (Katz) }\end{array}$ & \multicolumn{1}{|c|}{ Tipo de classificação } \\
\hline A & Independente para todas as atividades. \\
\hline B & Independente para todas as atividades menos uma. \\
\hline C & Independente para todas as atividades menos banho e mais uma adicional. \\
\hline D & Independente para todas as atividades menos banho, vestir-se e mais uma adicional. \\
\hline E & Independente para todas as atividades menos banho, vestir-se, ir ao banheiro e mais uma adicional. \\
\hline F & $\begin{array}{l}\text { Independente para todas as atividades menos banho, vestir-se, ir anheiro, transferência e mais } \\
\text { uma adicional. }\end{array}$ \\
\hline G & Dependente para todas as atividades. \\
\hline Outro & Dependente em pelo menos duas funções, mas que não se classificasse em C,D,E e F. \\
\hline
\end{tabular}


ANEXO II

\begin{tabular}{|c|c|c|c|c|c|}
\hline $\begin{array}{c}\text { Número } \\
\text { Região }\end{array}$ & $\begin{array}{c}\text { Número } \\
\text { UBS }\end{array}$ & Equipe & Microárea & $\begin{array}{c}\text { Número } \\
\text { Cadastro Família }\end{array}$ & $\begin{array}{c}\text { Número } \\
\text { Questionário }\end{array}$ \\
\hline & & & & & \\
\hline
\end{tabular}

ESCALA DE LAWTON

\begin{tabular}{|c|c|c|c|}
\hline \multicolumn{2}{|c|}{ Atividade } & \multicolumn{2}{|l|}{ Avaliação } \\
\hline 1 & $\mathrm{O}(\mathrm{a}) \mathrm{Sr}(\mathrm{a})$ consegue usar o telefone? & $\begin{array}{l}\text { Sem ajuda } \\
\text { Com ajuda parcial } \\
\text { Não consegue }\end{array}$ & $\begin{array}{l}3 \\
2 \\
1\end{array}$ \\
\hline 2 & $\begin{array}{l}\mathrm{O}(\mathrm{a}) \mathrm{Sr}(\mathrm{a}) \text { consegue ir a locais distantes, usando algum transporte, } \\
\text { sem necessidade de planejamentos especiais? }\end{array}$ & $\begin{array}{l}\text { Sem ajuda } \\
\text { Com ajuda parcial } \\
\text { Não consegue }\end{array}$ & $\begin{array}{l}3 \\
2 \\
1\end{array}$ \\
\hline 3 & $\mathrm{O}(\mathrm{a}) \mathrm{Sr}(\mathrm{a})$ consegue fazer compras? & $\begin{array}{l}\text { Sem ajuda } \\
\text { Com ajuda parcial } \\
\text { Não consegue }\end{array}$ & $\begin{array}{l}3 \\
2 \\
1\end{array}$ \\
\hline 4 & O(a) Sr(a) consegue preparar suas próprias refeições? & $\begin{array}{l}\text { Sem ajuda } \\
\text { Com ajuda parcial } \\
\text { Não consegue }\end{array}$ & $\begin{array}{l}3 \\
2 \\
1\end{array}$ \\
\hline 5 & $\mathrm{O}(\mathrm{a}) \mathrm{Sr}(\mathrm{a})$ consegue arrumar a casa? & $\begin{array}{l}\text { Sem ajuda } \\
\text { Com ajuda parcial } \\
\text { Não consegue }\end{array}$ & $\begin{array}{l}3 \\
2 \\
1\end{array}$ \\
\hline 6 & $\begin{array}{l}\mathrm{O}(\mathrm{a}) \mathrm{Sr}(\mathrm{a}) \text { consegue fazer trabalhos manuais domésticos, como } \\
\text { pequenos reparos? }\end{array}$ & $\begin{array}{l}\text { Sem ajuda } \\
\text { Com ajuda parcial } \\
\text { Não consegue }\end{array}$ & $\begin{array}{l}3 \\
2 \\
1\end{array}$ \\
\hline 7 & $\mathrm{O}(\mathrm{a}) \mathrm{Sr}(\mathrm{a})$ consegue lavar e passar sua roupa? & $\begin{array}{l}\text { Sem ajuda } \\
\text { Com ajuda parcial } \\
\text { Não consegue }\end{array}$ & $\begin{array}{l}3 \\
2 \\
1\end{array}$ \\
\hline 8 & O(a) Sr(a) consegue tomar seus remédios na dose e horários corretos? & $\begin{array}{l}\text { Sem ajuda } \\
\text { Com ajuda parcial } \\
\text { Não consegue }\end{array}$ & $\begin{array}{l}3 \\
2 \\
1\end{array}$ \\
\hline 9 & $\mathrm{O}(\mathrm{a}) \mathrm{Sr}(\mathrm{a})$ consegue cuidar de suas finanças? & $\begin{array}{l}\text { Sem ajuda } \\
\text { Com ajuda parcial } \\
\text { Não consegue }\end{array}$ & $\begin{array}{l}3 \\
2 \\
1\end{array}$ \\
\hline
\end{tabular}

TOTAL pontos 
ANEXO III

\section{UNIVERSIDADE DE SÃO PAULO ESCOLA DE ENFERMAGEM \\ Av. Dr. Enéas de Carvalho Aguiar, 419- CEP 05403-000 Tel.: (011) 3061-7548/8858 - Fax: (011) 3061-7548 São Paulo - SP - Brasil}

São Paulo, 19 de agosto de 2010.

Ilm. ${ }^{\mathrm{a}} \mathrm{Sr}{ }^{\mathrm{a}}$

Fernanda Amendola

Ref.: Processo $n^{\circ}$ 960/2010/CEP-EEUSP

Prezada Senhora,

Em atenção à solicitação referente à análise do projeto "Famílias em situação de vulnerabilidade relacionada ao surgimento de pessoas com perdas funcionais e dependência em seu domicílio", informamos que o mesmo foi considerado aprovado pelo Comitê de Ética em Pesquisa da Escola de Enfermagem da Universidade de São Paulo (CEP/EEUSP).

Analisado sob o aspecto ético-legal, atende às exigências da Resolução $n^{\circ}$ 196/96 do Conselho Nacional de Saúde.

Esclarecemos que após o término da pesquisa, os resultados obtidos deverão ser encaminhados ao CEP/EEUSP, para serem anexados ao processo.

Atenciosamente,

Maria fat finmandes

Prof. ${ }^{\text {a }}$ Dr. ${ }^{\text {a }}$ Maria de Fátima Prado Fernandes

Coordenadora do Comitê de Ética em Pesquisa da

Escola de Enfermagem da Universidade de São Paulo 


\section{ANEXO IV}

SAOO PAULO

\section{SECRETARIA MUNICIPAL DA SAÚDE Comitê de Ética em Pesquisa/SMS}

São Paulo, 24 de Novembro de 2010. PARECER No 410/10 - CEP/SMS

CAAE: 0190.0.162.196-10

IIma. Sra.

Fernanda Amendola

Projeto de Pesquisa: Famílias em situação de vulnerabilidade relacionada ao surgimento de pessoas com perdas funcionais e dependência em seu domicílio

Pesquisador Responsável: Fernanda Amendola

Instituição: Escola de Enfermagem da USP

Local onde os dados serão coletados: Unidades Básicas de Saúde com equipes do PSF das áreas de abrangência das subprefeituras da Cidade Ademar e da Lapa

Patrocinador: Pesquisadora ou Fapesp (se houver aprovação do auxílio solicitado)

\section{I - Sumário Geral do Protocolo}

Objetivo Geral: Construir um Índice de vulnerabilidade das famílias ao surgimento de pessoas com incapacidade e dependência no domicílio (IVUFID).

Objetivos Específicos:

1. Adaptar o IDF para o desenvolvimento de um índice de vulnerabilidade de famílias ao surgimento de incapacidade e dependência no domicílio;

2. Avaliar o construto do IVUFID por meio de um comitê de especialistas;

3. Desenvolver o IVUFID utilizando dados de famílias acompanhadas por equipes de saúde da família em duas regiões de diferentes vulnerabilidades sociais do município de São Paulo;

4. Validar o IVUFID em uma terceira região do município de São Paulo, em famílias acompanhadas por equipes de saúde da família.

Existe a necessidade de construção de instrumertos capazєs de captar a vulnerabilidade das famílias com pessoas com incapacidades e dependência. Tais instrumentos são potencialmente úteis no âmbito da Estratégia de Saúde da Família, pois podem facilitar o planejamento das ações de saúde das equipes de șaúde e desse modo podem potencializar os fatores de fortalecimento das famílias e atenuar o desgaste a que estão expostas.

Nos casos da condição já instalada, esses instrumentos permitirão quer as equipes mobilizem os recursos existentes no nível da Atenção Primária ou encaminhem as famílias aos serviços especializados, para que possam ser atendidas em suas necessidades.

\section{Metodologia}

Será realizada uma pesquisa exploratória, descritiva, transversal, de abordagem quantitativa, fundamentada no marco teórico-metodológico da vulnerabilidade para a construção de um indicador que sintetize as dimensões de vulnerabilidade ao surgimento de pessoas com incapacidade e dependência e que possa ser aplicado à avaliação da situação de famílias acompanhadas por equipes da atenção primária. O instrumento utilizado será uma adaptação do Índice de Desenvolvimento Familiar (IDF) que utiliza as informações disponíveis no questionário básico da Pesquisa Nacional por Amostra de Domicílio (PNAD). E é composto por seis dimensões das condições:

1. Ausência de Vulnerabilidade: algumas situações aumentam o volume de recursos que uma família necessita para satisfazer suas necessidades básicas como alimentação e assistência à saúde.

2. Acesso ao conhecimento

* Rua General Jardim, 36 - $1^{\circ}$ andar - V. Buarque - fone: 3397.2464 - email: smscep@gmail.com

http://www.prefeitura.sp.gov.br/cidade/secretarias/saude/comite_de_etica/ 


\section{SECRETARIA MUNICIPAL DA SAÚDE Comitê de Ética em Pesquisa/SMS}

\section{CAAE: 0190.0.162.196-10}

3. Acesso ao trabalho

4. Disponibilidade de recursos econômicos

5. Desenvolvimento Infantil

6. Condições habitacionais

Uma vez que a vulnerabilidade é um construto multidimensional e multicausal é necessário um indicador que seja capaz de combinar diversas dimensões do que se quer avaliar.

No presente serão utilizadas também informações sobre as condições de saúde e sobre a rede de suporte social, estudo, não informados pelo IDF.

\section{Avaliação do constructo}

O IVUFID (ANEXO II) será submetido a uma comissão formada por pesquisadores e profissionais de saúde, com expertise no tema (dois enfermeiros pesquisadores da área de gerontologia, um enfermeiro que trabalha na Estratégia Saúde da Família, um médico sanitarista que trabalha com assistência domiciliar na atenção básica, um pesquisador em vulnerabilidade e uma assistente social e gerontóloga pesquisadora.

Nessa etapa será utilizado o software desenvolvido pela Faculdade de Saúde Pública da Universidade de São Paulo, chamado QLQT on- line ${ }^{23}$. Trata-se de um software elaborado para realização de pesquisas quantiqualitativa, por meio de um formulário eletrônico, onde as pessoas podem acessar e responder aos questionários via internet.

Após esta análise o instrumento poderá ser modificado, tanto na sua estrutura quanto em seu conteúdo.

\section{Validação do Índice}

Para o desenvolvimento do IVUFID foram escolhidas 4 Unidades Básicas de Saúde(UBS) com PSF da subprefeitura da Cidade Ademar com alta vulnerabilidade 10 UBS da subprefeitura da Lapa com nenhuma vulnerabilidade. Serão sujeitos do estudo ; 44 famílias sorteadas de cada subprefeitura estudada, que serão entrevistadas no domicílio, com agendamento prévio e acompanhamento por um dos membros da equipe do PSF.

Para sua validação, o IVFID será aplicado em uma terceira população (mais 244 famílias) na região da subprefeitura do Butantã.

Critério de inclusão: Famílias cadastradas e acompanhadas pelas equipes de saúde da família.

\section{II - Considerações}

A Folha de Rosto está devidamente preenchida e assinada pela autoridade competente.

O currículo do pesquisador responsável está de acordo com a proposta da pesquisa.

O Orçamento detalhado está adequado e informa que a pesquisadora está solicitando auxílio financeiro à FAPESP.

Há tratamento adequado dos dados/informações.

A metodologia é adequada aos objetivos, impõe pequena condição de desconforto ao sujeito da pesquisa, porém tal condição encontra-se devidamente justificada no desenho da pesquisa.

Os direitos fundamentais do sujeito de pesquisa estão garantidos.

Parecer anteriormente emitido solicitou a elaboração de um novo Cronograma da pesquisa, pois o documento apresentado não especificava o mês do início da coleta de dados. Um novo Cronograma foi enviado e considerado adequado.

Também foi solicitada retificação no Termo de Consentimento Livre e Esclarecido (TCLE):O documento foi novamente enviado e considerado adequado.

* Rua General Jardim, 36 - $1^{\circ}$ andar - V. Buarque - fone:3397.2464 - email: smscep@gmail.com 


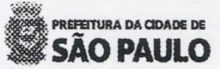

\section{SECRETARIA MUNICIPAL DA SAÚDE Comitê de Ética em Pesquisa/SMS}

CAAE: 0190.0.162.196-10

III - Situação do Protocolo: Aprovado

Antes do inicio da coleta de dados, alertamos para a necessidade de contato com o gerente da unidade quando não foi ele quem autorizou a realização da pesquisa.

Salientamos que o pesquisador deve desenvolver a pesquisa conforme delineada no protocolo aprovado. Eventuais modificações ou emendas ao protocolo devem ser apresentadas ao CEP de forma clara e sucinta, identificando a parte do protocolo a ser modificada e suas justificativas.

O relatório final deve ser apresentado ao CEP, logo que o estudo estiver concluído.

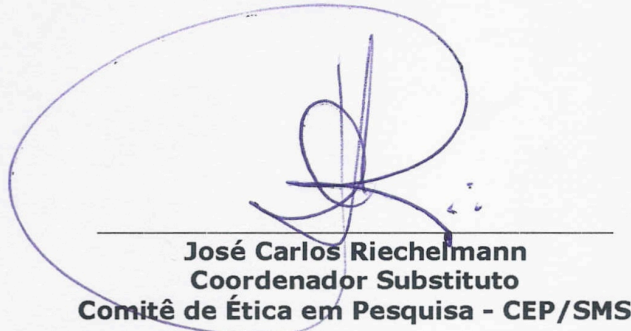

$/ \mathrm{Im}$

* Rua General Jardim, 36 - $1^{\circ}$ andar - V. Buarque - fone: 3397.2464 - email: smscep@gmail.com 


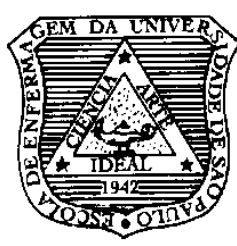

\section{ANEXO V \\ UNIVERSIDADE DE SÃO PAULO \\ ESCOLA DE ENFERMAGEM}

\section{DEPARTAMENTO DE ENFERMAGEM EM SAÚDE COLETIVA \\ Termo de Consentimento Livre e Esclarecido}

Meu nome é Fernanda Amendola, sou aluna do Programa de Doutorado da Escola de Enfermagem da USP e estou desenvolvendo a pesquisa "Famílias em situação de vulnerabilidade relacionada ao surgimento de pessoas com perdas funcionais e dependência em seu domicílio", que está sendo orientada pela Prof ${ }^{\mathrm{a}} \mathrm{Dr}^{\mathrm{a}}$ Maria Amélia de Campos Oliveira.

O objetivo geral da pesquisa é construir um Índice para avaliar a possibilidade das pessoas apresentarem incapacidade e dependência no futuro. Gostaria de convidá-lo(a) a participar desta pesquisa, respondendo algumas perguntas. Sua participação é voluntária, portanto, não é obrigatória e a qualquer momento você pode desistir de participar. A sua recusa ou desistência não trará nenhum prejuízo em relação aos cuidados prestados pela Unidade de Saúde.

Farei algumas perguntas para saber como é a sua família e verificar se há alguma chance de seus familiares tornarem-se dependentes para realizar as atividades do dia-a-dia. O tempo não deverá ultrapassar 20 minutos, pois, na maioria das questões, você deverá responder apenas 'sim' ou 'não'. As informações fornecidas serão confidenciais, isto é, o seu anonimato e sua privacidade serão assegurados.

Como pesquisadora, tenho o compromisso de apresentar os resultados da pesquisa para a Secretaria Municipal de Saúde de São Paulo, para os profissionais das Unidades de Saúde da Família, para as famílias que participaram da pesquisa e para população que utiliza os serviços de saúde. Se, durante a pesquisa, forem identificadas pessoas que com perdas funcionais e dependência nas famílias entrevistadas, esses casos serão informados à Unidade de Saúde para que possam ser tomadas as medidas necessárias para o atendimento das necessidades identificadas.

Se concordar em participar, você deverá assinar este Termo de Consentimento em duas vias. Uma cópia deste Termo será entregue a você e outra via ficará comigo.

Caso queira esclarecer dúvidas ou denunciar questões éticas relacionadas a este estudo, o telefone Comitê de Ética em Pesquisa da Secretaria Municipal de Saúde é 3397-2462 e o e-mail é: smscep@gmail.com.

Caso precise entrar em contato comigo ou com minha orientadora, o telefone e endereço para contato é:

Escola de Enfermagem da USP - Departamento de Enfermagem em Saúde Coletiva da USP Av. Dr. Enéas de Carvalho Aguiar, 419, $2^{\circ}$ andar - CEP -05403-000 - Telefone: (11) 3061-7652.

Declaro que entendi os objetivos da pesquisa, os riscos e os benefícios de minha participação e concordo em participar.

Data:

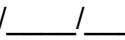

Nome do entrevistado:

Assinatura:

Nome do entrevistador:

Assinatura: 